Portland State University

PDXScholar

1990

\title{
Instrumentation for Multi-Electrode Voltammetry
}

I-Pin Ho

Portland State University

Follow this and additional works at: https://pdxscholar.library.pdx.edu/open_access_etds

Part of the Environmental Monitoring Commons

Let us know how access to this document benefits you.

\section{Recommended Citation}

Ho, I-Pin, "Instrumentation for Multi-Electrode Voltammetry" (1990). Dissertations and Theses. Paper 1141.

https://doi.org/10.15760/etd.1140

This Dissertation is brought to you for free and open access. It has been accepted for inclusion in Dissertations and Theses by an authorized administrator of PDXScholar. Please contact us if we can make this document more accessible: pdxscholar@pdx.edu. 
INSTRUMENTATION FOR MULTI-ELECTRODE VOLTAMMETRY

\author{
by \\ I-PIN HO
}

A dissertation submitted in partial fulfillment of the requirements for the degree of

\begin{abstract}
DOCTOR OF PHILOSOPHY
in

ENVIRONMENTAL SCIENCES AND RESOURCES:

CHEMISTRY
\end{abstract}

Portland State University

(C) 1990 
TO THE OFFICE OF GRADUATE STUDIES:

The members of the Committee approve the dissertation of I-Pin Ho presented April 27, 1990.

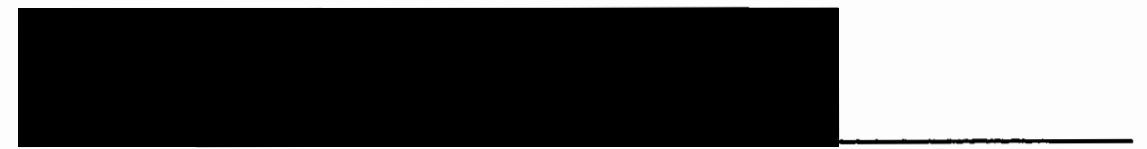

David K. Roe, Chair

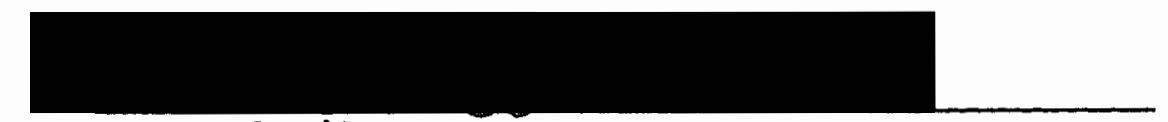

Bernard Silverman

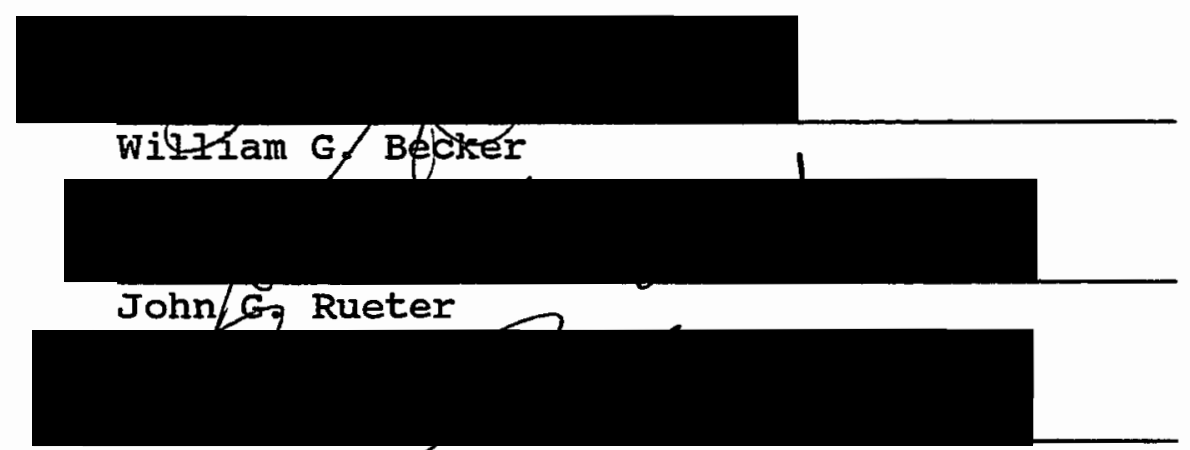

Ansel G. Jobhson

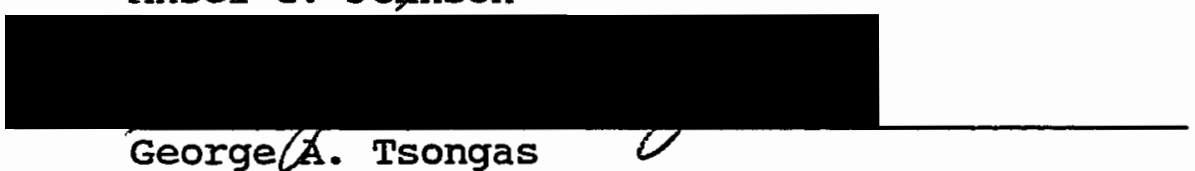

George ZA. Tsongas

\section{APPROVED:}

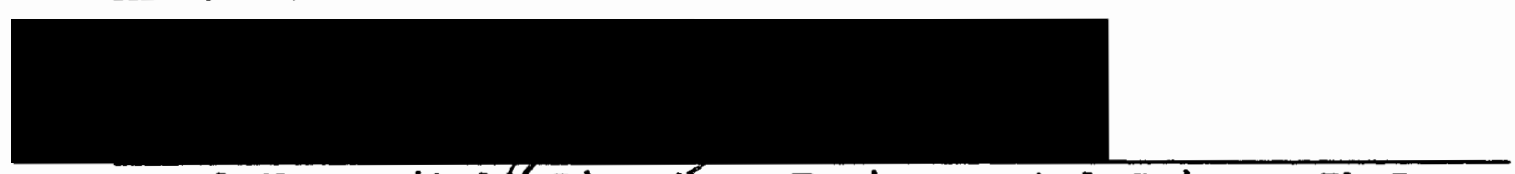

Pavel K. Smejtek, Director, Environmental Science Ph.D. Program

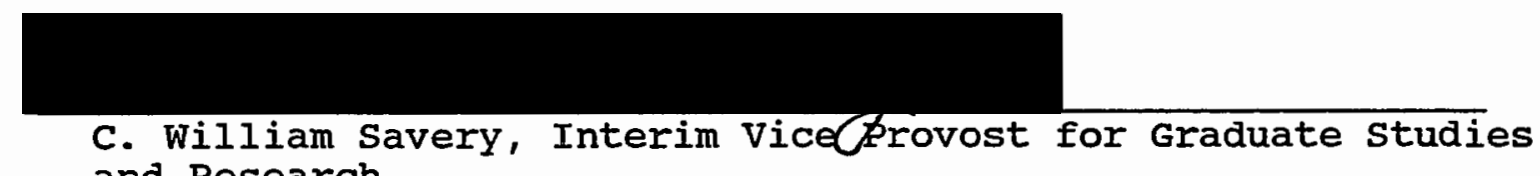
and Research 
developed to detect metal pollutants at very low concentration levels. However, one important factor is often ignored, i.e., rarely is species determination required. Electrochemical (EC) methods have the particular advantage of being, in principle, a species-sensitive method rather than an element-sensitive method for the study of metal speciation in natural waters.

The goal of this research was to develop an instrument using the EC technique for speciation and general voltammetric studies. It was accomplished by designing a flow-through EC cell containing multi-electrodes to which various fixed potentials over a selected range were applied. A special potentiostat was designed to supply a selected potential to each electrode in the cell. Potential control was provided by placing a combined counter-reference electrode at circuit ground and connecting each working electrode to the inverting input of a current follower which had a potential applied to its non-inverting input from two digital-to-analog converters and a resistor network. Integrating current followers were used for measuring signal currents generated by the electrolytes samples on each electrode. A multiplexing circuit, including an analog-todigital converter, was used to fulfill data acquisition. These circuits were interfaced to a computer and the readout was a pseudo-voltammogram which is a plot of amperometric currents versus various applied fixed potentials on each 
electrode. Details of the instrumentation, software, and some initial results are described. 
ACKNOWLEDGEMENTS

I would like to thank the members of my committee for their time and criticism. Especially, I would like to thank Dr. David K. Roe for all his assistance, advice, and patience through all these years.

Thanks is also extended to Robert cary for his knowledge of Commodore 64; to Peg Pankratz for her administrative details; to Brain McLaughlin for his emergency supply of electronics; to Rudolph Zupan and Garo Arakelian for machining much of the equipment; to the hospitable faculty and staff of the Chemistry Department of Portland state University.

Thanks and much appreciation also to my wife, Jane, for her encouragement and support during many difficult periods. 
TABLE OF CONTENTS

PAGE

ACKNOWLEDGEMENTS $\ldots \ldots \ldots \ldots \ldots \ldots \ldots \ldots \ldots \ldots \ldots \ldots$ ii

IIST OF TABLES $\ldots \ldots \ldots \ldots \ldots \ldots \ldots \ldots \ldots \ldots \ldots \ldots \ldots \ldots \ldots$

IIST OF FIGURES $\ldots \ldots \ldots \ldots \ldots \ldots \ldots \ldots \ldots \ldots \ldots \ldots \ldots \ldots$

CHAPTER

I INTRODUCTION $\ldots \ldots \ldots \ldots \ldots \ldots \ldots \ldots \ldots \ldots \ldots \ldots \ldots$

II FLOW INJECTION ANALYSIS SXSTEM AND

INSTRUMENTATION $\ldots \ldots \ldots \ldots \ldots \ldots \ldots \ldots \ldots \ldots \ldots \ldots$

Flow Injection Analysis system ....... 10

Instrumentation $\ldots \ldots \ldots \ldots \ldots \ldots \ldots \ldots . \ldots 26$

III MATERIALS AND APPARATUS ............... 36

Materials .................... 36

Apparatus .............................. 37

IV EXPERIMENTAL PROCEDURES ............... 39

Experiments with a Conventional

Electrochemical cell .............. 39

Experiments with the Multi-Electrode

cell ..........................40 40

V RESULTS AND DISCUSSION ................ 44

Reactivation of Carbon Fiber Array

Electrodes ..................... 48

Cyclic Voltammetry in a Flow Cell ...... 61

Characteristics of Flow Injection

Analysis system .................. 64 
The True Capacitance and Leakage

Current of the Integrator .......... 70

Normalization Factors of Carbon Fiber Array Electrodes in the Multi-Electrode cell ......................... 73

Multi-Electrode voltammetry ........ 79

vI CONCLUSION ........................ 89

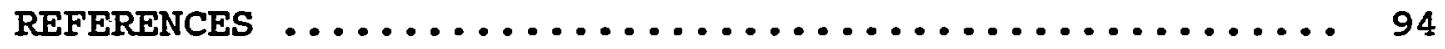

\section{APPENDICES}

A SCHEMATIC DIAGRAM OF THE CIRCUITRY WITH COMPONENT IDENTIFICATIONS $\ldots \ldots \ldots \ldots \ldots \ldots . . . .97$

B SOFTWARE "SET. 7548 .OUTPUT" .............. 99

C SOFTWARE "COLLECT.DATA" ............... 101

D SOFTWARE "DATACQ" .................. 114

E SOFTWARE "NORMALIZE" ................. 127

F SOFTWARE "RESULT" .................. 142 


\section{IIST OF TABLES}

TABLE

PAGE

I Relationship of Pump scale and Flow Rate .... 71

II Resistance, Ieakage current, and

Capacitance of the Integrator ........ 73

III Influence of the Flow Rate on the carbon

Fiber Array Electrode Response Current .. 77

IV Correlation between Flow Rate and

Normalization Factors ............. 78

V Repeatability of Carbon Fiber Array Electrode

Response Currents at Applied Potential

of $+1.95 \mathrm{v} \ldots \ldots \ldots \ldots \ldots \ldots \ldots \ldots \ldots \ldots . \ldots . \ldots . \ldots$

VI Reproducibility of Carbon Fiber Array

Electrode Response Currents at Applied

Potential of $+1.95 \mathrm{v} \ldots \ldots \ldots \ldots \ldots \ldots \ldots \ldots$

VII Carbon Fiber Array Electrode Normalization

Factors for Pseudo-Voltammograms ....... 82

VIII Reproducibility of Multi-Electrode

voltammetry .................... 83

IX Data obtained for Pseudo-Voltammograms at

a Flow Rate of $3.33 \mathrm{~mL} / \mathrm{Min} \ldots \ldots \ldots . . . .86$ 


\section{LIST OF FIGURES}

FIGURE

PAGE

1. Block Diagram of the Entire Instrumentation

2. Schematic Illustration of a single Unit of the Electrochemical cell, containing a Reference Electrode Compartment ....... 14

3. Schematic Illustrations of the Working

Electrode Disk Fabrication Mold and

a Working Electrode Disk ............ 21

4. Schematic Illustration of the Wall-Jet Type Multi-Electrode Cell ............. 23

5. Flow Injection Analysis system setup ....... 25

6. Block Diagram of the Electronic Instrumentation $\ldots \ldots \ldots \ldots \ldots \ldots \ldots \ldots . \ldots 27$

7. Block Diagram of the Computer system ....... 28

8. Block Diagram of the Potential source ...... 30

9. Block Diagram of the Integrating current Follower Unit $\ldots \ldots \ldots \ldots \ldots \ldots \ldots \ldots \ldots \ldots$

10. Block Diagram of the Data Acquisition System 33

11. Cyclic Voltammograms of 0.1 M Acetate Buffer at a Carbon Fiber Array Electrode ...... 45 
12. Effects of Carbon Fiber Array Electrode Surface Preparation upon the Cyclic voltammogram ................ 47

13. Time Effects upon the Cyclic Voltammogram ... 49

14. Effects of an Applied Potential at

a Carbon Fiber Array Electrode upon the Cyclic Voltamogram ............ 51

15. Effects of Lower Potential Limit of a Square Wave upon the cyclic voltammogram ...... 54

16. Effects of Upper Potential Limit of a Square Wave upon the Cyclic Voltammogram ..... 56

17. Effects of Frequency of a Square Wave upon the Cyclic voltammogram ........... 57

18. Effects of Duration of a Square Wave upon the Cyclic voltammogram .......... 58

19. Decay of a Charging Current after the Applied Potential at a Carbon Fiber Array Electrode Was Switched to 0 Volt ....... 60

20. Scanning Electron Micrograph of a Carbon Fiber Array Electrode ............. 62

21. X-Ray Photoelectron Spectrum of a Carbon Fiber Array Electrode ............. 63

22. Effects of Tightness of the Cell Screws upon the Cyclic Voltammogram ......... 65

23. Correlation between the Flow Rate and the Pump scale ................ 71 
24. Pseudo-Voltammograms of Hydroquinone at Different Concentrations .......... 85

25. Calibration Curve of Multi-Electrode

voltammetry .................. 87

26. Flow Chart of Software "COLLECT.DATA" ...... 103

27. Flow Chart of Software "DATACQ" .......... 116

28. Flow Chart of software "NORMALIZE" ........ 129

29. Flow Chart of software "RESULT" ........... 144 


\section{CHAPTER I}

\section{INTRODUCTION}

Life begins in water. Life forms in water exposed to numerous metals. Since the late 1960s and early 1970s metal ions and their complexes have gained great attention in environmental studies because of the wide spread occurrence and toxicological importance of metal pollutants in the aquatic environment (1) .

Many metals in the aquatic environment have more than one oxidation state and species. The toxicity of this metal toward the aquatic environment is far more dependent on the activity of certain metal species than the activity. of the total concentration of that metal (2). The determination of the total concentration in a sample does not clearly describe the potential risks associated with its toxicity and the resulting hazard from exposure. For example, chromium can exist in the $+2,+3,+4,+5$, and +6 oxidation states in aqueous solution. Among these oxidation states, the most common states are $\operatorname{Cr}($ III) and $\operatorname{Cr}(\mathrm{VI})$. Whereas Cr(III) is non-toxic and may exist as anionic or cationic species, $\mathrm{Cr}$ (VI) complexes are highly toxic (3) and exist as anionic species (4). Numerous sophisticated techniques and instruments have 
been developed to detect metal pollutants at low concentration levels. However, one important factor is often ignored. That is, rarely is species determination done. Some of the most sensitive analytical techniques, such as atomic absorption spectrophotometry, atomic emission spectrophotometry, and $\mathrm{x}$-ray fluorescence, are not suitable for species studies because they determine only the total concentration of a metal. These techniques may be accompanied with some preliminary treatment and separation methods, e.g. complex formation (5), or high-performance liquid chromatography (HPLC) (6) for the determination of metal species. However, they have serious drawbacks, such as introduction of contaminants, and incomplete separation, by these preliminary procedures.

During the past decade, there has been a rapid increase in the use of the various forms of electrochemical (EC) methods for speciation. Osteryoung (7) reviewed voltammetric techniques for determining trace metals. Florence (2) reviewed the EC approaches to metal speciation in waters. There is a growing interest in EC detection with the simultaneous use of two or more working electrodes. For example, Iunte et al. (8) used dual-electrode detectors to improve selectivity, detection limits and qualitative information content relative to single-electrode detectors. Several characteristics make EC methods attractive for metal species analysis and studies of environmentally 
significant metals in all types of waters. First, EC methods have the particular advantage of being, in principle, a species-sensitive method rather than an element-sensitive method since current is proportional to concentration and potential is proportional to chemical potential (free energy) of each species. Second, they also have sensitivities for simultaneous determination of various metals. Finally, EC methods have important advantages in that the sample requires much less handling and is in contact with fewer sources of contamination than when other speciation methods, such as solvent extraction, dialysis, or ultrafiltration, are used.

There has also been increasing emphasis in recent years on the need for continuous or automated monitoring in areas such as environmental monitoring and pollution control. This trend leads to the use of EC techniques in conjunction with a flow injection system for the analysis of small samples. Several factors have motivated this recent effort. The primary reason for this trend is its high sensitivity. This is due to an improved mass transfer rate that is caused by pumping the solution toward the electrode surface since most of the analyte in an unstirred cell is not located at the electrode surface. Secondly, the hydrodynamic boundary theory (9) of the diffusion layer has been well developed. Third, EC methods include a tendency to reject timeconsuming methodologies of conventional voltammetric 
electrolysis applied to static solutions in macrocells which are usually associated with manual transfer of solutions and lengthy deaeration periods. Finally, it is relatively simple, reproducible, and economic. Furthermore, one particular advantage of the use of flow injection for EC detection is the ease of mixing reagent streams, including supporting electrolyte, with the sample stream to promote the detection process. The other intrinsic qualities of this system which are favorable include small sample volumes, minimal reagent consumption, and a high sample throughput.

EC methods have some drawbacks. One of the main limitations of EC methods is generation of charging current, which causes sensitivity decrease, due to potential scans. EC methods are dynamic systems that draw current through the solution and disturb ionic equilibria. Davison (10) found that, during the metal deposition step, the equilibrium among metal species was disturbed as a result of the electrode potential across the electrode-solution interface. The gradual fouling of the electrode surface is always a problem with EC methods. Wang (11) and DeCastro (12) found the gradual loss of electrode activity by various organic surfactants during cyclic scans. The interference due to intermetallic compounds and adsorption-desorption processes on the electrode surface is another problem (2). The use of series and parallel combinations of working 
electrodes in a flow stream can avoid the need for potential scans which are often impractical due to generation of charging currents during potential scans and short duration of solute peaks. The combination of coulometric and amperometric electrode designs is a potentially powerful technique to remove interferences and improve detection limits. Extension of these ideas leads to multi-electrode voltammetry (MEV) in which an array of electrodes in a flowthrough cell at different potentials provides a pseudovoltammogram for speciation studies (13).

These ideas can be accomplished by designing a flowthrough EC cell containing multi-electrodes to which various fixed potentials in a range are applied. The number of electrodes required by this system depends upon the accessible potential range of electrode material and the potential difference between the neighboring electrodes. Commercial instrumentation for electrochemical measurements of this type costs several thousand dollars and one instrument would be required for each electrode. Hence, a special inexpensive potentiostat will be needed to supply the selected potential range to this multi-electrode cell. Potential control can be provided by placing a combined counter-reference electrode at circuit ground and connecting each working electrode to the inverting input of a current follower which has a control potential applied to its noninverting input from a resistor network. Current followers 
are used for integrating signal currents generated by the analytes on each electrode, respectively. The dynamic range of the current follower can be extended by placing a capacitor and a parallel switch instead of a resistor in the feedback loop. The output of each integrating current follower, corresponding to total faradaic charge, can be converted to digital values for easy handling, processing, and storing. Hence a custom designed and built circuitry will be needed to fulfill data acquisition since no commercial instruments of this type are available.

Finally, all of the circuits can be controllable by a personal computer through a computer interface and software programs. With a large, but reasonable number of electrodes at tens of millivolt intervals, a current-potential curve of adequate resolution can be constructed in a fraction of a second with no degradation of signal-to-noise ratio compared to single electrode detection. The qualitative and quantitative results of speciation can be obtained through a pseudo-voltammogram which is a plot of currents (charge per time interval) versus selected, applied potentials on each electrode. This pseudo-voltammogram may have the classical voltammogram shape.

The main advantages of this system will be that (i) the double layer charging current will not enter the measurement and therefore the sensitivity and accuracy will increased; (ii) the rate of mass transfer at the electrode surface will 
be larger than that of diffusion alone and therefore the signal will be increased and the detection limit will be lowered; (iii) minimum sample handling will be required to avoid contamination; (iv) the instrument can be used for routine analysis like other EC techniques and reliably differentiate metal species; and $(v)$ the system can also be used as a detector for HPLC and ion chromatography. Furthermore, the EC cell in a flow system linked with this data acquisition system will make this technique even more attractive. 
CHAPTER II

\section{FLOW INJFCTION ANALYSIS SYSTEM AND INSTRUMENTATION}

The entire system consists of a flow injection analysis (FIA) system, a potential source, an integrating current follower unit, and a data acquisition system, all interfaced with a Commodore 64 personal computer (C-64) system. The block diagram is shown in Figure 1. The c-64 sends out the signals via the control of the software to the digital-toanalog converters which then generate and deliver the required potentials to the electrodes of the FIA system via a voltage divider. The analog currents produced by electrolysis at each electrode are sent to the current follower unit to be integrated. The data acquisition system then converts these integrated analog signals, one by one, to the digital values through the selection of the multiplexers. These values are then temporarily saved in the RAM of the c-64. Finally, these values are combined according to the "resolution time", the time interval as a basic unit for current integration, in order to reduce the requirement of the RAM of the c-64. These combined values are saved on a floppy disk for further data manipulation. Details of each unit, including interface, are discussed in 


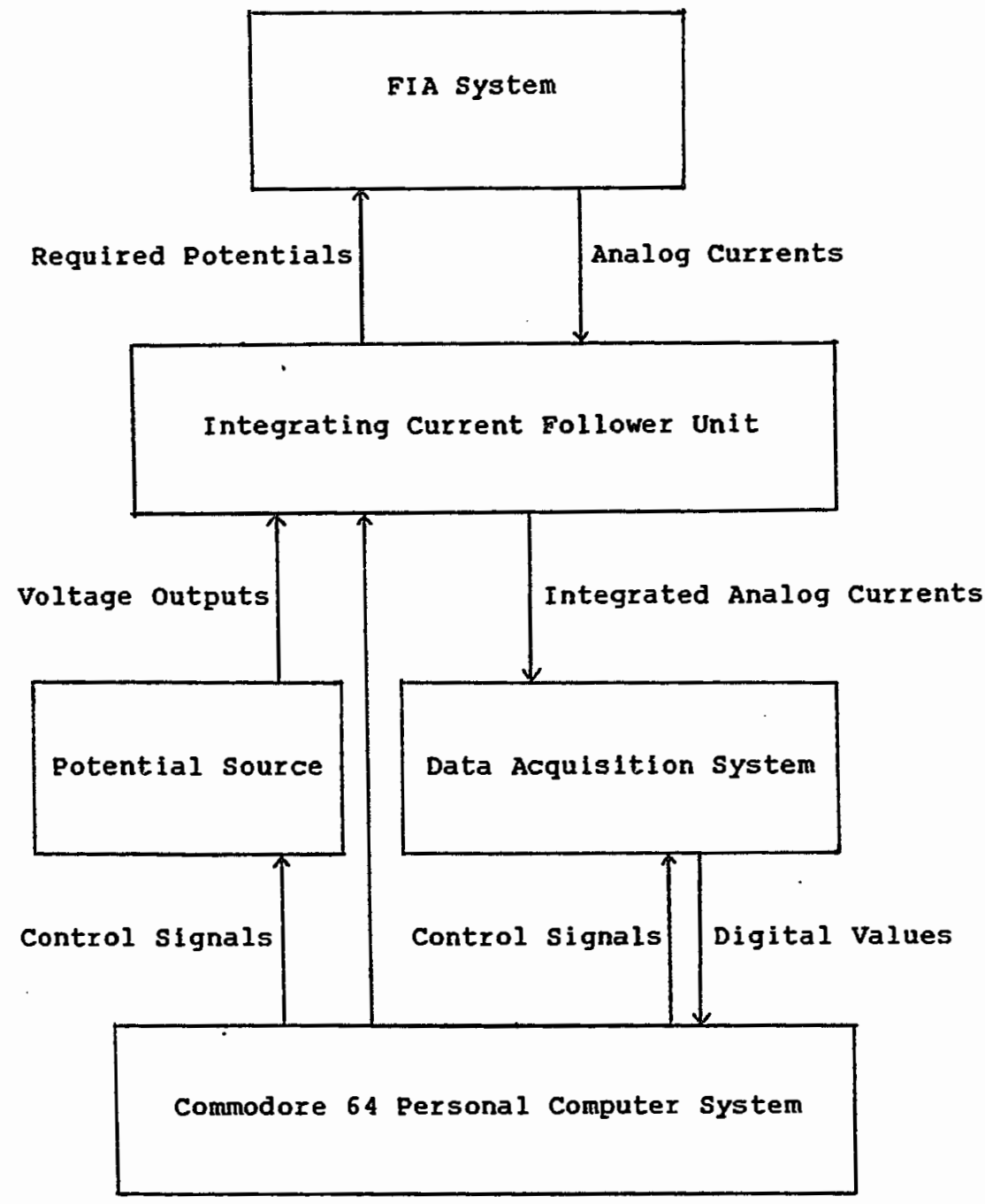

Figure 1. Block diagram of the entire instrumentation. 
the following sections.

\section{FIOW INJECTION ANALYSIS SYSTEM}

The Flow Injection Analysis (FIA) system used for this research consists of a supporting electrolyte reservoir, a pump, a pulse damper and ground current isolator, a sample injection valve, and a flow-through electrochemical (EC) cell.

\section{Electrochemical cell configuration}

The heart of an FIA system is a flow-through EC cell. The concerns of the EC cell design for quantitative applications are the linearity of the response, the precision, and the long term stability. The concerns for qualitative applications are accurate control of electrode potential and an adequate response time for electrochemical tasks. In either case, the sensitivity and the detection limit are of concern. In order to obtain the optimum performance of this cell, certain design conditions have to be kept in mind. These include (i) high sensitivity, (ii) well-defined hydrodynamic characteristics, (iii) low effective volume, (iv) low ohmic drop, (v) ease of construction and maintenance, and (vi) a constant effective electrode area. The performance of this cell depends on the electrode material, the electrode configuration, and the cell configuration.

A variety of cell geometries, differing mainly in the 
flow type and the position of the electrode, has been explored over the course of two decades. Stulik and Pacáková (14) have discussed the different flow-through EC cell geometries, including the tubular, planar, and wall-jet type. The characteristic common to most of these configurations is that the rate of transport of electrochemically active species to the electrode surface is determined by the flow rate of solution.

However, according to theoretical comparison of the performance of these EC cells by Hanekamp and de Jong (15), the best design of flow-through EC cell is the wall-jet type. The term "wall-jet", first defined by Glauert (16), describes the phenomenon when a jet of fluid strikes a wall perpendicularly and then spreads rapidly over the surface of the wall. The electrode is mounted in the wall. The hydrodynamic theory and applications of the wall-jet electrode are fully developed. Yamada and Matsuda (17) have derived the theoretical expression of the limiting diffusion current and the experimental verification of the theoretical predictions for this type electrode. Gunasingham and Fleet (9) have derived the equation for the hydrodynamic boundary layer thickness in terms of the hydrodynamic parameters characteristic of the wall-jet type electrode. The hydrodynamic properties and mass transfer characteristics of this type of EC cell have also been investigated by Dalhuijsen et al.(18). The wall-jet type EC cell offers 
high sensitivity, low solution hold-up, and is thus suited for EC measurements in flowing solution. Therefore, a walljet type EC cell design is chosen for this research.

since the behavior of the wall-jet type EC cell depends on whether or not the cell allows for unrestricted development of the hydrodynamic boundary layer, the cell fabricated for this research is somewhat different from that of the original wall-jet soncept and is, in effect, a constricted wall-jet with the working electrodes forming a smaller cell volume compared to the earlier design of Yamada and Matsuda (17) and the original design by Fleet and Iittle (19).

In a multi-electrode (ME) cell, the effluent from the up-stream unit will be analyzed at the down-stream working electrode. Therefore, neither Ag/AgCl nor saturated calomel electrode (SCE) can be used as a reference electrode because the chloride ion in the reference electrode compartment may leak into the flow stream and be oxidized at the down-stream working electrode. On the other hand, $\mathrm{zn} / \mathrm{Zn}^{2+}$ in $1 \mathrm{M}$ sodium acetate electrode is well-known and the half-cell potential of this electrode is very stable at low current densities. Hence, the zinc/zinc acetate electrode was chosen as the reference electrode for this research. 
Fabrication of Wall-Jet Type Electrochemical Cell Body

The fabrication of a single unit of the EC cell body, containing a reference electrode compartment, is described as follows. Kel-F (poly(chlorotrifluoroethylene)) (3M, USA) is used as the material to fabricate the cell body because of its wide range of desirable properties, including its being electrochemically inert and its ease of fabrication in any desired shape. Figure 2 shows a single unit of the EC cell body. In each unit a short piece, ca. $2 \mathrm{~cm}$ length, of zinc strip housed in an annulus compartment surrounding the inlet nozzle is soldered to a copper wire which is sealed by epoxy in a hole through the side of the cell. The inlet nozzle diameter is $0.34 \mathrm{~mm}$ with a funnel-shaped opening on the upstream side.

Working Electrode Material and Configuration

The heart of EC cells is the working electrode. The working electrodes in the EC cell must: (i) ideally be stable for an infinite period of time, (ii) be simple to prepare; and (iii) most importantly, have an excellent signal-to-noise $(\mathrm{S} / \mathrm{N})$ ratio. Employing electrode materials and configurations, which have a minimum amount of residual current and yet yield maximum current in response to electrochemically active species, can maximize the $\mathrm{S} / \mathrm{N}$ ratio. 


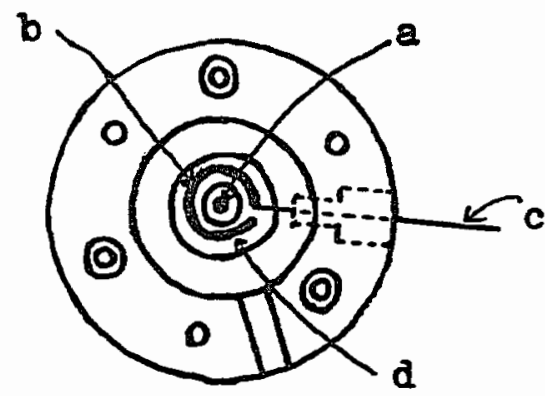

\section{Top View}

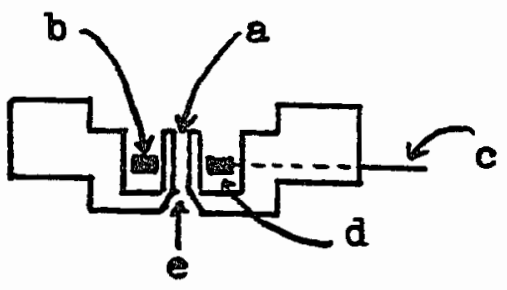

\section{Side View}

Figure 2. Schematic illustration of a single unit of the electrochemical cell, containing a reference electrode compartment. (a) Flow inlet with $0.34 \mathrm{~mm}$ diameter; (b) zinc strip; (c) lead;

(d) reference electrode compartment; (e) flow direction. 
The use of solid electrodes, including carbon and metal electrodes, in EC cells has gained popularity. One of the primary reasons for this is their applicability to anodic oxidations. Such electrodes thus permit important analytical applications not amenable to the mercury electrode. Secondarily, they are easy to construct and use in a flow system. The sensitivity and detection limit are thus increased by placing an electrode in the flow system. However, metal electrodes such as platinum and gold have not been as widely used as carbon electrodes because they tend to exhibit higher detection limits when used at positive potentials. This is because higher anodic residual currents arise from the oxygen evolution at lower positive potentials (20).

A variety of carbon electrodes has been used in EC cells for a long time mainly because they produce better $\mathrm{S} / \mathrm{N}$ ratio in response to electrochemically-active species in contrast to other electrode materials. Furthermore, several different forms of the carbon used as electrode materials are also readily available. However, most of the carbon used as electrode material has drawbacks. Pure graphite has had limited use as an electrode material because it exhibits high porosity which leads to high residual or background currents (21). Glassy carbon (22) has been popular because of its relatively reproducible performance. It can also be used at both positive and negative potentials in aqueous 
solution with a range of ca. $2 \mathrm{~V}$. However, glassy carbon electrodes have residual currents that are higher and tend not to give such a favorable $S / N$ ratio compared with carbon paste or composite electrodes (23). Carbon paste electrodes (20) have been extensively used for anodic oxidation reactions due to their low residual current and wide positive potential range. However, these electrodes also have several drawbacks. First, from preparation to preparation, carbon paste electrodes have variations. Second, the dissolution of binder in organic solution restricts the use of this kind of electrode. Third, the binder may restrict the potential range of the electrode. Electrochemists noted that composite electrodes such as Kel-Graf, which consist of $\mathrm{Kel}-\mathrm{F}$ and graphite, showed improved $\mathrm{S} / \mathrm{N}$ ratio (24). These electrodes also exhibit less dependence on flow-dependent noise. These improvements are attributed to the existence of small graphite particles. When the surface of the electrode is examined under the microscope, the small graphite particles existing on the surface of the electrodes are isolated from each other and act as a multiple array of microelectrodes. Anderson et al. (25) have found that small diameter electrodes are easier to use at high potential, have less noise at all potentials, and have higher sensitivity than ordinary homogeneous electrodes.

Two theories have been derived to explain these 
results. First is the edge effect (26). At large

electrodes, the majority of the steady current arises mainly from the diffusion of the analyte in a region of solution perpendicular to the electrode surface. The amount of current due to the analyte arriving from the lateral part of this volume is negligible. If the electrode surface has a large perimeter-to-area (P/A) ratio such as graphite particles, lateral diffusion will become more important. Therefore, an increase of the $P / A$ ratio of an electrode can increase the sensitivity and lower the detection limit.

The second effect is the noise dependency on surface area. There is an identified noise source, i.e., incomplete wetting of the electrode surface (27). It causes variations in the path of solution flow and fluctuations in the applied potential. Since these two variations are proportional to the electrode surface areas, a reduction in the electrode surface area will reduce this noise level. Therefore, using microelectrodes can capture the advantages of both the edge effect and the less noise dependency on electrode diameter. The $S / N$ ratio can be increased with these microelectrodes.

At present, carbon fibers have been shown to be the most promising electrode materials and are used as microelectrodes due to their possession of characteristics of small electrodes that overcome many of the imperfections of carbon paste electrodes and other carbon electrodes. For example, although the carbon fiber microelectrode has a 
sensitivity similar to the glassy carbon electrode, the detection limits improve relative to glassy carbon electrode at more positive potentials because the background signal of the carbon fiber microelectrodes is less dependent on fluctuations in the velocity of the mobile phase (27). Schulze and Frenzel (28) have shown that caroon fiber microelectrodes give a very low backgrounc current, good peak resolution, and good reproducibility.

Several electrochemists have demonstrated that the carbon fiber array electrode (CFAE) (24), i.e., multiple carbon fiber microelectrodes connected in parallel, yield much higher currents which have the same desirable features of single carbon fiber microelectrodes. In addition to the current amplification effect, a number of other advantages have recently been reported (27). These are an improved $S / N$ ratio, flow independence, and higher sensitivity in flowthrough EC cells. Furthermore, the EC response of this kind of electrode has also been shown to be relatively constant with time. Hence, carbon fibers were chosen as the electrode material to fabricate CFAEs.

Carbon fibers are microscopic carbon materials formed from the pyrolysis of pitch or polyacrylonitrile. These fibers bonded with polymer can be formed in a variety of shapes and can also be machined to optimum dimensions. The documented morphology (29) and manufacture of carbon fibers suggests that the surface of the fiber perpendicular to the 
fiber axis is ideal for electrochemical applications. Therefore, the electrodes are fabricated with the electrode surface perpendicular to the fiber axis.

Fabrication of the Carbon Fiber Array Electrode

The carbon fiber array electrode (CFAE) is fabricated by inserting a bundle of $10-\mathrm{cm}$ long carbon fibers of $8 \mu \mathrm{m}$ nominal diameter (Panex 30, Stackpole Fibers Co., Mass), ca. $0.0015 \mathrm{~g}$, into a short piece of thin-walled Teflon tube of $0.30 \mathrm{~mm}$ inner diameter so that ca. 8-9 cm of the fiber bundle protrudes. This protruded portion of the fiber bundle is thoroughly coated with an excess of an epoxy mixture consisting of 5 parts ISOCHEMREZ $1312 \mathrm{LV}$ resin mixed with 1 part 15AX hardener (Isochem Resins Co., Lincoln, R.I.). Then, the fiber bundle is pulled into the Teflon tube. The fiber bundle is then cured overnight at $60^{\circ} \mathrm{C}$ to form a solid rod. The rod containing epoxy-embedded carbon fibers is cut into $0.8 \mathrm{~cm}$ lengths to make several CFAEs. Then, electrical contact to the electrode is made by using electrically conducting silver-loaded paint (Silver Print, GC Electronics, Rockford, II) to connect a copper lead to one end of a CFAE.

Fabrication of the Working Electrode Disk Containing 4 CFAEs Four CFAEs and four 2-cm long pieces of Teflon tube of $0.76 \mathrm{~mm}$ outer diameter are carefully arranged to ensure that all electrical contacts of CFAEs are completely buried in 
the epoxy mixture and all electrodes and Teflon tubes are also centered in the mold, shown in Figure 3. The same composition epoxy mixture is injected into the mold by means of a plastic syringe, then cured for 24 hours at $60^{\circ} \mathrm{C}$ to form a Working Electrode Disk (WED). After the WED is released from the mold, four Teflon tubes are removed. Both sides of the disk are polished with 600 grit emery paper perpendicular to the carbon fiber axis until the surface is flat. The surface with exposed CFAEs is then successively polished on a felt polishing cloth (Buehler Ltd., Evanston, IL) with $5.0,1.0,0.3$, and $0.05 \mu \mathrm{m}$ diameter alumina mixed with distilled water until a mirror finish is obtained. Residual polishing material is removed from the surface by sonication in a water bath for five minutes after each polishing process. In all polishing steps, a figure-8 pattern is employed to prevent uneven polishing of the WED surface. CFAEs contained in a WED and prepared by these procedures require electrochemical activation before use. The fabricated WED was designed to be used in the walljet type EC cell. Examination of the disk surface under a low-power microscope (of power 35X) revealed an array of carbon fibers whose ends are exposed in the plane of the WED. 


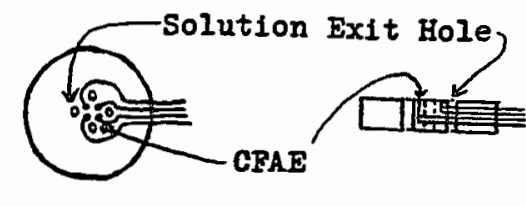

Top View

Side View

Working Electrode Disk
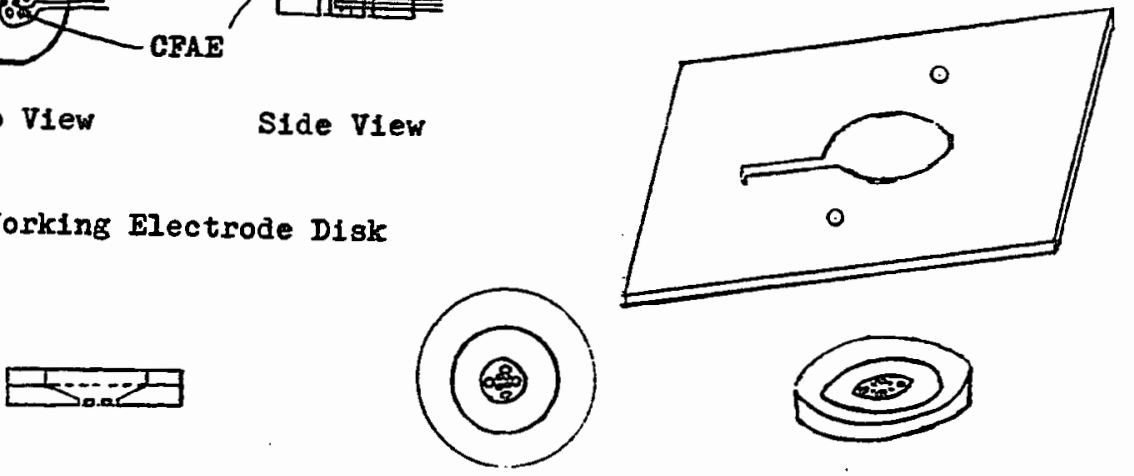

Front View

Top View
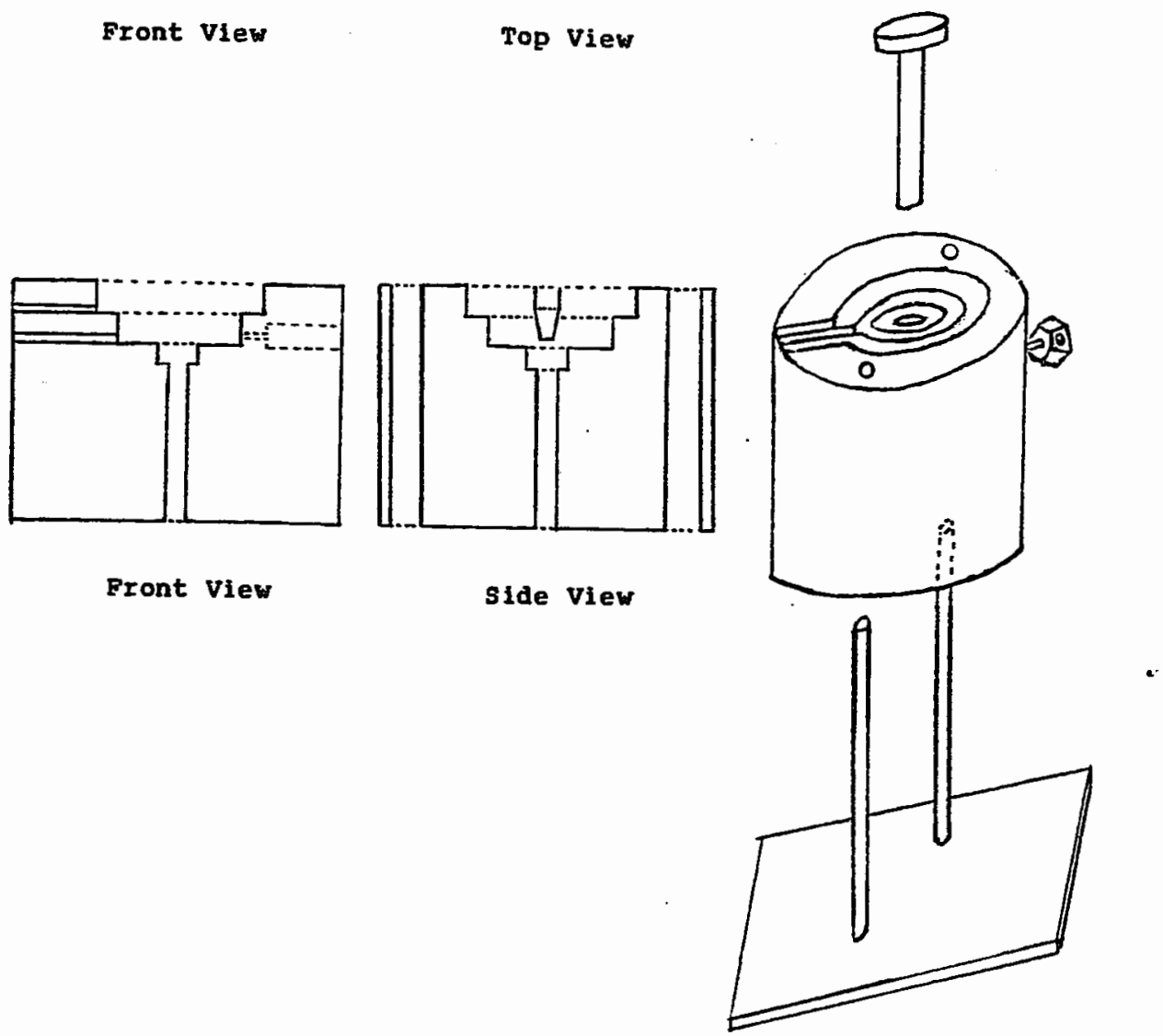

Side View

Figure 3. Schematic illustrations of the working electrode disk fabrication mold and a working electrode disk. (a,e) Mold holder; (b) positioner of CFAE and solution exit hole; (c) stainless plug; (d) mold body. 


\section{Wall-Jet Type Electrochemical Cell Assembly}

A single unit assembly of the EC cell is schematically illustrated in Figure 4. A zinc/zinc acetate reference electrode is made by completely filling the annulus compartment surrounding the inlet nozzle with 1 M sodium acetate solution. The potential of this zinc/zinc acetate reference electrode measured versus a SCE is $-1.055 \mathrm{~V}$. This reference electrode makes contact with the cell cavity via a piece of annulus-shaped Nafion-12 film (E.I. duPont de Nemours \& Co.(Inc.), DE). The Nafion-12 film contains a centered hole, which is large enough to just uncover the nozzle but completely covers the reference electrode compartment. A WED sandwiched by two gaskets is incased into the upper compartment of the cell body. Gaskets which contain a centered hole large enough to expose the central area of the WED are made from Kalrez sheet (\#K05011, E.I. duPont de Nemours \& Co.(Inc.), DE). The solution introduced through the inlet nozzle hits the center of the WED, spreads radially, exits through the four holes in that disk, and then enters into the nozzle of the next unit of the EC cell. Each single unit is connected on-line by three screws, which compress both Kalrez gaskets when tightened to prevent solution leaks. The inlet-electrode separation can be varied by tightening the three bolts on the cell. Four single units are then stacked together to form a wall-jet type ME cell. However, any number of single units may be 
Pront View

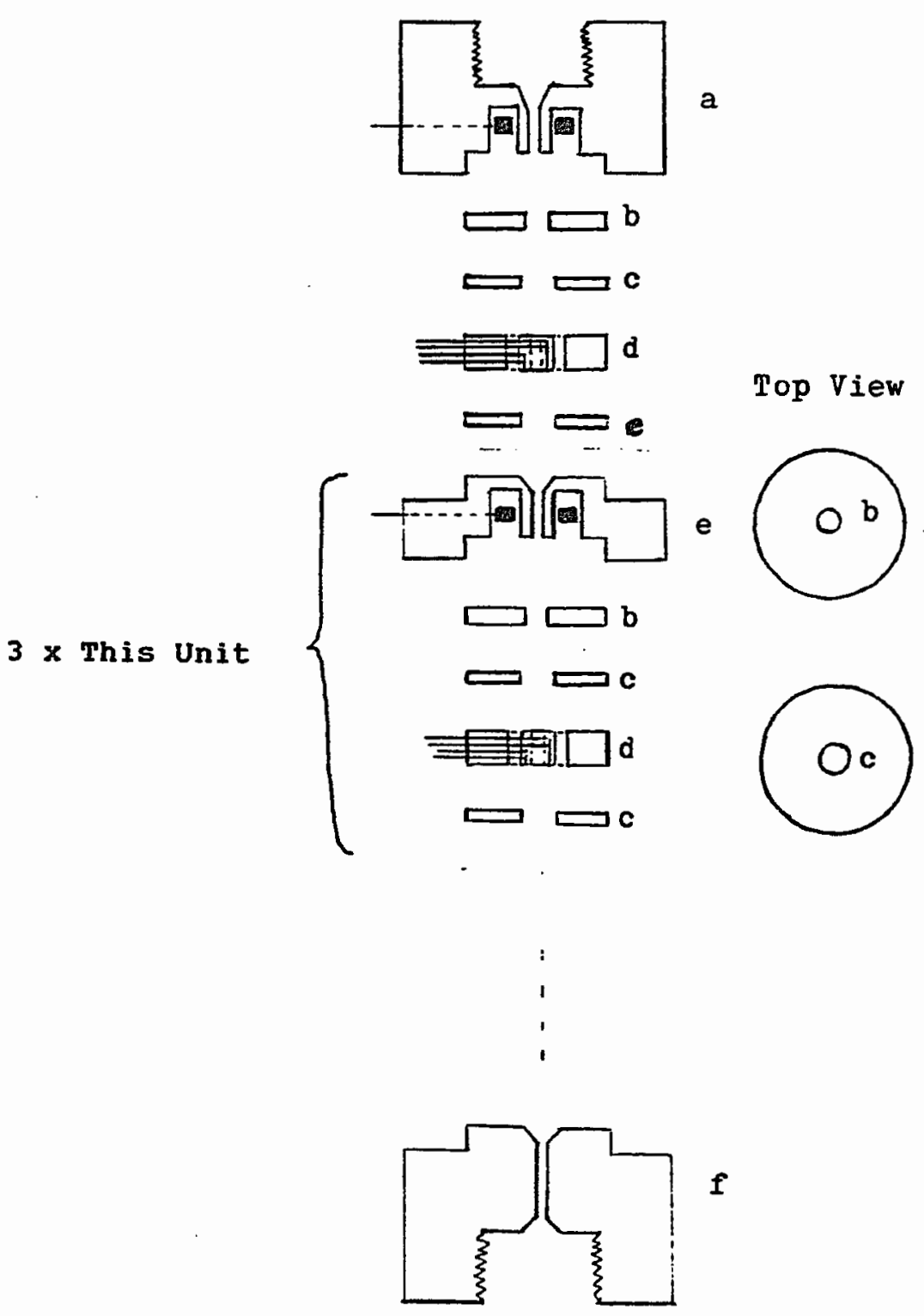

Figure 4. Schematic illustration of the wall-jet type multi-electrode cell. (a) Top piece; (b) Nafion film; (c) Kalrez spacer; (d) working electrode disk; (e) reference electrode holder; (f) bottom piece. 
stacked together to form an ME cell. The cell is simple to construct, and the cell components are demountable for ease of maintenance.

Flow Injection Analysis system Assembly

The schematic diagram of the assembled FIA system is shown in Figure 5. Teflon tubing with $1.59 \mathrm{~mm}$ outer diameter and polyethylene fittings are used for all flow lines and connections between units except where specified. A graduated cylinder serves as a reservoir (a) to store the supporting electrolyte solution. A $0.45 \mu \mathrm{m}$ filter (b), connected to the suction side of a minipump (d) (IDC/Milton Roy, Model 396-57, Reviera Beach, FL) through a piece of $3.18 \mathrm{~mm}$ outer diameter Teflon tube, is submerged in the supporting electrolyte solution. At the discharge side of the pump, a pressure gauge (e) is connected to the outlet of the pump and a plastic tube (g), ca. $70 \mathrm{ml}$ capacity. The plastic tube acts as a flow pulse damper and ground-current insulator. At the down stream of the plastic tube, a sample injection valve (Hamilton, Model HV LX6-6, Reno, NV) with a sample loop (h) of $1 \mathrm{ml}$ is connected on-line just ahead of the multi-electrode (ME) cell containing sixteen CFAEs and four zinc/zinc acetate reference electrodes. The connection tube between the sample injection valve and the ME cell is made as short as possible. The outlet of this ME cell is put into a waste solution container. 


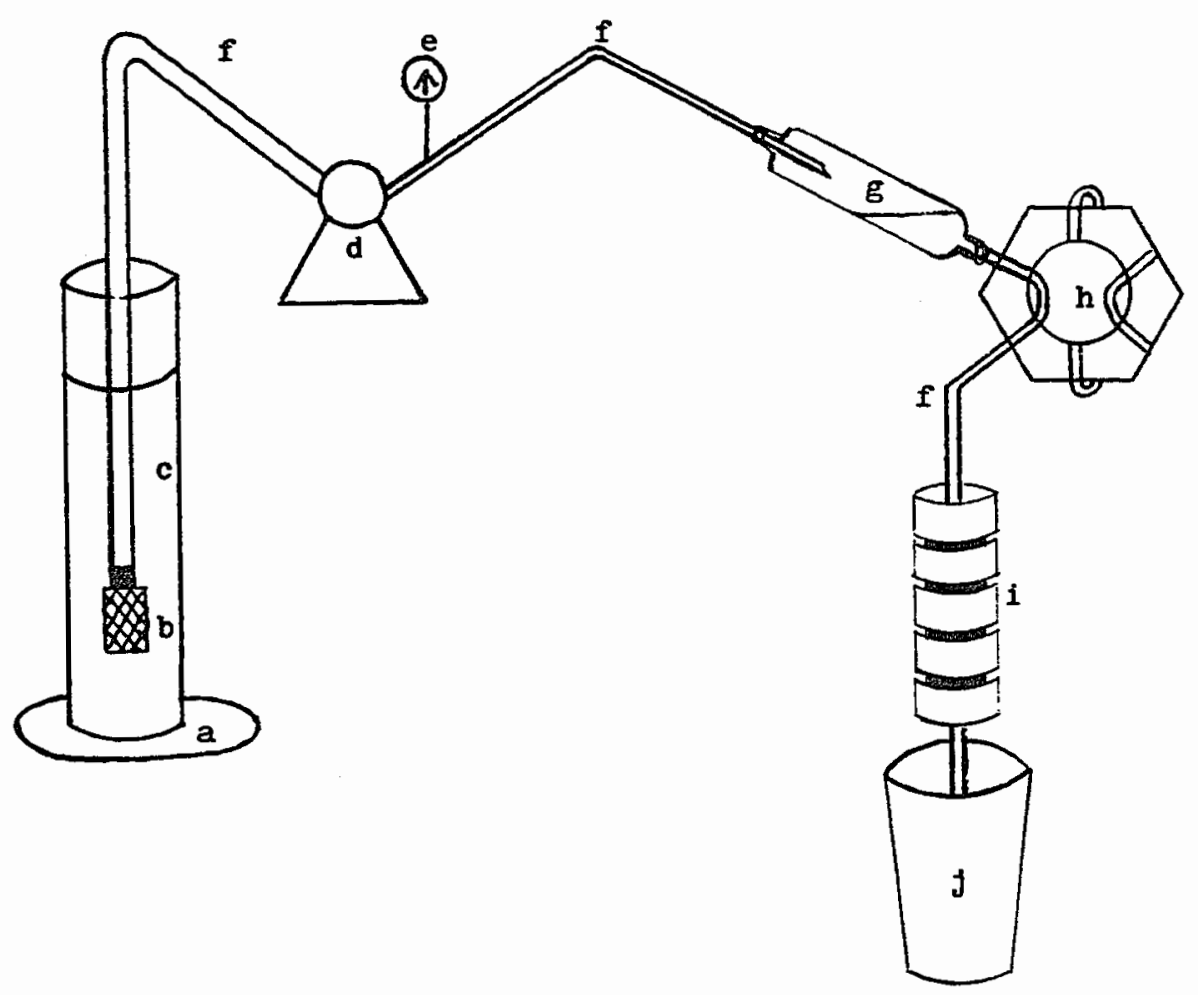

Figure 5. Flow injection analysis system setup. (a) Supporting electrolyte reservoir; (b) filter; (c) supporting electrolyte; (d) minipump; (e) pressure gauge; (f) Teflon tube; (g) pulse damper and ground current insulator; (h) sample injection valve with a sample loop; (i) multi-electrode cell; (j) waste solution container. 


\section{INSTRUMENTATION}

The circuits, including two digital-to-analog converters (DACs), an integrating current follower unit, a data acquisition systen, and an interface, are contained on two circuit boards. These two circuit boards are connected together by two ribbon cables. An external power supply of $+/-15$ volt and +5 volt is also required. A block diagram of the entire instrumentation is shown in Figure 6. The details of these units, including the interface, are discussed in the following sections. A complete schematic diagram of the circuitry with the component identification is shown in Appendix A.

\section{Computer system}

A Commodore 64 personal computer $(C-64)$ based on a 6510 microprocessor is used for data control. It is connected to (i) a Commodore 1541 floppy disk drive; (ii) a Philco TV monitor; and (iii) a Fujitsu DX 2100 printer to handle command executions for the control of the potentiostat, data acquisition, data storage, and data management. The block diagram of the computer system is shown in Figure 7. The signal lines, including the address bus and the data bus, of the expansion port of the c-64 are buffered by two tristate buffers (IS 245 \& LS 244) because they have limited drive capacity . 


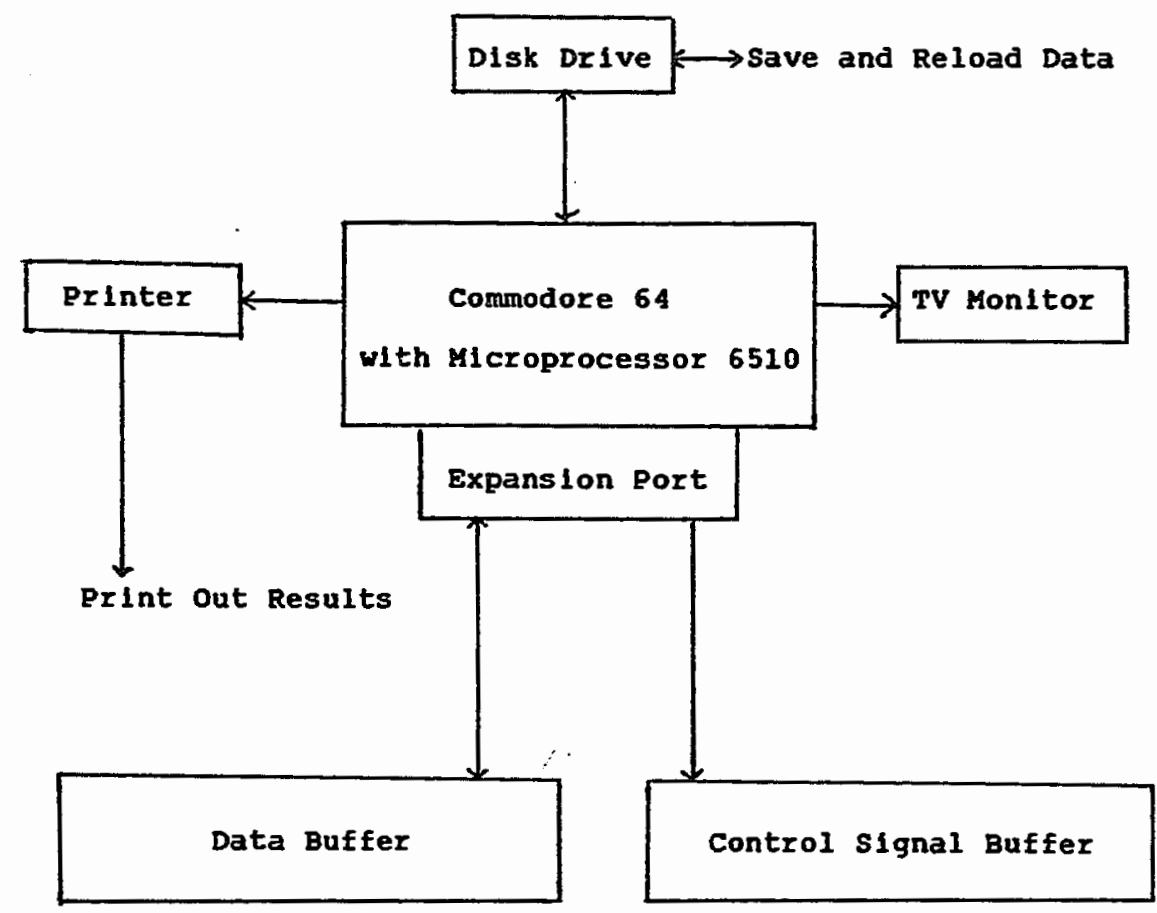

Figure 6. Block diagram of the electronic instrumentation. 


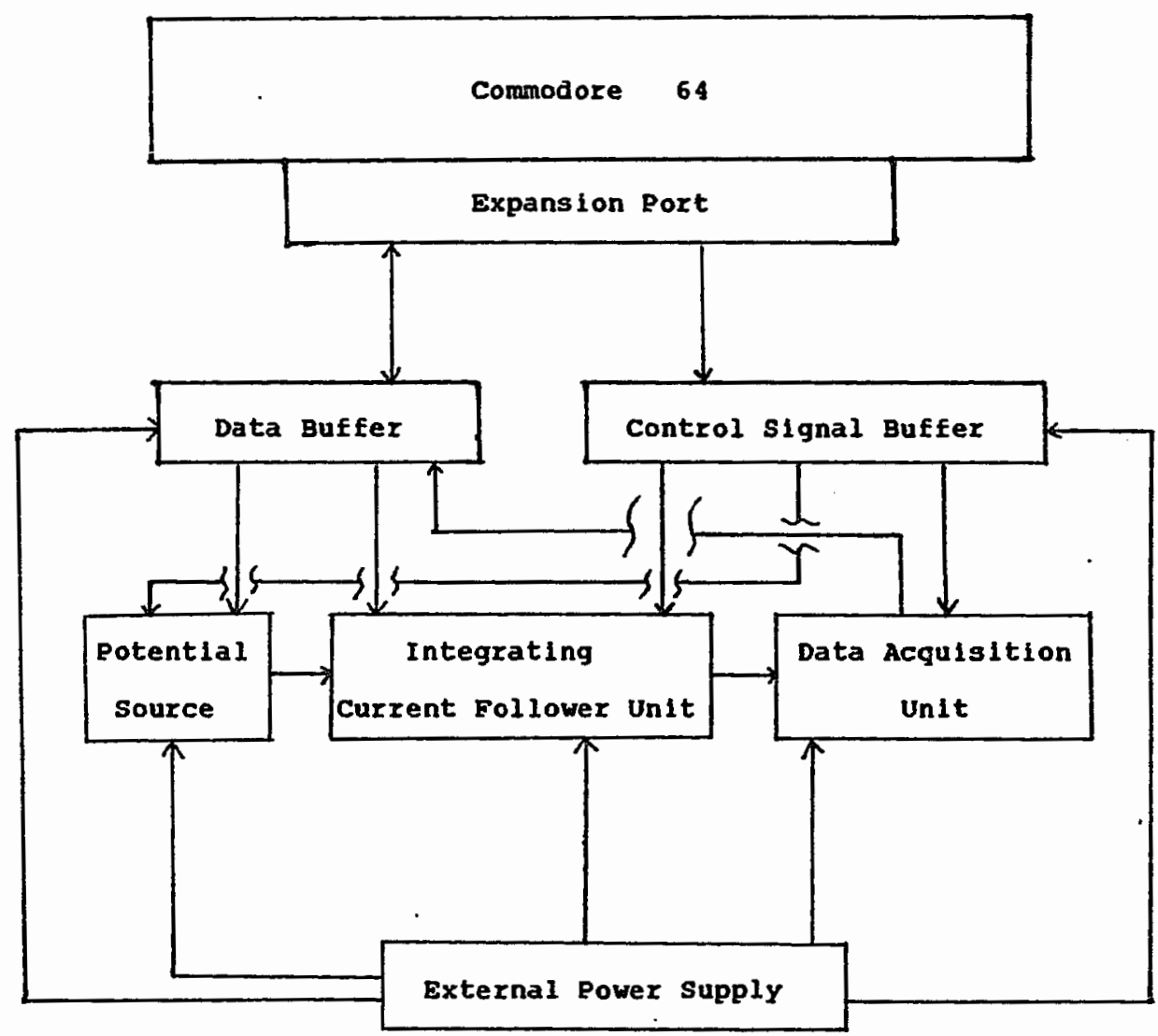

Figure 7. Block diagram of the computer system. 


\section{Potential source}

The block diagram of the potential source, which supplies the required potentials to the working electrodes relative to the reference electrode (i.e., circuit ground), is shown in Figure 8. A short BASIC program as shown in Appendix B and a digital voltmeter are used to set up the voltage outputs.

The input signals are obtained from two 12-bit DACs. The two constant current outputs from these two DACs are set, respectively, via the control of the software. These two current outputs are then converted into two voltages by two operational amplifiers. Both voltage outputs are connected to a voltage divider consisting of fifteen $1-\mathrm{K}$ ohm resistors (R2) in series. These voltage outputs can be changed via the control of the same software.

\section{Integrating current Follower Unit}

A block diagram of the integrating current follower unit is shown in Figure 9. It consists of sixteen integrating current followers with sixteen reset switches, respectively, and switch-controlling circuitry. The inverting input of each current follower is connected to one electrode in the multi-electrode cell. The noninverting inputs are connected to the voltage divider, described in the previous section. The analog signals generated by the electrodes are fed to the integrating current followers and 


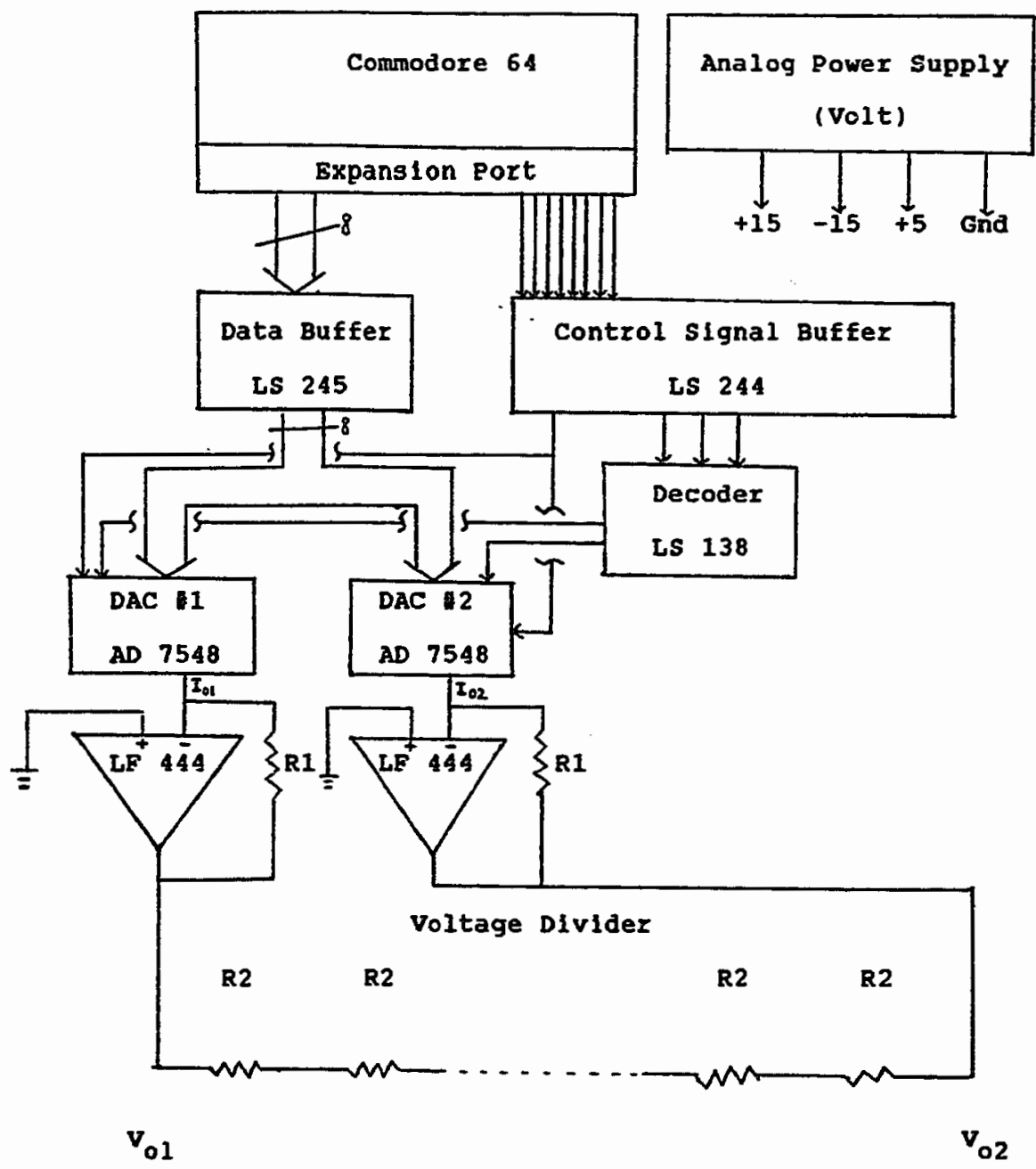

Figure 8. Block diagram of the potential source. 


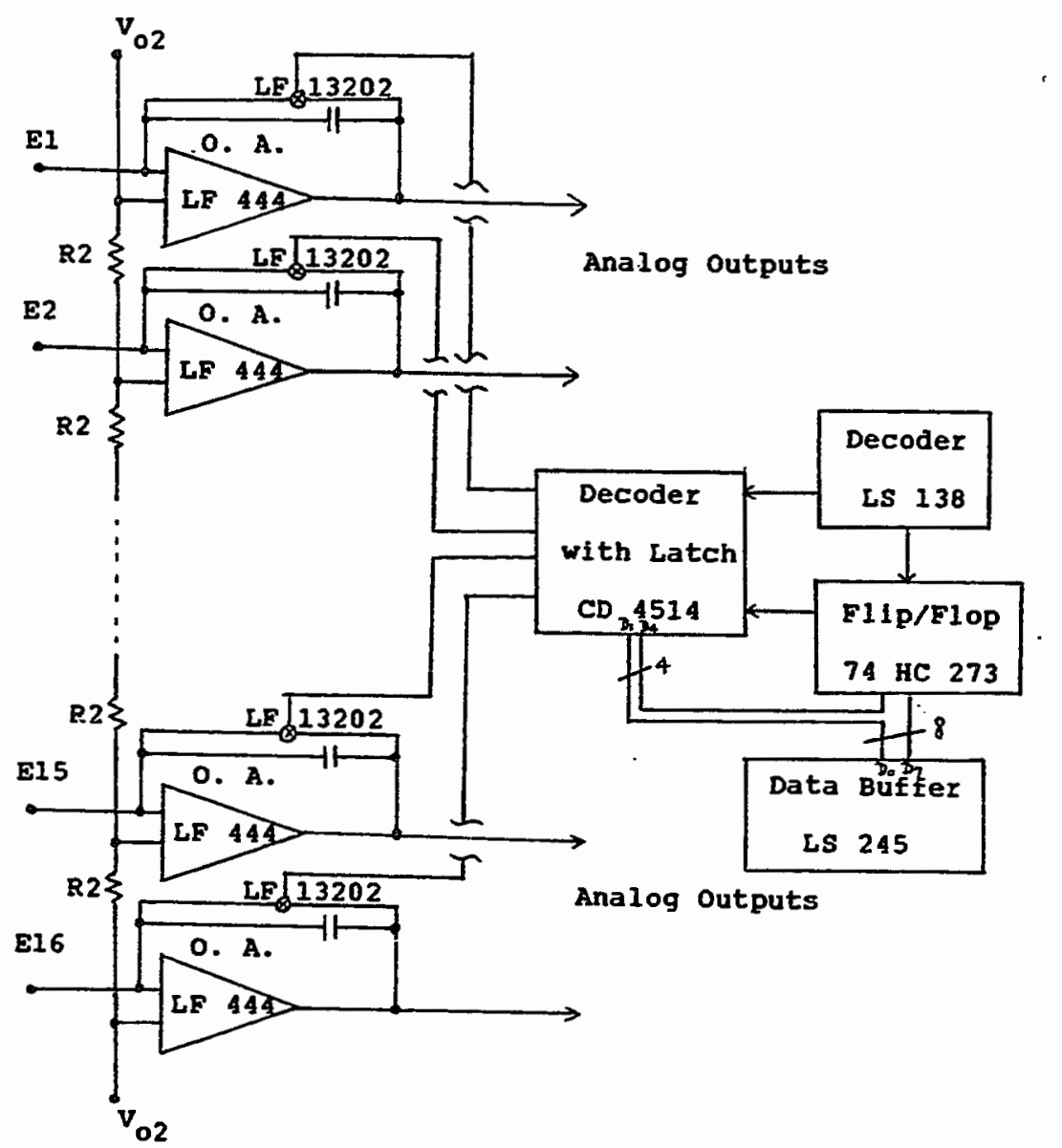

Figure 9. Block diagram of the integrating current follower unit. 
continuously integrated. All integrators can be reset, one by one, via the control of an assembly language subroutine as described in Appendix $D$.

\section{Data Acquisition System}

Figure 10 shows a block diagram of the microprocessorbased data acquisition system. It is comprised of the following components: (i) A sample and hold (S/H) amplifier, including an S/H chip (LF 298, National Semiconductor), to perform the "hold" state for the conversion of analog signals which are generated by the electrolytes to the digital values; (ii) A peripheral interface adapter (PIA) circuitry, including a PIA chip (MC 68B21P, Motorola) which contains two 8-bit bi-directional data buses and four interrupt/control lines for interfacing the C-64 with the peripheral devices; (iii) A 12-bit analog-to-digital converter (ADC) (AD574A, Analog Devices) for converting electrical signals from the analog domain to the digital domain. This 12-bit ADC resolves the full-scale voltage range into 4096 units. (iv) A multiplexer circuitry, including three multiplexers (DG 508 \& LF 13508), forming a two-level structure for sequentially allowing only one output of the current followers to reach the $S / H$ chip (LF 298) at a time. (v) A decoder circuitry, including a decoder chip (LS 138) that is used to address and control several chips. 


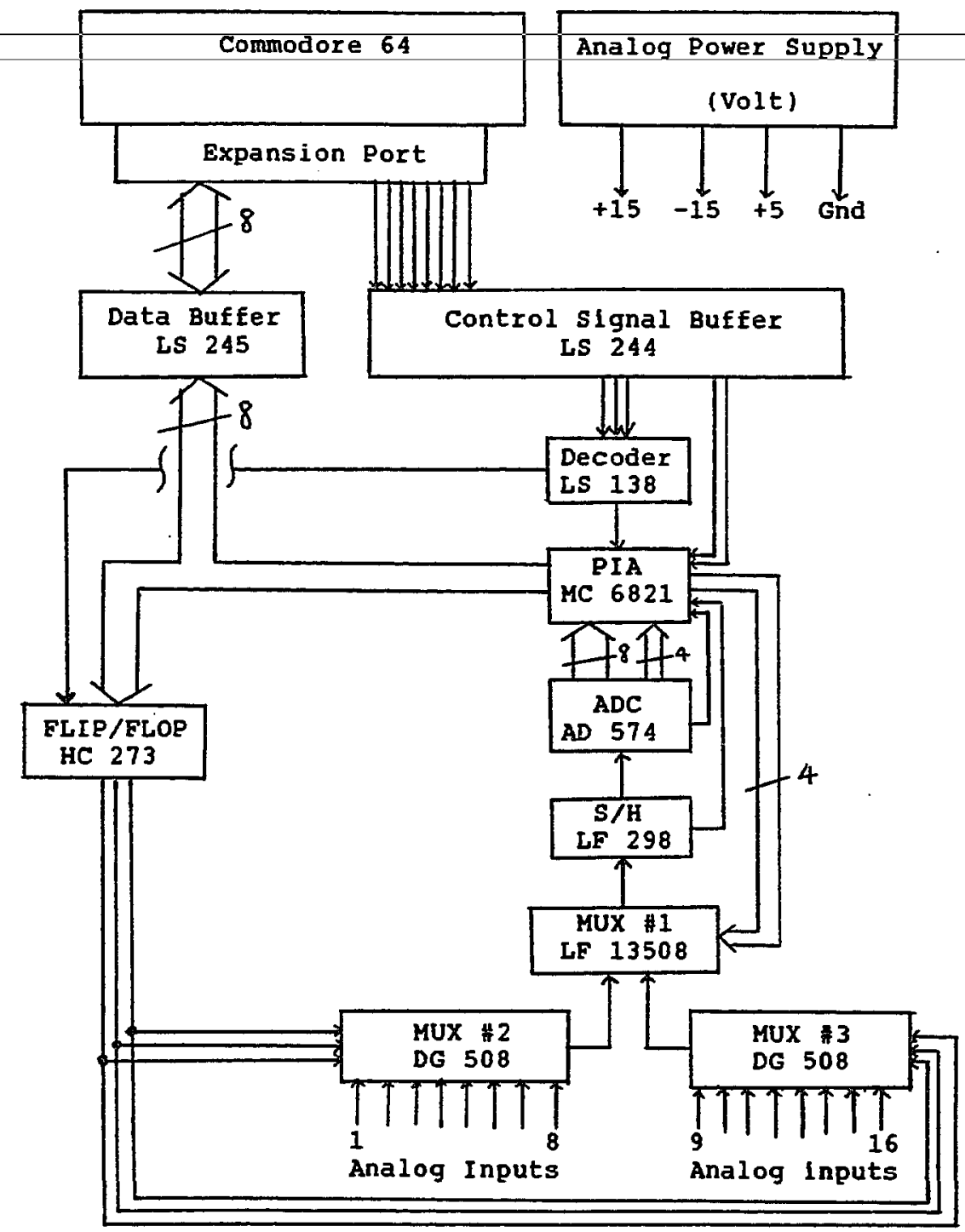

Figure 10. Block diagram of the data acquisition system. 
Under the control of the software, only one output of the current followers is selected and reaches the $\mathrm{S} / \mathrm{H}$ chip via the multiplexers. Then the A/D conversion circuitry converts this analog signal from the output of the current follower to a I2-bit parallel digital signal. The output of the 12-bit $A / D$ conversion is read in as two bytes and is addressed in the memory space to be stored to accommodate the 6510 microprocessor's 8-bit data bus. After the signal is stored, the output of next current follower is sent to the $S / H$ chip via a different combination of the opened channels of the multiplexers. Then the cycle is repeated again and again until the preset time period is over.

The A/D conversion cycle is timed under the control of a cycle-counting subroutine in an assembly language subroutine. The c-64 itself provides two presettable 16-bit down counters (30) which can be either independently programed as two separated timers or jointly programed to form a clock. The data acquisition frequency is controlled by these two presettable 16-bit down-counter timers. Timer \#1 is used to set a time interval for each integrating current collected. It is set as a multiple of $1 / 60 \mathrm{sec}$ (60 $\mathrm{Hz}$ ) in order to get rid of the noises generated by $60 \mathrm{~Hz}$ power lines. Timer \#2 is set so that the time of a cycle is one second longer than that of Timer \#1 in order to acquire the integrating time of current signals. The parameters to set up these two timers are interrelated. They also 
depended on the sample size, the sample concentration, and the RAM capacity of the C-64. The combination of Timer \#2 and a cycle counter is used to record the real time at each data acquisition and the total covered time period for each on-line analysis.

\section{Software}

Several software programs are used in conjunction with this multi-electrode voltammetric instrumentation. All of them are written in BASIC language except one, named "DATACQ", which is written in assembly language. The main program, named "COLLECT.DATA", is used to control the entire instrumentation; to obtain coulometric data, and to save data onto a disk. "DATACQ" software is a subroutine called up by this main program to convert analog signals generated at the electrodes to digital values and to store them in the RAM of the c-64. Two more software programs are used for further data management. The first one, named "NORMALIZE", is used for the surface area normalization factors of 16 CFAEs in the ME cell. The second one, named "RESULT", is used to get amperometric data for plotting pseudovoltammograms after the data have been normalized. All software programs are discussed and attached in Appendices C, D, E, and F. 
CHAPTER III

MATERIALS AND APPARATUS

MATERIALS

\begin{abstract}
All the materials used are analytical grade and are used without any further purification. The water used to prepare all solutions is triply distilled in a quartz still (Q-water) and stored in 1-liter polyethylene bottles.

I M Acetate Buffer stock Solution
\end{abstract}

$82.03 \mathrm{~g}$ of anhydrous sodium acetate and $17.2 \mathrm{ml}$ of glacial acetic acid are dissolved and diluted with $Q$-water to equal 1 liter. The solution is then filtered through 0.45 micrometer Millipore filters (Millipore, TYpe HA). This solution is prepared weekly.

\title{
Argon Gas
}

Argon gas (AIRCo Inc., Montvale, N.J.) without any further purification is used.

\section{D.I M Acetate Buffer solution}

$0.1 \mathrm{M}$ acetate buffer solution is prepared by dilution of $I M$ acetate stock solution with Q-water. 


\section{Millimolar Hyaroquinone Sample Solution}

Hydroquinone solutions are prepared daily by dissolving the appropriate amount of hydroquinone in $0.1 \mathrm{M}$ acetate buffer solution, followed by deoxygenation with argon gas for 1 hour prior to use.

\section{M Sodium Acetate Solution}

$8.20 \mathrm{~g}$ of anhydrous sodium acetate is dissolved and diluted by $Q$-water to $100 \mathrm{ml}$.

\section{APPARATUS}

\section{Apparatus for Cyclic Voltammetry}

A 25-mL beaker is employed as an electrochemical (EC) cell body. A carbon fiber array electrode (CFAE) contained in a working electrode disk (WED) is used as a working electrode, a saturated calomel electrode (SCE) as a reference electrode, and a platinum wire as an auxiliary electrode. All three electrodes are joined to the beaker through holes in its plastic cover to form a conventional EC cell. This cell in conjunction with a potentiostat (HEKA, Type PG28, West Germany) and an $\mathrm{X}-\mathrm{Y}$ recorder (Linear Instruments corporation, Model 8036, Irvine, $C A$ ) is used to perform cyclic voltammetry. A square wave function generator iEXACT Electronics, Inc., Model 120, Hillsboro, OR) is used in conjunction with the potentiostat to reactivate the CFAEs. Potentials are monitored with a digital multimeter (John Fluke Co. Inc., Model FLUKE 75, 
Everett, WA). AII potentials measured and reported for this 3-electrode cell are referred to the SCE.

\section{Apparatus for Pseudo-Voltammetry}

The previously discussed multi-electrode (ME) cell and instrumentation are used to perform the measurements. In the ME cell, 16 CFAEs contained in 4 WEDs are deployed as working electrodes. For each 4 CFAEs on the same WED, a zinc strip in $1 \mathrm{M}$ sodium acetate solution is used as a reference electrode. The potential of these reference electrodes measured versus a SCE is $-1.055 \mathrm{~V}$. The potentials applied on the CFAEs are generated by the potentiostat via the control of the sofitware. The whole flow injection analysis system is as described in the previous chapter. 


\section{CHAPTER IV}

\section{EXPERIMENTAL PROCEDURES}

EXPERIMENTS WITH A CONVENTIONAL ELECTROCHEMICAL CELL

Since the electrochemical (EC) behavior of electrodes can be evaluated by cyclic voltammetry, cyclic voltammograms were used to examine the performance of carbon fiber array electrodes (CFAEs) on the working electrode disk (WED). All preliminary experiments were performed in an unstirred solution with a conventional EC cell. This conventional EC cell is described in the previous chapter. All potentials were measured and reported versus a saturated calomel electrode (SCE) for this conventional cell.

All cyclic scans, which were performed with the same CFAE on a WED in a solution containing approximately $I \mathrm{mM} \mathrm{HQ}$ in $0.1 \mathrm{M}$ acetate buffer $(\mathrm{AB})$ solution at a scan rate of 20 $\mathrm{mv} / \mathrm{sec}$, started at $+0.0 \mathrm{~V}$ with automatic scan reversal at $+0.9 \mathrm{~V}$ and then scanned back to $+0.0 \mathrm{~V}$ except where specified. The cyclic voltammograms obtained were recorded on the $X-Y$ recorder.

Square Wave Parameter optimization

To evaluate the results of CFAE reactivation, the same conventional EC cell was used to perform cyclic voltammetry. 
The electrode reactivation process involves cycling a square wave, generated by a function generator, on a CFAE dipped in a $20 \mathrm{ml} 0.1 \mathrm{MAB}$ solution for a period of time. The different combinations of the square wave parameters, including the upper and lower potential limits, frequencies, and duration, were studied in order to find the optimized parameters of a square wave for CFAE reactivation.

After potential cycling, the electrode was moved to a hydroquinone (HQ) solution which had been purged by argon gas and held at the initial potential $(+0.0 \mathrm{~V})$ of a cyclic scan for a time delay period until the current generated by the electrode reactivation process on the CFAE subsided. Different time delay periods were also investigated. Finally, a cyclic scan with a scan rate of $20 \mathrm{mV} / \mathrm{s}$ was performed as described in the previous section.

\section{EXPERIMENTS WITH THE MULTI-ELECTRODE CELL}

Before WEDs were deployed in the flow cell, every CFAE on WEDs was individually examined for noise level and current leakage by cyclic voltammetry with a conventional cell. After the assembly of the ME cell, CFAEs were never polished again. All the potentials measured and reported for this ME cell referred to the zinc/zinc acetate reference electrode.

The experimental procedures are the same for both CFAE normalization factors and pseudo-voltammetry. A complete 
experimental cycle involves three steps: connection of the ME cell on-line, reactivation of CFAEs in the cell (including time delay for subsidence of the currents generated by the reactivation process), and coulometric data collection.

\section{Multi-Electrode cell on-Line}

The $0.1 \mathrm{M} A B$ solution was first pumped through the flow system at a constant flow rate produced by a minipump without connection of the ME cell to the circuits. This avoids supplying an unpredictable voltage to CFAEs in the cell, which may cause damage to the CFAEs. The flow rate was measured with a graduated cylinder and a stop watch. The ME cell was then pumped several times by using a plastic syringe (which was temporarily connected with the outlet of the cell via a connector) in order to avoid air bubbles being trapped in the cell.

Prior to performing the experiments, the potentials required at all CFAEs in the cell for either CFAE normalization factors or pseudo-voltammetry were determined by the cyclic voltammograms obtained from the preliminary experiments. For normalization factors of CFAE surface areas in the ME cell, a constant potential of $+1.95 \mathrm{~V}$ was applied to all CFAEs. In contrast, the potentials in the range between $+1.05 \mathrm{~V}$ and $+1.95 \mathrm{~V}$, equally divided, were applied to CFAEs, respectively, in ME cell for pseudovoltammetry. This potential range started before the 
oxidation of $\mathrm{HQ}$ occurs and ended at where maximum steadystate current is reached, i.e., the concentration of HQ at the electrode surface approaches zero.

The software program "COLLECT.DATA", loaded in the RAM of the c-64, was activated first. Then, the experimental conditions were input through the keyboard. After the instrument warmed up, the required potentials for CFAEs, generated by the digital-to-analog converter (DAC) units on the circuit board, were ready. The zinc/zinc acetate reference electrodes in the ME cell were connected to the circuit ground. The CFAEs in the cell were connected, in order, to the inverting input of the current follower, respectively.

Reactivation of CFAEs in the ME Cell

During working with CFAEs, inconsistent performance and high background current with noise were always observed after they were in contact with the supporting electrolyte solution for a long period of time. The sensitivity of CFAEs was also diminished during the successive scans without the electrode reactivation. Therefore, reactivation of CFAEs was performed just prior to data collection.

The reactivation process of the CFAEs in the ME cell was performed by using a square wave which was generated by the DACs via the control of the same program. The parameters of this square wave were as follows: frequency, ca. $5 \mathrm{~Hz}$; upper potential limit, $+2.05 \mathrm{~V}$; lower potential 
limit, +1.05 V; and duration, 5 seconds. After the CFAEs were reactivated, each CFAE was held at the required potential 4 minutes to allow the residual current generated by this electrode surface reactivation process to subside.

\section{Collection of Coulometric Data}

During the wait for the subsidence of the residual currents, a sample was loaded into the sample injection loop. After the time delay period was over, data acquisition was performed as described in Appendix D. During the first 20 seconds the data collected represented the integrated background currents. After that, the sample injection loop was manually switched into the flow stream. The data collected after this point corresponded to the composition of the sample solution.

When either the setup of the sampling time was over or the RAM of the c-64 was filled up with the data, data collection was stopped. Then the data were combined according to the resolution time, followed by saving combined data onto a floppy disk along with all experimental information for either the normalization factors of CFAEs or the construction of pseudo-voltammograms. 


\section{CHAPTER V}

\section{RESULTS AND DISCUSSION}

For voltammetric studies in water, the supporting electrolyte selected must be very inert and also have high overvoltages associated with the formation of hydrogen and oxygen. That was why $0.1 \mathrm{M}$ acetate buffer (AB) was chosen as the supporting electrolyte for this study.

The accessible potential range of $0.1 \mathrm{M} \mathrm{AB}$ solution was determined by cyclic voltammetry in a conventional electrochemical (EC) cell with a carbon fiber array electrode (CFAE) contained in a working electrode disk (WED). As shown in Figure 11, the cyclic voltammograms (CVs) were obtained in the $\mathrm{AB}$ solution either without or with deoxygenation, respectively. Compared with each other, a reduction wave, caused by the reduction of $\mathrm{O}_{2}$ to hydrogen peroxide (31), is observed at potential ca. $-0.6 \mathrm{~V}$ in Figure 11a. However, in both CVs the currents increased notably with potentials either more positive than $+1.5 \mathrm{~V}$ or more negative than $-1.4 \mathrm{~V}$, which was due to the evolution of oxygen and hydrogen from water, respectively. Hence, the accessible potential range of $0.1 \mathrm{MAB}$ solution at CFAEs is between $-1.4 \mathrm{~V}$ and $+1.5 \mathrm{~V}$ with deoxygenation; otherwise, between $-0.3 \mathrm{~V}$ and, $+1.5 \mathrm{~V}$. 


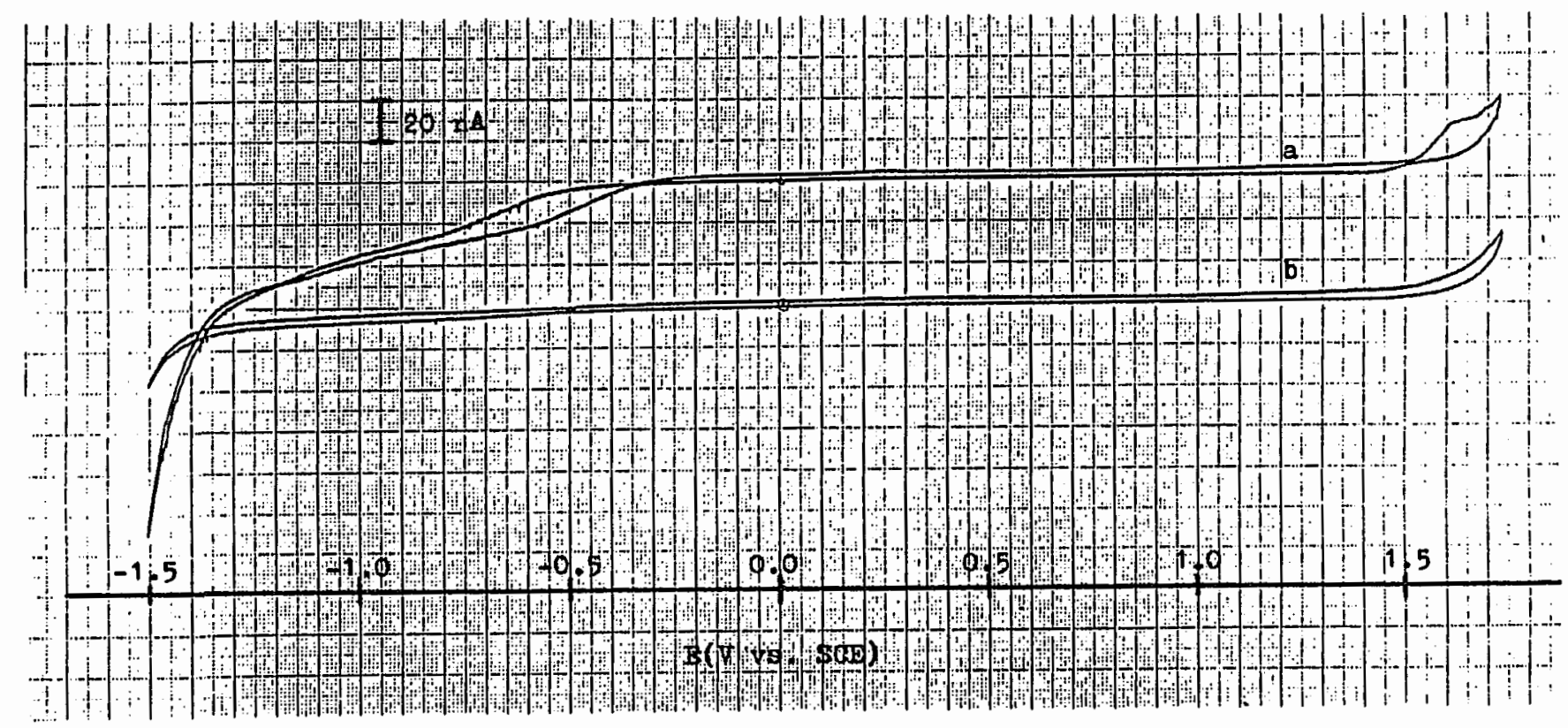

Figure 11. Cyclic voltammograms of $0.1 \mathrm{M}$ acetate buffer at a carbon fiber array electrode. Scan rate, $50 \mathrm{mV} / \mathrm{sec}$; (a) without deoxygenation; (b) with deoxygenation. 
With consideration of the accessible range of the $A B$ solution without deoxygenation, hydroquinone (HQ) was chosen as the probe to evaluate the results obtained from all experiments because its EC behavior is well-defined and it is also very sensitive to the surface state of the electrode. Furthermore, its oxidation wave falls in the potential range of $0.1 \mathrm{M} \mathrm{AB}$ solution where no other redox wave is produced.

Surface preparation is crucial for optimal performance of the cFAEs. Figure 12 shows the results of cyclic scans obtained after different polishing methods were performed. A freshly emery-polished CFAE without any other treatment showed good sensitivity, as shown in Figure 12a. However, the observed background current, noise levels, and half-wave potentials ( $E_{1 / 2} ' s$ ) of $\mathrm{HQ}$ obtained after each polishing of a CFAE were different; even though identical polishing procedures were employed. Kamau (22) has found that a variety of surface functional groups created by polishing causes the variation of the background current and noise level. The $E_{1 / 2}$ shift may be caused by anodization of the electrode surface. The background current and noise level were decreased dramatically by using a freshly aluminapolished CFAE, as shown in Figure 12b. The $E_{1 / 2}$, compared with Figure 12a, shifts to a more anodic value. If the alumina-polished CFAE was cleaned either by sonic waves or a cyclic scan, the noise level and background current 

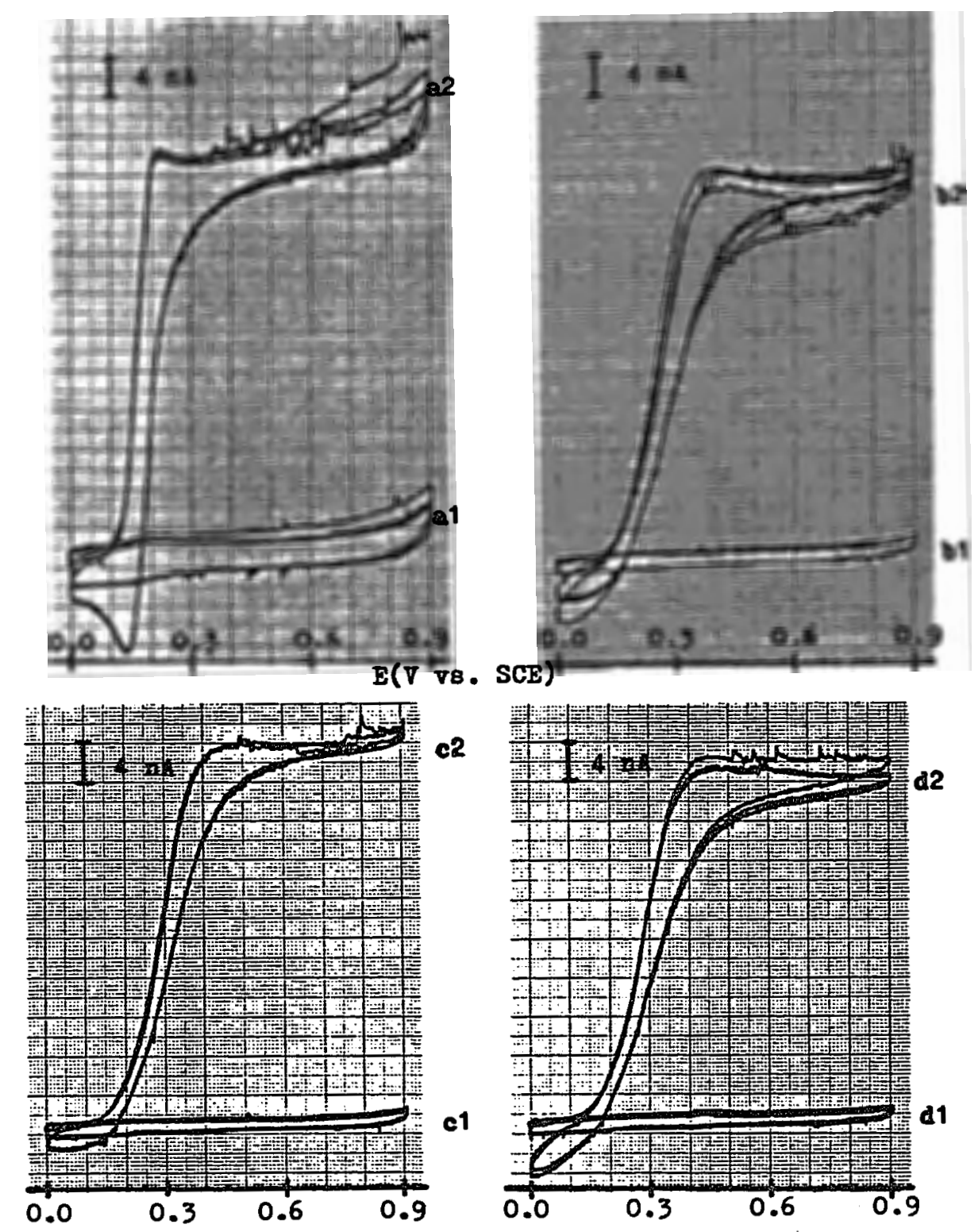

Fiqure 12. Effects of carbon fiber array electrode surface preparation upon the cyclic voltammogram. Scan rate, $20 \mathrm{mV} / \mathrm{sec} ;$ (1) $0.1 \mathrm{M} \mathrm{AB}$; (2) $1 \mathrm{mM} \mathrm{HQ;} \mathrm{(a)} \mathrm{freshly} \mathrm{emery-polished} \mathrm{CFAE;} \mathrm{(b)}$ freshly alumina-polished CFAE; (c) freshly sonic wave-cleaned CFAE; (d) freshly cyclic scan-cleaned CFAE. 
decreased a small amount as shown in Figure $12 \mathrm{c}$ and $12 \mathrm{~d}$. The $E_{1 / 2}$ shifts slightly in the anodic direction.

\section{REACTIVATION OF CARBON FIBER ARRAY ELECTRODES}

Electrochemists have observed that the performance of electrodes is always hampered by a gradually fouling of the surface during exposure of an electrode to solutions (31, 32). This leads to a gradual decrease in detection limit and sensitivity of the electrode. Such loss of electrode surface activity is usually attributed to the adsorption of analyte itself, reaction products, or impurities on the electrode surface (32).

The occurrence of analyte adsorption on the CFAE surface is demonstrated in Figure 13. Figure 13b shows a small bump at ca. $+0.3 \mathrm{~V}$ (VS. SCE) after leaving a CFAE in HQ solution with $0.0 \mathrm{~V}$ applied on it for 1 hour. However, Figure 13a does not have any bump after leaving the same electrode in $A B$ solution for the same time. This indicates that slow impurities adsorption on the CFAE surface was taking place during CFAE exposure to HQ solution. It also indicates that the adsorbent on the CFAE surface is HQ. Furthermore, the amount of HQ adsorbed on the electrode surface is proportional to time, as shown in Figure 13c, $d$, and e. However, this small bump disappeared and a reproducible $\mathrm{CV}$ was obtained after several successive scans, as shown in Figure 13c. It indicates that the adsorbent on 


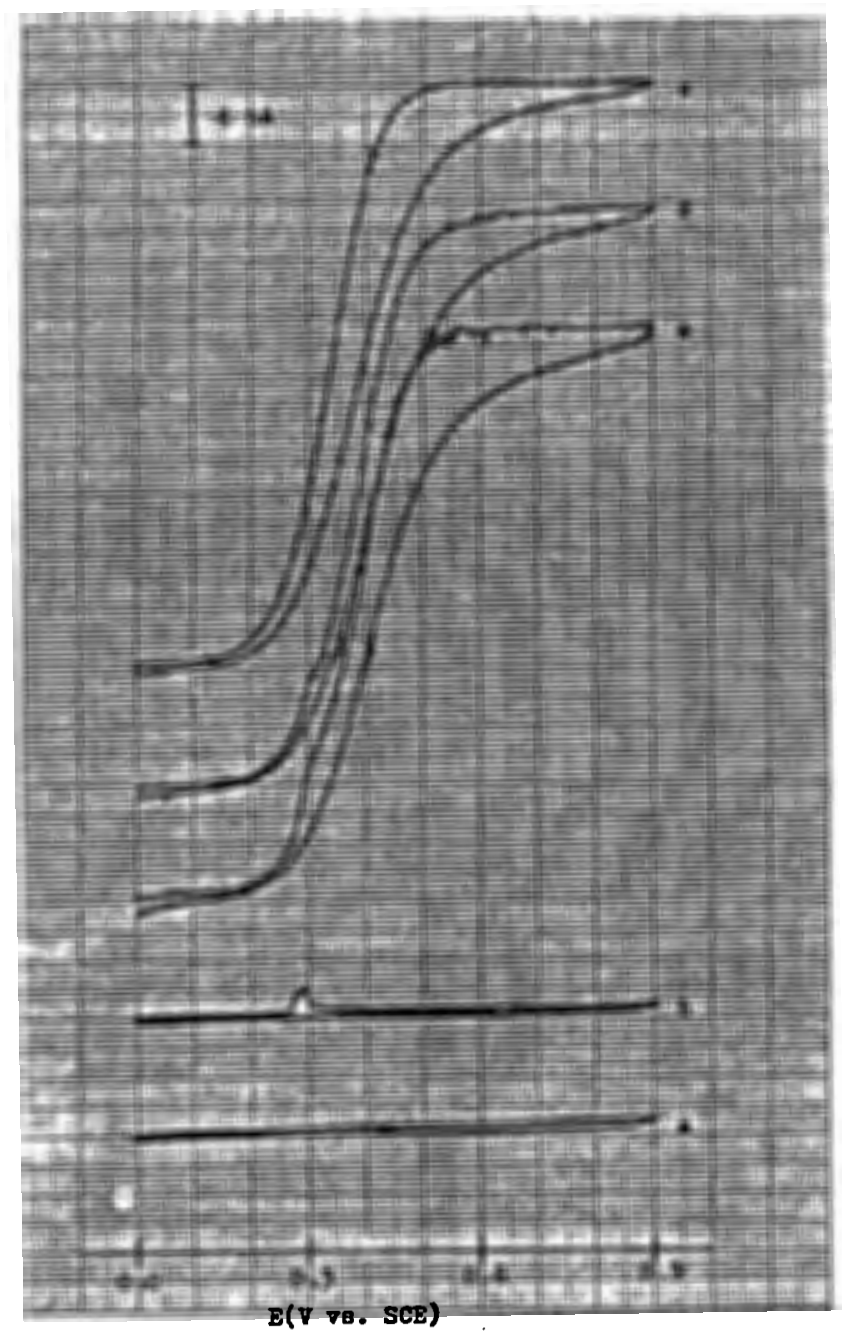

Figure 13. Time effects upon the cyclic voltammogram. Scan rate, $20 \mathrm{mV} / \mathrm{sec} ;$ (a) after leaving a CFAE in $A B$ for $I$ hour with 0 volt applied at it; $(b, d)$ after leaving a CFAE in $\mathrm{HQ}$ solution for 1 hour; (e) after leaving it in $\mathrm{HQ}$ solution for 3 hours; (c) after successive cyclic scans. Voltammograms are obtained with $(a, b) 0.1$ $\mathrm{M} \mathrm{AB} ;(c, d, e) 1 \mathrm{mM} \mathrm{HQ}$. 
the electrode surface can be removed by cyclic scans. It also indicates that CFAEs can reach a reproducible condition.

After leaving this activated CFAE in $A B$ solution overnight and without potential applied at it, the $E_{1 / 2}$ shift in the cathodic direction by up to $200 \mathrm{mV}$ and the decreased separation $\mathrm{E}_{\mathrm{p}}-\mathrm{E}_{\mathrm{p} / 2}$ were observed, as shown in Figure 14a, compared with the values obtained in Figure 13c. It indicates that the electrode reverted to a typical condition after leaving it in the $\mathrm{AB}$ solution overnight without a potential applied on it. Fortunately, during successive cyclic scans between $+0.0 \mathrm{~V}$ and $+0.9 \mathrm{~V}$ in $\mathrm{HQ}$ solution, the $E_{1 / 2}$ gradually shifted back. And a reproducible $\mathrm{CV}$ was obtained eventually, as shown in Figure 14b. It indicates that the electrode surface is in a reproducible condition. This process can also be hastened by applying a positive potential at the CFAE, depending on how positive the potential is and how long it is applied. Therefore, CFAEs must be reactivated in order to get a reproducible result. A simple and rapid electrode reactivation method for the CFAEs in a multi-electrode (ME) cell needs to be found to produce a reproducible surface condition. 


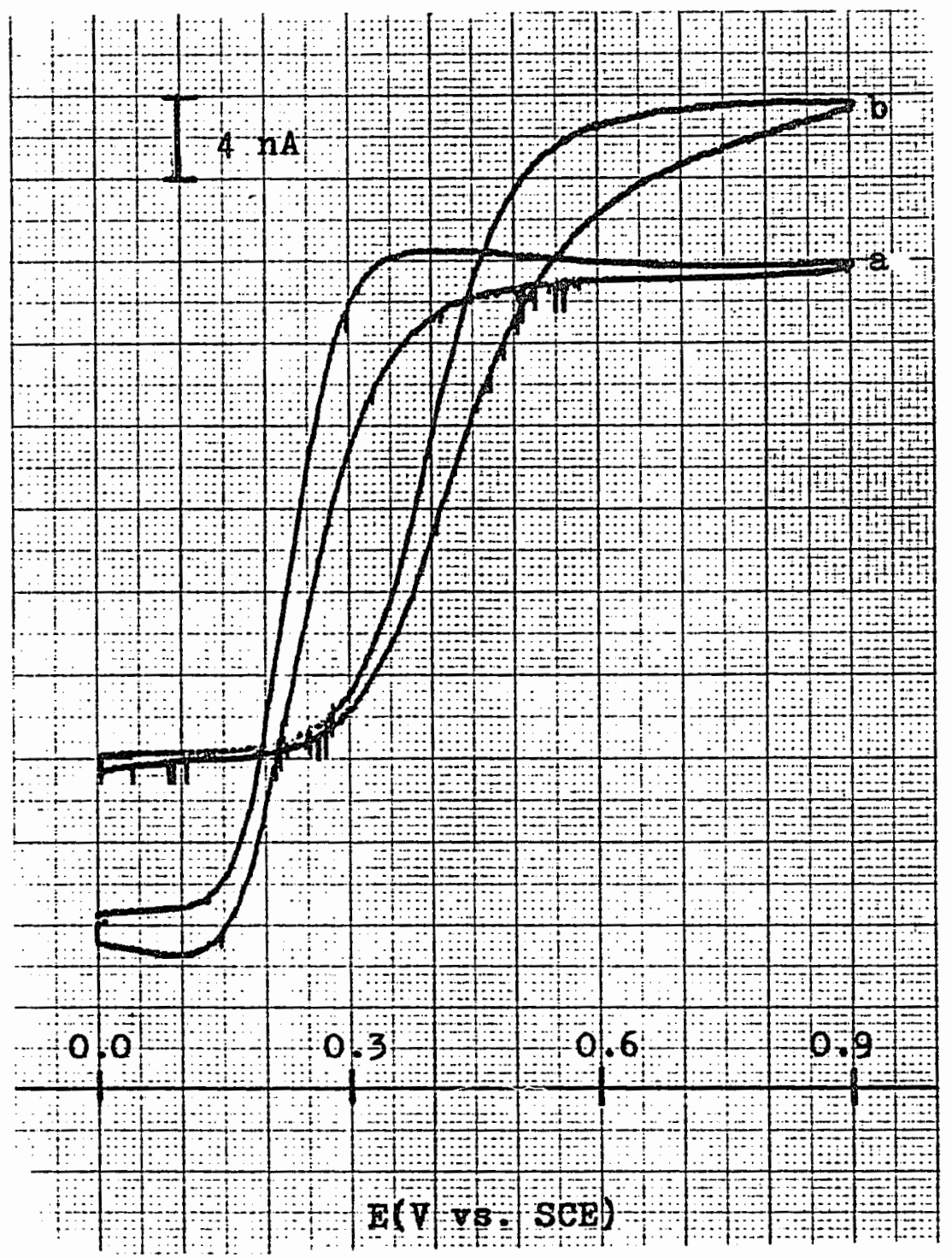

Figure 14. Effects of an applied potential at a carbon fiber array electrode upon the cyclic voltammogram. Solution, $0.9 \mathrm{mM} \mathrm{HQ;} \mathrm{scan} \mathrm{rate,} 20$ $\mathrm{mV} / \mathrm{sec}$; (a) after leaving a CFAE in $0.1 \mathrm{M} \mathrm{AB}$ overnight and without potential applied at it; (b) after the reproducible result obtained with cyclic scans in $0.1 \mathrm{M} \mathrm{AB}$. 


\section{In Situ Carbon Fiber Array Electrode Reactivation}

Many methods used to reactivate electrode surfaces have been reported (33), such as a surface polished with an abrasive material, treated with radio frequency plasmas, heated at low pressures, irradiated with a laser, and treated with potential cycling. with the consideration of the configuration and instrumentation of multi-electrode voltammetry (MEV), the electrode surface reactivation with a square wave appears to be the most convenient means of achieving in situ surface activation to improve the performance of graphite electrodes in the cell. The primary reason is because a square wave is very easy to generate with software. The CFAEs placed in the ME cell are intended to be used for a considerable time without cell disassembly. When CFAEs become fouled, they can be reactivated by this method without the need of cell disassembly.

The work discussed herein is to determine the parameters of the square wave used for CFAE reactivation and to improve the sensitivity and reproducibility of CFAEs. The parameters inclicie the upper and lower potential limits, frequency, and duration. A CFAE known to exhibit good performance was used to test the different combinations of experimental conditions and to determine all the parameters of the square wave. The apparatus and experimental procedures were described in chapter III and IV. AII potentials measured and reported in this section are versus 
the saturated calomel reference electrode (SCE) except where specified. The effect of CFAE surface reactivation using a square wave is evaluated by potential shifts and limiting current variations of cyclic voltammograms generated by the HQ solution.

Applying a very positive potential on the CFAE is not advisable because this may cause the destruction of the electrode (20). According to the preliminary experiments, a dramatic loss of sensitivity was observed if the upper potential limit of the square wave supplied at a CFAE was over $+2.0 \mathrm{~V}$ and lasted a period of several minutes. The sensitivity lost under this condition can not be recovered by EC reactivation except by repolishing the electrode. Also, the accessible range of $A B$ solution is between $-1.4 \mathrm{~V}$ and $+1.5 \mathrm{~V}$ (VS. SCE). Beyond that range, gas bubbles due to the formation of $\mathrm{H}_{2}$ and $\mathrm{O}_{2}$ by the decomposition of $\mathrm{H}_{2} \mathrm{O}$ may be trapped on the electrode surface and cause a change of electrode activity. Therefore, the potential limits for the square wave need to be between $-1.4 \mathrm{~V}$ and $+1.5 \mathrm{~V}$.

Figure 15 shows the CVs of HQ obtained after a CFAE reactivated by a square wave at frequency of $0.5 \mathrm{~Hz}$, duration of $30 \mathrm{sec}$, upper potential limit of $+0.9 \mathrm{~V}$, but with different lower potential limits. Comparison of all CVs in Figure 15, $E_{1 / 2}$ as well as the limiting currents on the plateau shows that they are the same. The results obtained are independent of the lower potential limit of the 


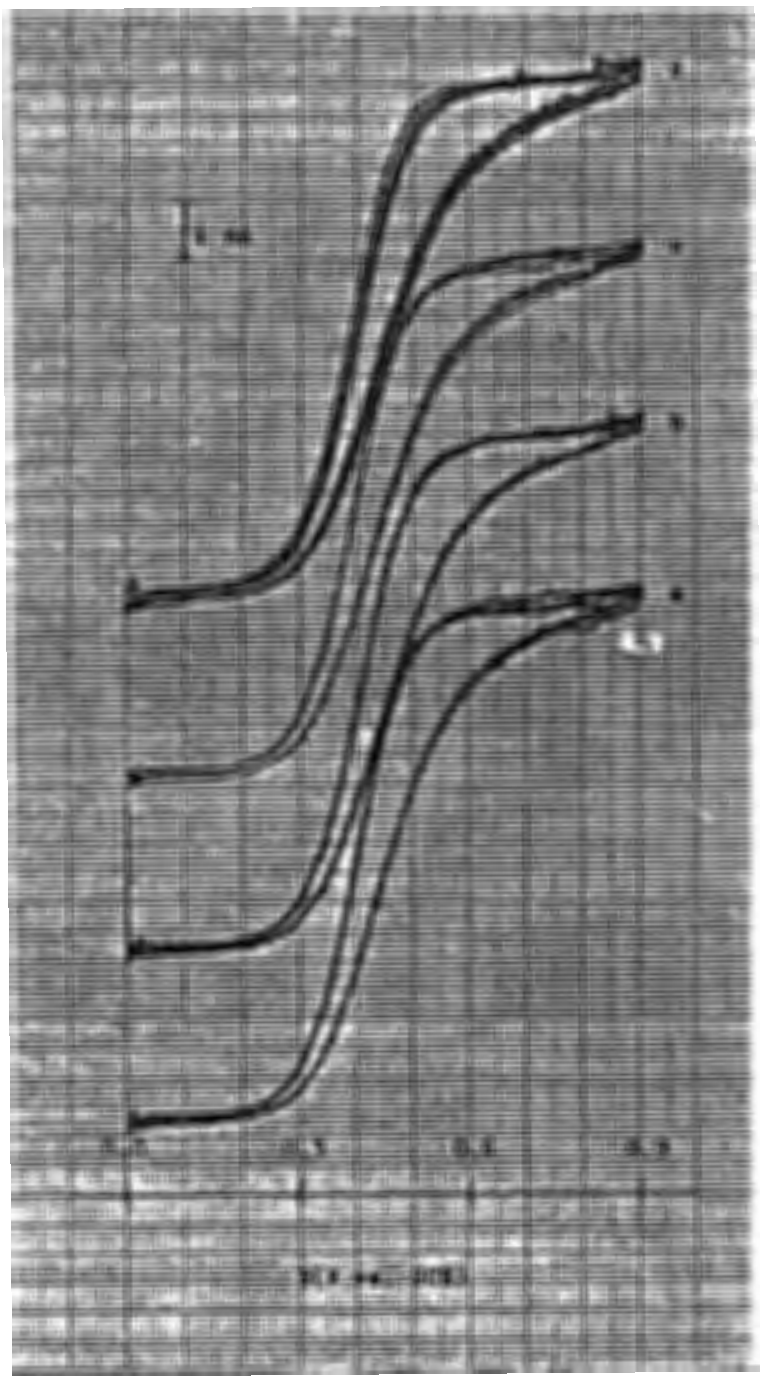

Figure 15. Effects of lower potential limit of a square wave upon the cyclic voltammogram. Solution, $1 \mathrm{mM} \mathrm{HQ}$; scan rate, $50 \mathrm{mV} / \mathrm{sec}$; (a) a cyclic scan-reactivated CFAE; a square wavereactivated CFAE with parameters: upper potential limit, +0.9 V; lower potential limit, (b) $-0.2 \mathrm{~V}$, (c) $-0.6 \mathrm{~V}$, (d) $-1.6 \mathrm{~V}$; frequency, $0.5 \mathrm{~Hz}$; duration, $30 \mathrm{sec}$; delay, $4 \mathrm{~min}$. 
square wave.

The correlation between the upper potential limit of the square wave and the EC behavior of the reactivated CFAE is shown in Figure 16. The experimental conditions were the same as in Figure 15 except the lower potential limit is $0 \mathrm{~V}$ and with different upper potential limits, respectively. Comparison of all cVs in Figure 16 shows that the $E_{1 / 2}$ 's are constant when the upper potential limits of the square wave are not greater than $+1.4 \mathrm{~V}$. The shape of curves and the limiting currents on the plateau are the same. However, as the upper potential limit of the square wave is made more positive than $+1.4 \mathrm{~V}$, remarkable effects on the curve shape are observed, i.e., a poorly-defined wave and $\mathrm{E}_{1 / 2}$ shift toward more anodic direction, as shown in Figure $16 \mathrm{~d}$. Therefore, the upper potential limit of the square wave chosen must be not greater than $+1.4 \mathrm{~V}$.

The correlation between the frequency of the square wave and the EC behavior of the reactivated CFAE is shown in Figure 17. The experimental conditions were the same as in Figure 16 except the upper and lower potential limits of the square wave were $+1.0 \mathrm{~V}$ and $-0.1 \mathrm{~V}$, respectively, and with different frequencies. Comparison of these curves shows that there is no significant difference when a variety of frequencies are applied. Figure 18 shows the correlation between the duration of the square wave and the EC behavior of the reactivated CFAE. The experimental conditions were 


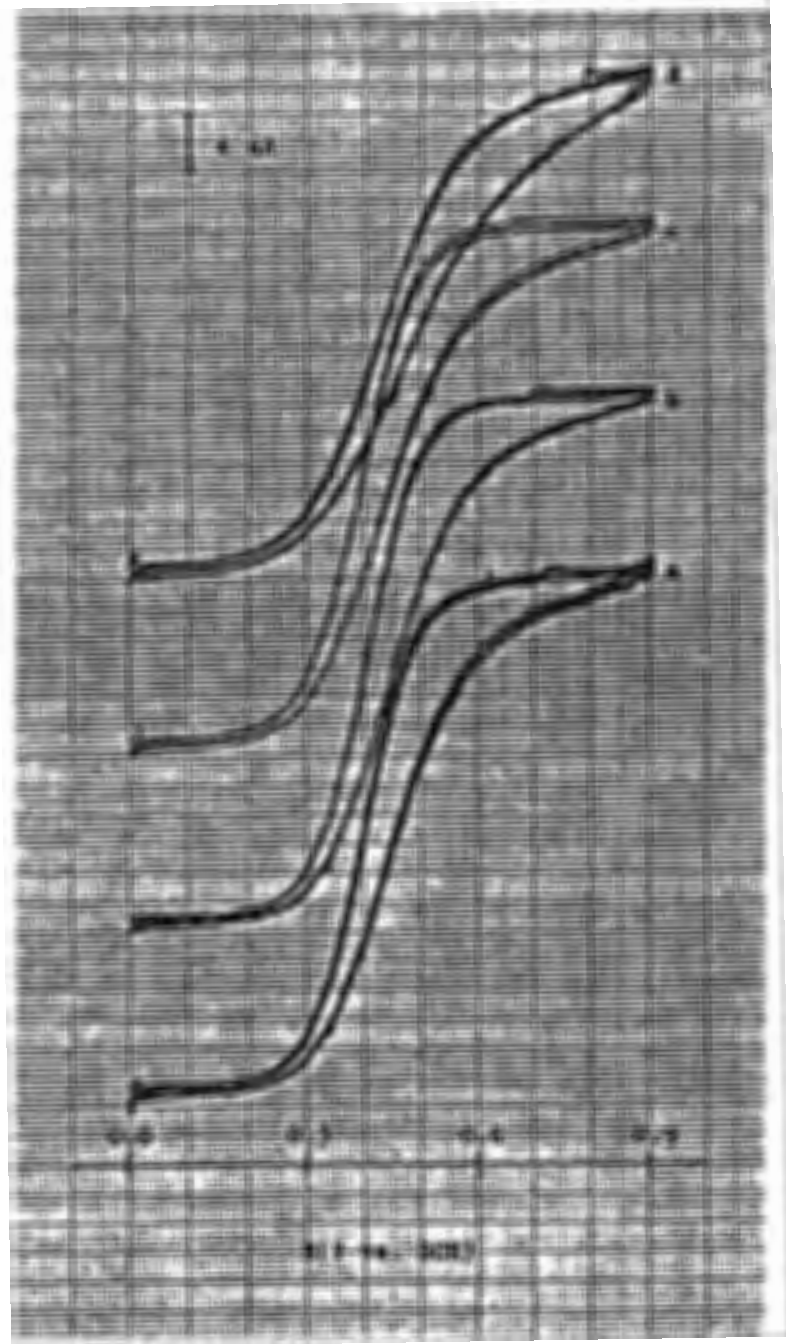

Figure 16. Effects of upper potential limit of a square wave upon the cyclic voltammogram.

Solution, $1 \mathrm{mM} \mathrm{HQ;} \mathrm{scan} \mathrm{rate,} 50 \mathrm{mV} / \mathrm{sec}$; (a) a cyclic scan-reactivated CFAE; a square wavereactivated CFAE with parameters: upper potential limit, (b) $+1.1 \mathrm{~V}$, (c) $+1.3 \mathrm{~V}$, (d) $+1.5 \mathrm{v}$; lower potential limit, $0 \mathrm{~V}$; frequency, $0.5 \mathrm{~Hz}$; duration, $30 \mathrm{sec} ;$ delay, $4 \mathrm{~min}$. 


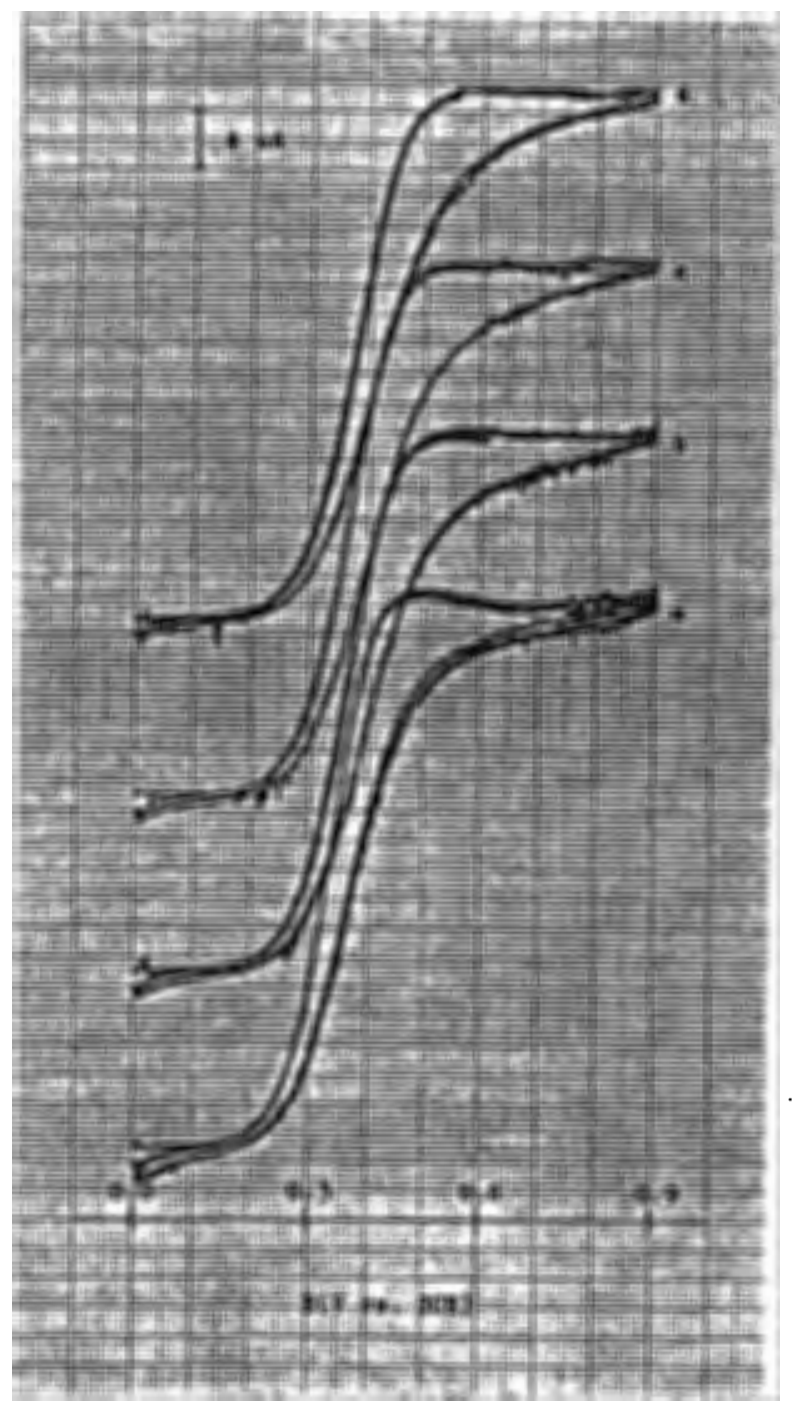

Figure 17. Effects of frequency of a square wave upon the cyclic voltammogram. Solution, I $\mathrm{mM} \mathrm{HQ}$; scan rate, $50 \mathrm{mV} / \mathrm{sec;}$ (a) a cyclic scanreactivated CFAE; a square wave-reactivated CFAE with parameters: upper potential limit, $+1.0 \mathrm{~V}$; lower potential limit, $-0.1 \mathrm{~V}$; frequency, (b) 5 $\mathrm{Hz}$, (c) $50 \mathrm{~Hz}$, (d) $500 \mathrm{~Hz}$; duration, $30 \mathrm{sec}$; delay, 4 min. 


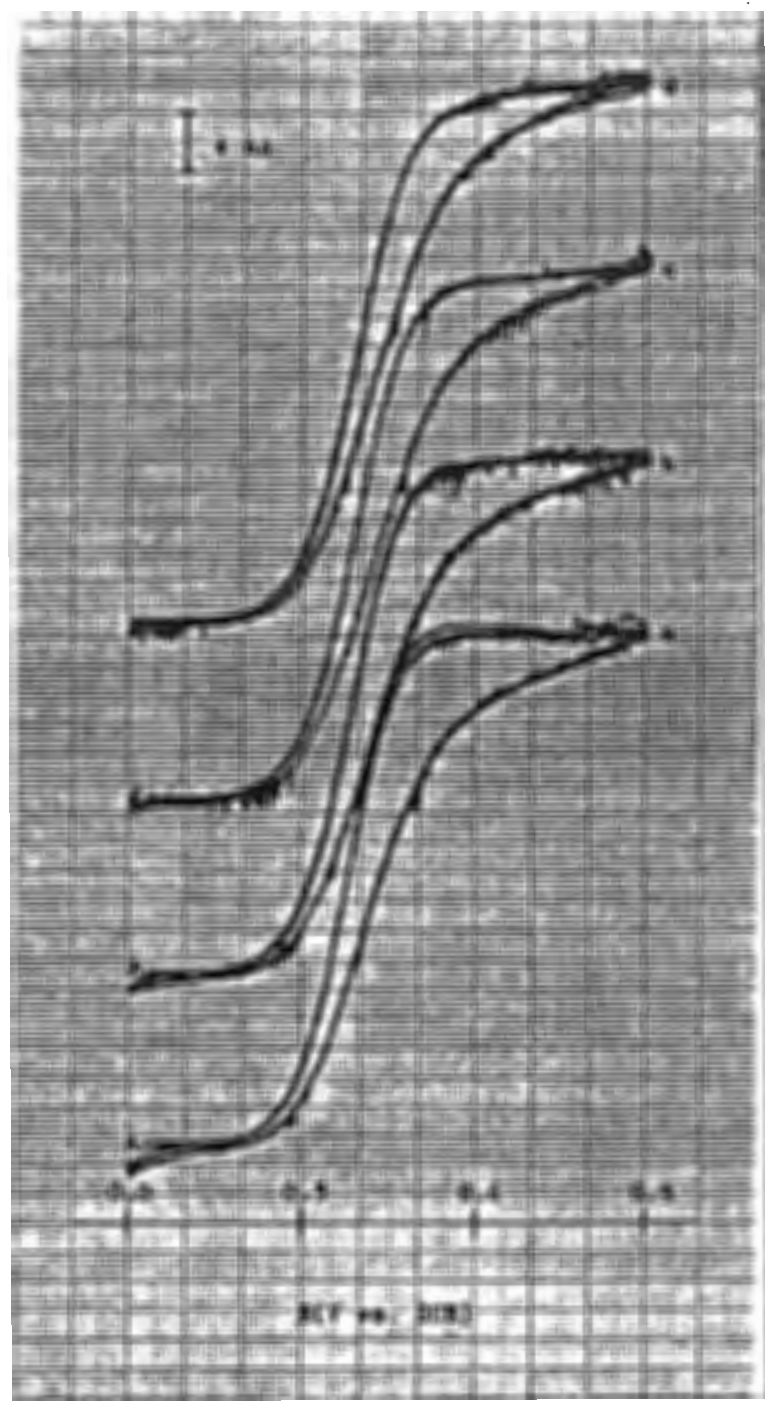

Figure 18. Effects of duration of a square wave upon the cyclic voltammogram. Solution, $1 \mathrm{mM} \mathrm{HQ}$; scan rate, $50 \mathrm{mV} / \mathrm{sec}$; (a) a cyclic scanreactivated CFAE; a square wave-reactivated CFAE with parameters: upper potential limit, $+1.0 \mathrm{~V}$; lower potential limit, $-0.1 \mathrm{~V}$; frequency, $0.5 \mathrm{~Hz}$; duration, (b) $5 \mathrm{sec,} \mathrm{(c)} 15 \mathrm{sec,} \mathrm{(d)} 30 \mathrm{sec;}$ delay, 4 min. 
the same as in Figure 17 except the frequency was $0.5 \mathrm{~Hz}$ and with different durations. Comparison of all CVs also shows that the EC behaviors of the CFAE shows no significant changes when different duration square waves are applied. Therefore, EC behavior of the reactivated CFAE are independent of the frequency and the duration of the square wave.

\section{Subsidence of the Charging current}

After the CFAE reactivation process stopped, the switch of the potential at CFAEs to the required potentials for data collection generates a current spike which is due to double-layer charging. Figure 19 shows the decay of this current versus time immediately after a CFAE was reactivated with a square wave, which had the upper potential limit, $+1.0 \mathrm{~V}$ i the lower potential limit, $-0.1 \mathrm{~V}$; duration, 30 sec; and frequency, $0.5 \mathrm{~Hz}$. This current decayed very rapidly during the first two minutes, then gradually decreased at a constant rate. Prior to performing a cyclic scan, a fourminute delay was used to allow decay of the current generated by the electrode reactivation; this procedure was adopted for all the following experiments. During this time of delay, the potential at a CFAE was held at the required value for data collection. Therefore, a square wave having an upper potential limit, $+1.0 \mathrm{~V}$; a lower potential limit, $0.1 \mathrm{~V}$; a frequency, $1.1 \mathrm{~Hz}$; and duration, $30 \mathrm{sec}$; with delay 


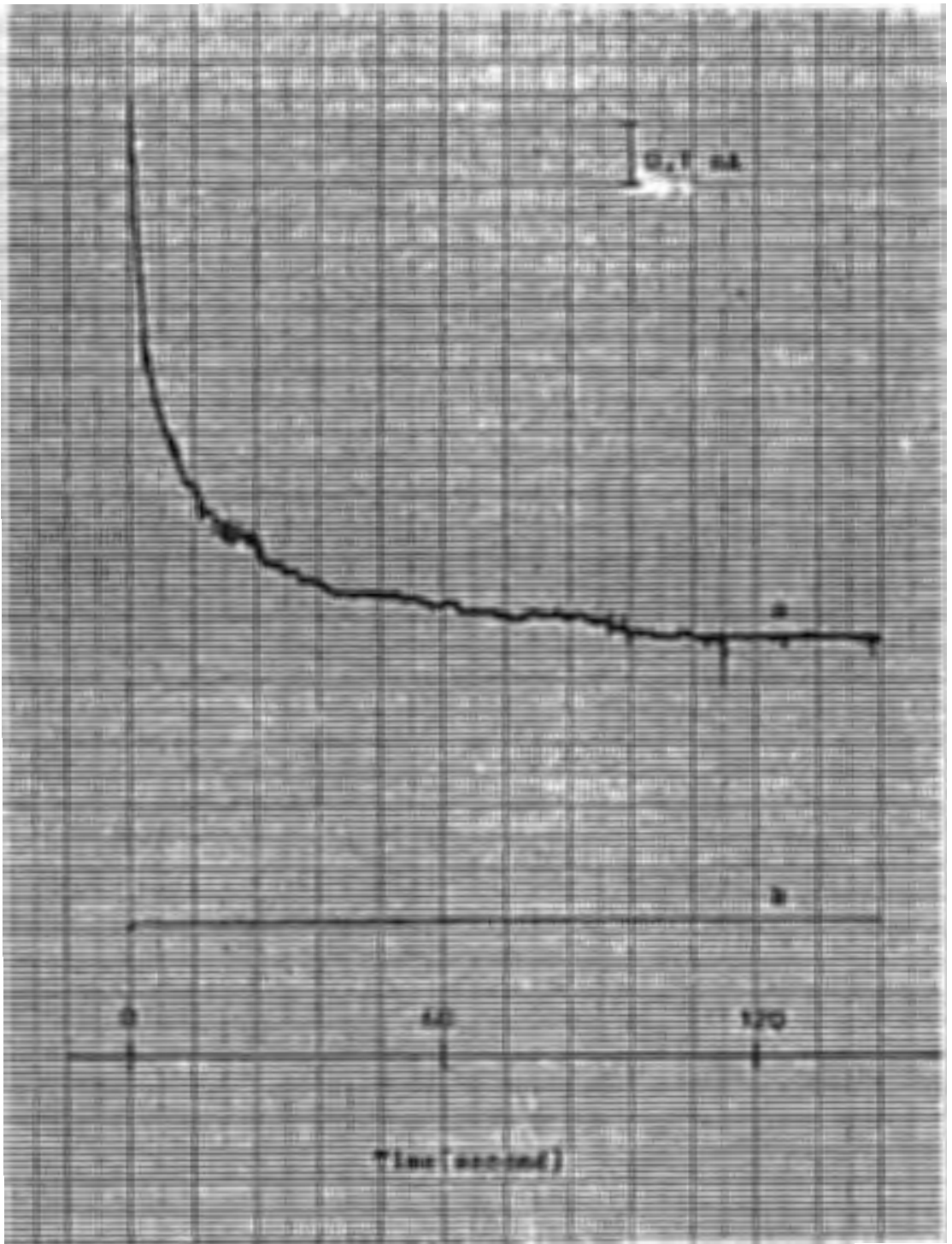

Figure 19. Decay of a charging current after the applied potential at a carbon fiber array electrode was switched to $0 \mathrm{~V}$. 
time, $4 \mathrm{~min}$; was chosen for the CFAE reactivation. And the CVs obtained were reproducible if the CFAEs were reactivated with these optimized parameters.

\section{Surface Morphology of the Reactivated CFAE}

After a CFAE was reactivated by a square wave, the electrode surface was examined by scanning electron microscopy (SEM) and X-ray photoelectron spectrum (XPS) with the assistance of Dr. John Dash (34). The SEM of the CFAE surface showed, as in Figure 20, that carbon fibers are parallel-aligned and the ends of carbon fibers extended out of the epoxy surface. Most carbon fibers are partially isolated from each other. This arrangement of carbon fibers in a CFAE will give good sensitivity and low detection limit due to the edge effect. The XPS of the CAFE surface is shown in Figure 21. The surface is not completely cleaned and still have trace amounts of different metals, such as Al and si. The dispersed alumina and emery particles are present on the electrode surface even after cleaning by sonic waves and square waves.

\section{CYCLIC VOLTAMMETRY IN A FLOW CELL}

In order to compare the performance of CFAEs in the designed ME cell with that in a conventional cell, a ME cell having a single electrode disk was assembled, as described in Chapter II. The experimental procedures were the same as 


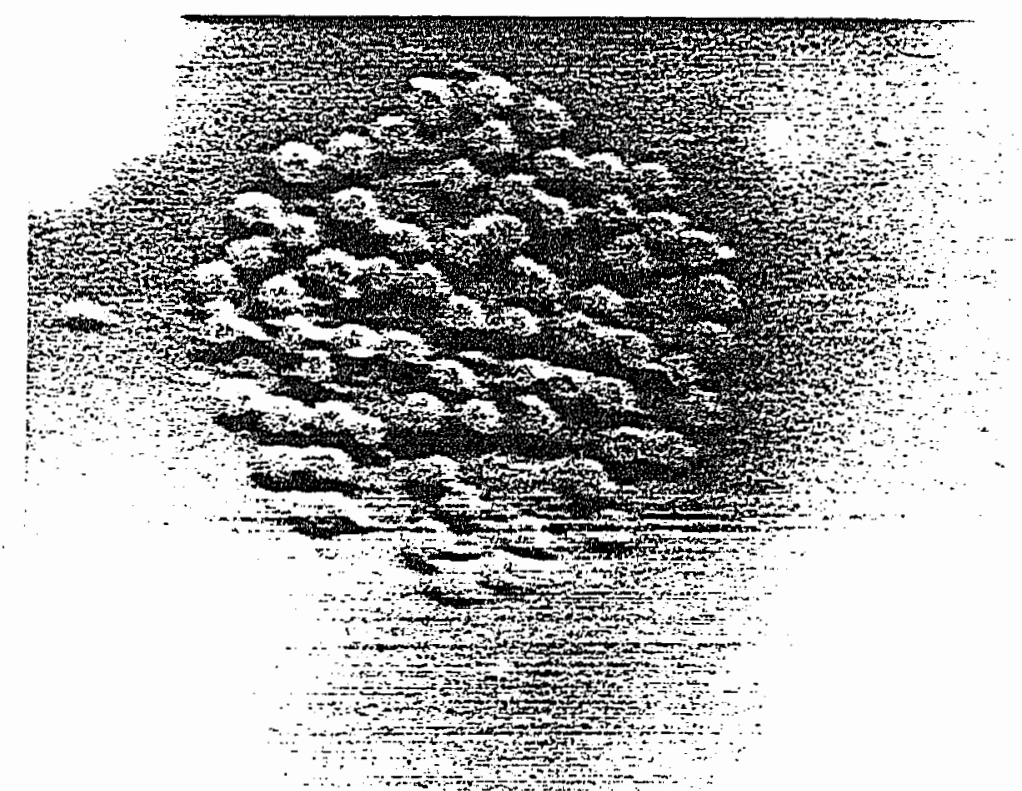

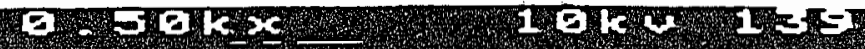

Figure 20. Scanning electron micrograph of a carbon fiber array electrode. Magnification is $500 \mathrm{X}$. 


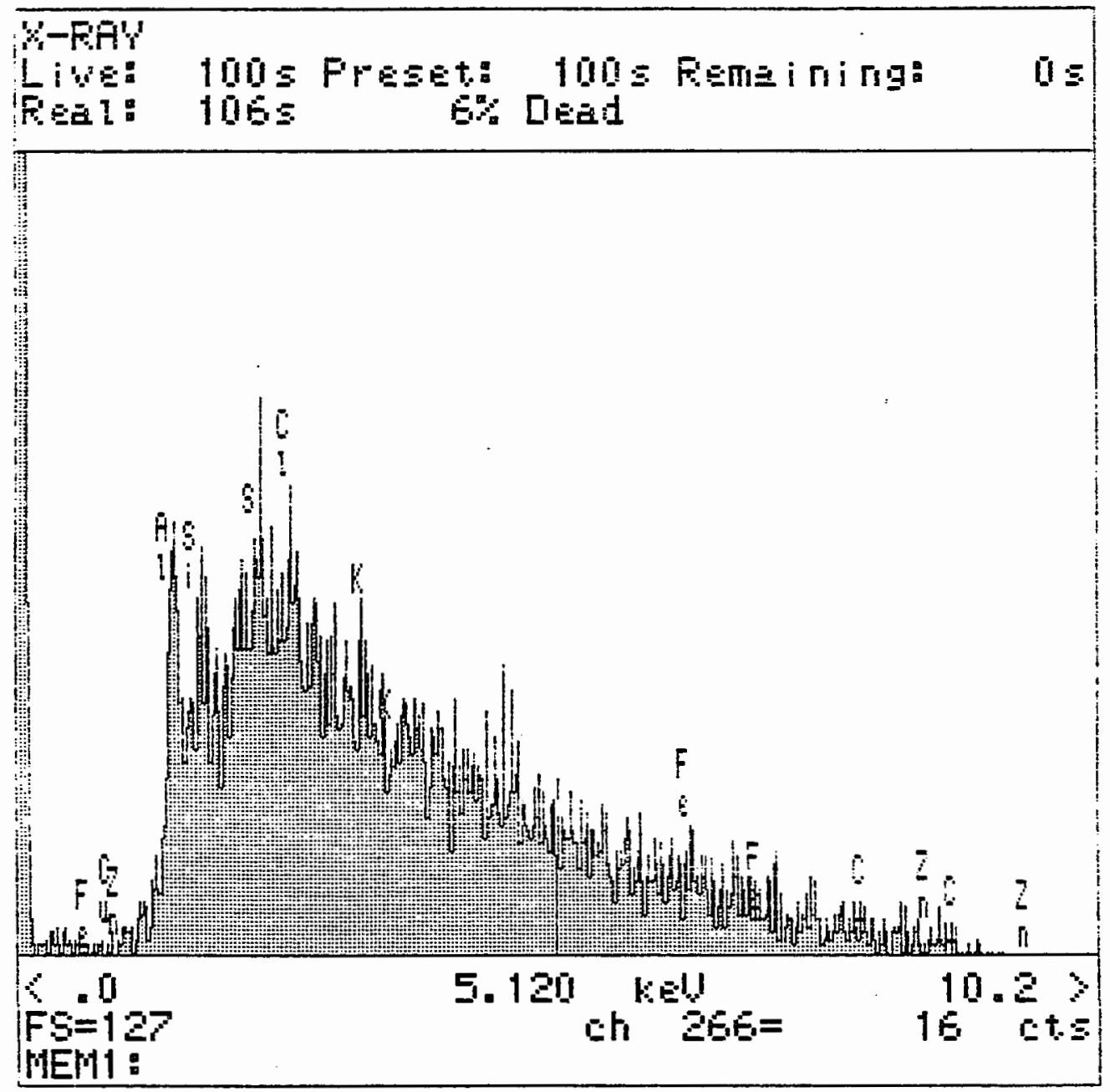

Figure 21. X-ray photoelectron spectrum of a carbon fiber array electrode. 
described in Chapter IV except the pump was stopped after the HQ solution was injected into the EC cell. The potential held at the CFAE was $+1.05 \mathrm{~V}$ (Vs. the zinc/zinc acetate electrode) during the subsidence of the charging current. After that, cyclic scans were performed at a scan rate of $50 \mathrm{mV} / \mathrm{s}$. The shape of voltammograms, as shown in Figure 22, is strongly dependent upon the tightness of the screws. The residual currents increased as the screws of the flow cell were tightened up, as shown in Figure 22 . This change in residual current was believed to be caused by the severe distortion of the CFAE disk in the flow cell due to the unevenly tightened screws. Also, the shape of the cyclic voltammogram of HQ became not well-defined, as shown in Figure 22b. A small bump was also shown at ca. $+1.3 \mathrm{~V}$, which might be caused by the trapped HQ in the crack adsorbing on the electrode surface. If the screws were not completely tightened, air bubbles trapped in the flow cell were not able to be removed by applying vacuum. The zinc acetate solution encapsulated in the reference electrode compartment could leak out. This problem was not correctable without changing the design of the cell body and the fabrication method of WED.

$$
\text { CHARACTERISTICS OF FLOW INJECTION ANALYSIS SYSTEM }
$$

Minimization of the Potential Drop in the ME Cell One of the primary concerns of designing an EC cell is 

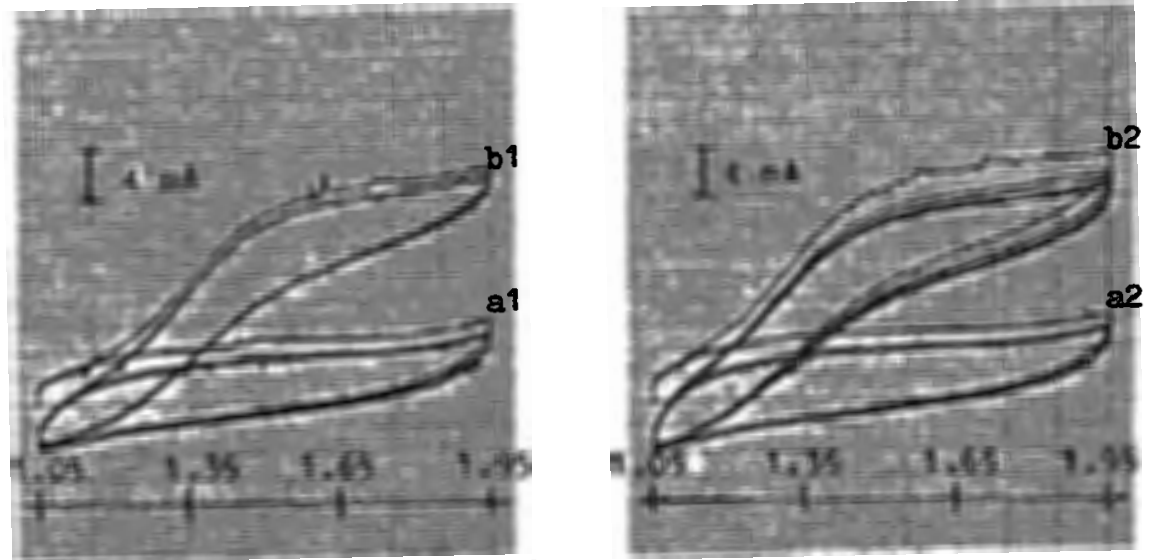

$$
\mathrm{E}\left(\mathrm{V} \text { vs. } \mathrm{Zn} / \mathrm{Zn}^{2+} \text { in } 1 \mathrm{M} \mathrm{NaCH}_{3} \mathrm{COO}\right)
$$
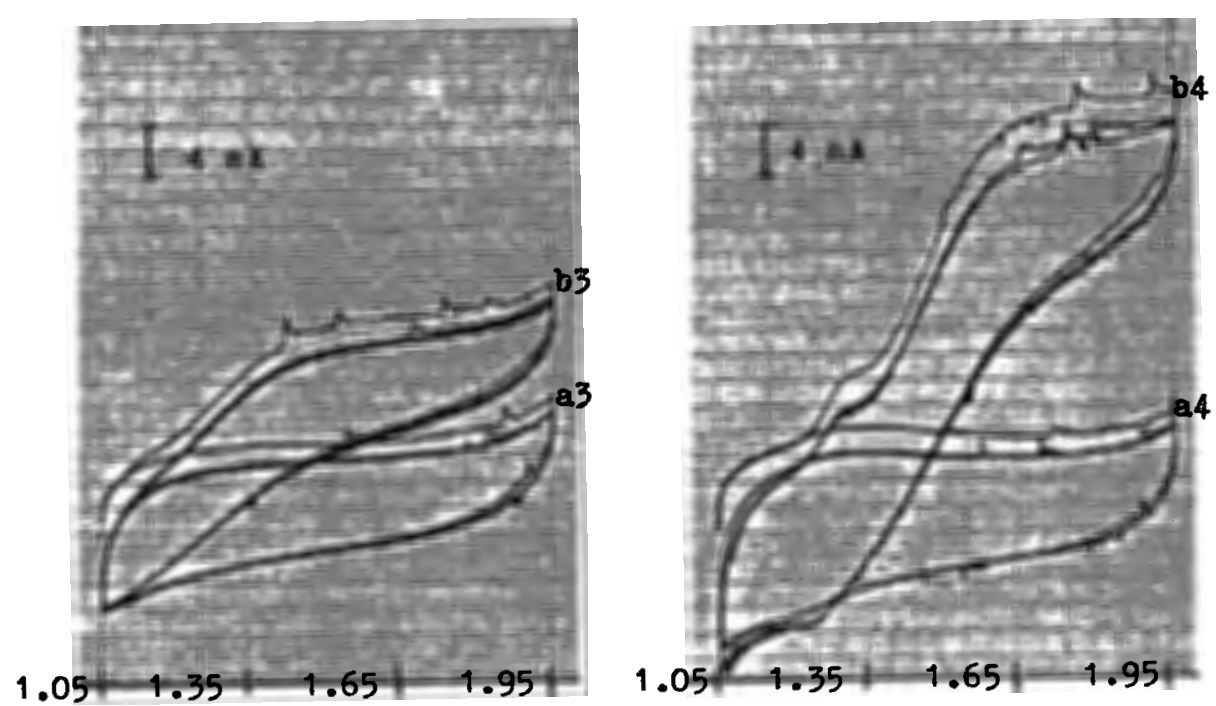

Figure 22. Effects of tightness of the cell screws upon the cyclic voltammogram. (a) $0.1 \mathrm{M}$ $\mathrm{AB} ;$ (b) $1 \mathrm{mM} \mathrm{HQ}$; tightness of the screws: (1) very loose, (2) loose, (3) tight, (4) very tight. 
to minimize the potential drop across a solution. This concern is especially important for designing a ME cell. A flow cell generally has an advantage of high mass-transport rate of analytes, which increases sensitivity due to current increase. However, this current increase may also lead to an increased potential drop and consequent impairment of efficient potential control at the working electrode. In a ME cell, the current response at one electrode which causes a potential drop across the solution may also affect the potentials across all electrode-solution interfaces. This resulting "cross-talk" can render a ME cell useless if the potential drop is too large. Both can be minimized by decreasing either the cell impedance or the current. The minimization of current response at CFAEs was accomplished by making the electrode surface area small. The minimization of the cell impedance was achieved by using the supporting electrolyte combined with positioning the reference electrode as close as possible to the working electrode, i.e., by placing a zinc/zinc acetate reference electrode in a compartment directly across a thin layer from the CFAEs with the separation of a Nafion film, as shown in Figure 4 .

\section{Nozzle-Electrode surface separation}

For the flow cell, although the equation for the limiting current derived by Yammada and Matsuda (17) does not contain any term relating to the inlet-electrode surface 
separation, it has been well-known that, according to the theory (35), the jet nozzle must be located outside the hydrodynamic boundary layer for the maximum efficiency obtained from the electrode; otherwise, interference of the flow in the boundary layer would result in a loss of current efficiency. Also, the jet nozzle-electrode surface separation must not be too far; otherwise the jet may spread out and cause loss of resolution as the distance from the nozzle increased.

with these considerations in mind, the jet nozzle must be designed to remain outside the hydrodynamic boundary layer even at high flow rate. The hydrodynamic boundary layer thickness $\left(\delta_{b l}\right)$ has been calculated with the following equation by Gunasingham and Fleet (9).

$$
\delta_{\mathrm{bl}}=5.8 \pi^{3 / 4} \mathrm{a}^{1 / 2} \mathrm{v}^{3 / 4} \mathrm{x}^{5 / 4} \mathrm{v}^{-3 / 4}
$$

where a : diameter of the nozzle (cm).

$\mathrm{V}$ : a volume flow rate $\left(\mathrm{cm}^{3} / \mathrm{s}\right)$.

$\mathrm{v}$ : the kinematic viscosity $\left(10^{-2} \mathrm{~cm}^{2} / \mathrm{s}\right.$ for aqueous system).

$x$ : the distance from the electrode surface (cm).

Substituting representative values for this flow system into the above equation, where $v=10^{-2} \mathrm{~cm}^{2} / \mathrm{s}$, inlet diameter of $0.343 \mathrm{~mm}$, an electrode with a radius of ca. $1 \mathrm{~mm}$ at flow rate between $1.1-3.3 \mathrm{~cm}^{3} / \mathrm{min}$, the boundary layer thickness 
is between 0.4 and $0.8 \mathrm{~mm}$. The jet nozzle-electrode separation of this ME cell was ca. $0.8 \mathrm{~mm}$, i.e., a thickness of a Nafion film and a Kalrez film, which is just adequate to keep the nozzle of the inlet outside the hydrodynamic boundary. This separation can be slightly adjusted by tightening the screws. The diameters of the centered hole on the Nafion film and the Kalrez spacer are large enough to avoid disturbing the hydrodynamic boundary layer of the jet flow. The inlet diameter of the jet was $0.343 \mathrm{~mm}$ because the cross section of an ideal wall-jet need to be as small as possible, compared to the electrode surface area.

\section{Geometric and Effective ME Cell Volumes}

One of the characteristic features of the wall-jet cell, not present in other designs, is that the effective cell volume is only the order of the hydrodynamic boundary layer and not the geometric cell volume. since the effective cell volume at each CFAE is very small, as seen from the previous section, the detection process does not produce appreciable change of sample concentration down stream. Although the larger geometric cell volume does not effect the hydrodynamic boundary layer, it may cause broadening of the sample band. The cell volume needs to be as small as possible. 
The geometric cell volume is calculated as follows:

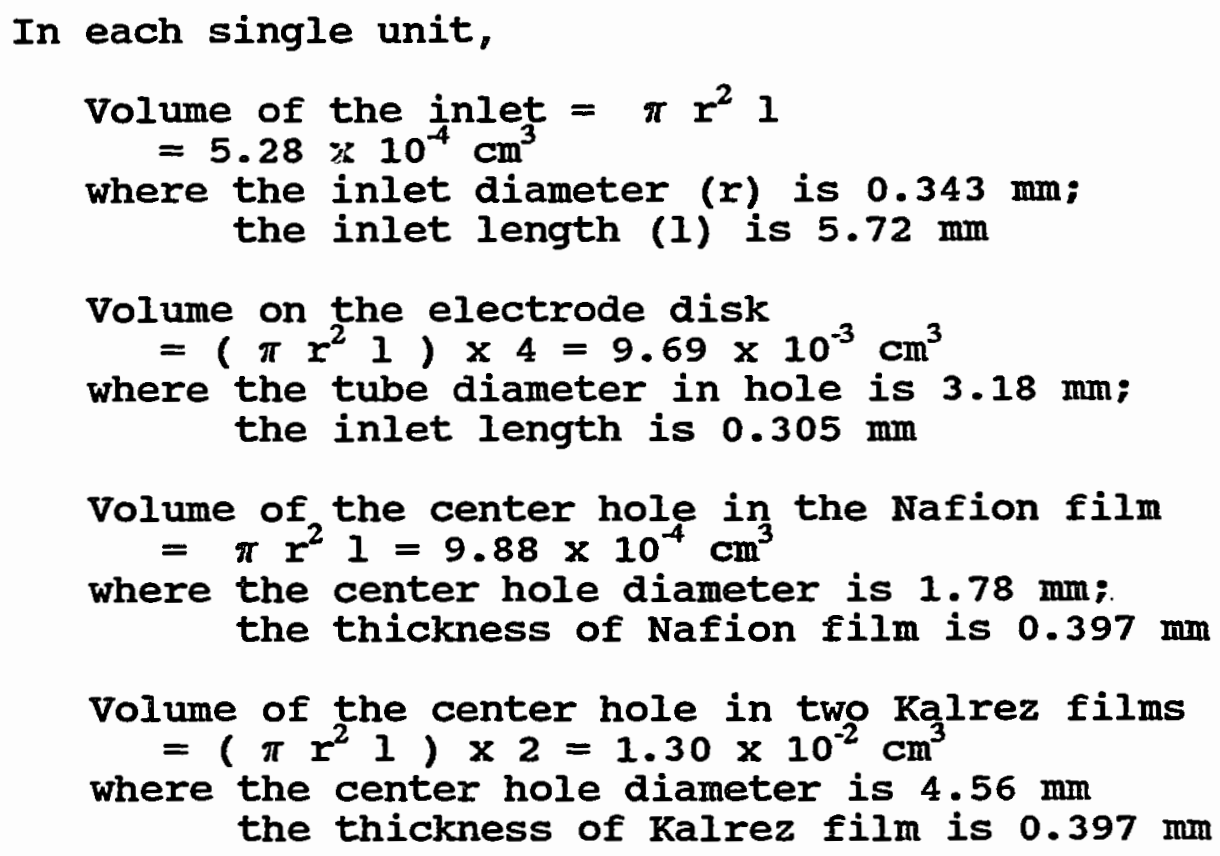

There are four units in the ME cell. The total geometric volume is ca. $9.7 \times 10^{-2} \mathrm{~cm}^{3}$. Since the geometric cell volume is small, compared with the sample in the sample injection loop (ca. $0.8 \mathrm{ml}$ ), and the distance between the sample injection valve and the cell was made very short, the sample band broadening by diffusion was insignificant through the whole cell.

\section{The Pulse Damper and Ground Current Insulator}

The minipump used to pump solutions through the flow system is a synchronous reciprocating pump which has advantages of having reproducible flow and a small internal volume. The relationship between pump scale and flow rate is shown in Table I. Figure 23 shows that the flow rate is 
proportional to the pump scale, but not linear. This pump also produces a pulsating flow in the flow system and conducts a small ground current through the system from the AC power line. Since the mass-transport rate of analytes or impurities in the solution is proportional to the flow rate, this flow fluctuation caused by the minipump was a noise source for MEV. The unwanted ground current conducted by the pump was imposed on the measured current and caused the sensitivity to be decreased. A simple device was made to overcome both drawbacks. It is made from two pieces of plastic syringe tube connected with a piece of glass tube, then placed between the minipump and the sample injection valve. This tube was only partially filled with solution. The empty part of the capacity served as both the pulse damper and the ground current isolator. With the use of this device flow fluctuation was decreased dramatically and so was noise. The ground current was also insulated from the ME cell.

THE TRUE CAPACITANCE AND LEAKAGE CURRENT OF THE INTEGRATOR

Although the nominal values of the capacitance of the integrators are known from the specifications, the true values can be different. The leakage current may be generated by the offset voltage between positive input and negative input of the amplifier. A set of dummy resistors 
TABLE I

$\begin{array}{cc}\text { RELATIONSHIP OF PUMP SCALE AND FIOW RATE } \\ \text { Pump Scale } & \text { Time for } 10 \mathrm{~mL} \text { (sec) } \\ 20.0 & 540 \\ 30.0 & 352 \\ 40.0 & 265 \\ 50.0 & 210 \\ 60.0 & 180\end{array}$

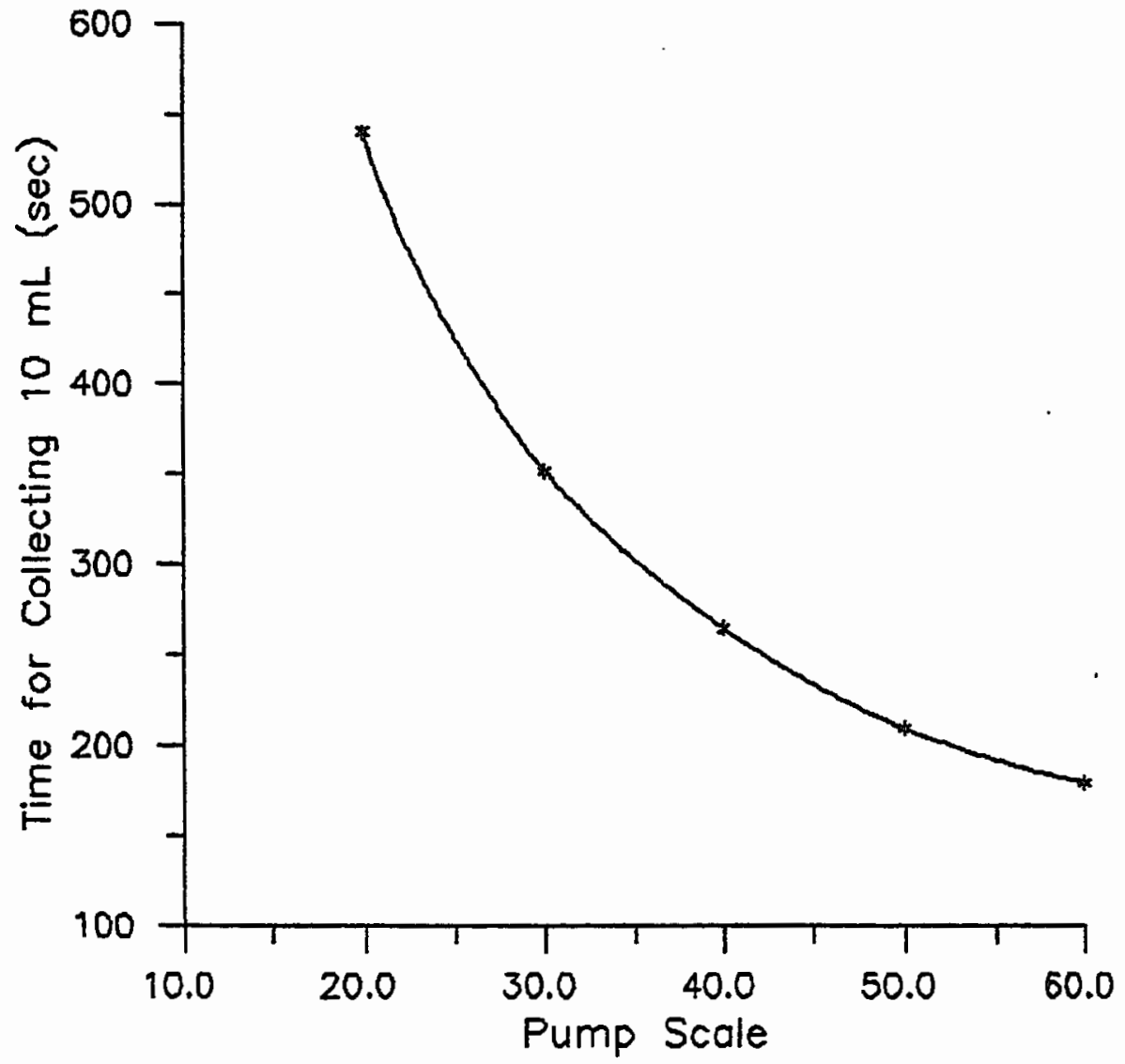

Figure 23. Correlation between the flow rate and the pump scale. 
and a voltage source were used to simulate the current generation by the electroactive species at each capacitor and the current leakage generated by the offset voltage of the amplifier. One side of the resistor was connected with the negative input of the amplifier. The other side was connected with a potential source. Two potentials which were symmetrical to the circuit ground were used to obtain the currents which was generated by the voltage drop across the resistor in order to solve the combined equations for two unknown values of every integrator. The equation used is as follows:

$$
E_{\text {out }}=\frac{1}{c} \int \frac{V}{R} d t+\frac{1}{c} \int i_{\text {leak }} d t
$$

where $E_{\text {out }}$ : output voltage of an amplifier;

c: capacitance in coulomb:

V: potential applied at electrode;

$\mathrm{R}$ : measured resistance in ohm;

t: time in sec;

$i_{\text {leak }}$ : leakage current of current follower:

$10 \mathrm{M} \Omega$ resistors were chosen in order to lessen the chance of too large a signal entering the current integrating circuits, whose maximum limit is $+/-12 \mathrm{v}$. The true resistance of each resistor was measured by a digital multimeter. The calculated capacitance of each capacitor and 
leakage current of each integrator are shown in Table II. The calculated leakage currents were all very small, compared with the resolution ability of the analog-todigital converter. They were insignificant and were ignored during the data handling for MEV.

\section{TABLE II}

RESISTANCE, LEAKAGE CURRENT, AND CAPACITANCE OF THE INTEGRATOR

$\begin{array}{crcr}\text { Integrator } & \begin{array}{c}\text { Resistance } \\ (\mathrm{M} \Omega)\end{array} & \begin{array}{c}\text { Capacitance* } \\ \text { (nF) }\end{array} & \begin{array}{c}\text { Leakage Curre } \\ \text { (nA) }\end{array} \\ \# 1 & & & \\ \# 1 & 10.10 & 0.901 & 0.225 \\ \# 2 & 9.97 & 0.863 & 0.276 \\ \# 3 & 10.07 & 0.898 & 0.340 \\ \# 4 & 10.13 & 0.841 & 0.262 \\ \# 5 & 9.93 & 0.839 & 0.369 \\ \# 6 & 10.09 & 0.902 & 0.315 \\ \# 7 & 9.98 & 0.895 & 0.240 \\ \# 8 & 9.95 & 0.867 & 0.474 \\ \# 9 & 10.13 & 0.924 & -0.040 \\ \# 10 & 10.24 & 0.892 & -0.083 \\ \# 11 & 10.14 & 0.897 & -0.306 \\ \# 12 & 10.12 & 0.897 & -0.016 \\ \# 13 & 9.98 & 0.913 & 0.258 \\ \# 14 & 9.95 & 0.892 & 0.020 \\ \# 15 & 10.08 & 0.824 & 0.099 \\ \# 16 & 9.87 & 0.856 & 0.047\end{array}$

* Measured by a multi-digital meter. ** Based on 4 sets of data.

\section{NORMALIZATION FACTORS OF CARBON FIBER ARRAY ELECTRODES IN THE MULTI-ELECTRODE CELL}

In the ME cell, 16 CFAEs are employed. Careful procedures have been taken to assure that reproducible results were obtained at each electrode, such as electrode reactivation procedures. The pseudo-voltammograms 
constructed are based on the data collected at all 16 CFAEs. The signals generated at each CFAE under the same experimental condition may differ because the electrode surface areas are not always the same, which might be caused by some carbon fibers being broken during the fabricating process, even though all CFAEs were fabricated the same way. Depending on the way the ME cell was assembled, the flow patterns at each CFAE in the cell may also differ. It has also been shown CFAEs foul gradually due to the adsorption of impurities on the surface. Hence, the surface areas of CFAEs in the ME cell need to be calibrated just prior to the collection of data for MEV in order to obtain the active electrode surface.

The experimental procedures of electrode surface area normalization were described in chapter IV. The manipulation of amperometric data for CFAE normalization factors were described in Appendix E. All potentials measured and reported in this section are relative to the zinc/zinc acetate reference electrode. Prior to data collection for normalization factors of the CFAEs in the ME cell, a potential sufficient to spontaneously oxidize HQ and also to provide the maximum sensitivity at CFAEs needs to be determined. The potential meeting this requirement is in the limiting-current plateau of the $\mathrm{cV}$. However, when the applied potential at CFAEs is at the positive end of the $\mathrm{CV}$ plateau, the increases of the background current generated 
by the oxidation of $\mathrm{H}_{2} \mathrm{O}$ and of the noise level caused by the evolution of $\mathrm{O}_{2}$ become limiting factors. Hence, the best sensitivity can be obtained by choosing a potential which is near the middle of the $\mathrm{CV}$ plateau. A potential of $+1.95 \mathrm{~V}$ was chosen as a compromise between maximizing the analyte current response and minimizing the background current for CFAE surface area normalization. $0.5 \mathrm{mM}$ HQ solution was used for optimum $S / N$ ratio and system performance.

\section{Flow Rate Dependency}

A disadvantage of amperometric electrodes in flow cells is the noticeable effect of flow rate on the analytical signal since mass transfer in the flow system is proportional to flow rate. The flow rate dependence of the current is substantially reduced when microelectrodes are used in flow cells $(27,36)$. The dependency of the flow rates for normalization factors of CFAEs in the ME cell was therefore studied.

During preliminary experiments, sudden disappearance of signals at some electrodes and the expulsion of small gas bubbles from the ME cell into its outlet occurred more often when the flow was slower. It indicates that small gas bubbles generated by the fluctuation of pressure in the cell are adsorbed on the electrode surface more often when the flow is slow. Inhomogeneity of the sample solution caused by dispersion of sample was observed. Low flow rates were excluded from the study. When the flow rate is too high, 
the pulse damper becomes ineffective because cyclicly fluctuating data due to pulsating flow have been observed. Hence, a range of flow rate from 1.67 to $3.33 \mathrm{ml} / \mathrm{min}$ was studied, i.e., the pump scale set between 30.0 and 60.0 . To evaluate the performance of the ME cell, the residual currents and the net currents obtained at an applied potential of $+1.95 \mathrm{~V}$ (vs. Zinc/zinc Acetate electrode) in $5.45 \times 10^{-4} \mathrm{HQ}$ solution with different flow rates are compared. Table III shows the residual currents and the net currents obtained at different flow rates. Both the residual and the net currents show only a small dependence on flow rate as is expected for ultramicroelectrodes.

The currents are different at each electrode because the effective areas are different. A normalizing factor can be obtained from the data of Table III by calculation the ratio of the current at each electrode to the current at one electrode. Table IV shows the normalized factors of CFAEs relative to electrode \#2 at different flow rates. The relative standard deviations are between $0.5 \%$ and $3.6 \%$.

\section{Repeatability and Reproducibility}

Insufficient stability and reproducibility are often drawbacks of EC flow cells. Since air bubbles were much easier to be formed at the low flow rate, both stability and 
TABLE III

INFLUENCE OF THE FLOW RATE ON THE CARBON FIBER ARRAY ELECTRODE RESPONSE CURRENT

\begin{tabular}{|c|c|c|c|c|}
\hline \multirow[b]{2}{*}{ Electrode } & \multicolumn{4}{|c|}{$\begin{array}{l}\text { Current (Amp) } \\
\text { at Flow Rate of }\end{array}$} \\
\hline & $\begin{array}{c}1.67 \\
\text { Residual }\end{array}$ & $\underset{\text { Net }}{/ \text { Min }}$ & $\begin{array}{c}2.22 \\
\text { Residual }\end{array}$ & 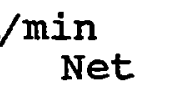 \\
\hline $\begin{array}{lc}\# & 1 \\
\# & 2 \\
\# & 3 \\
\# & 4 \\
\# & 5 \\
\# & 6 \\
\# & 7 \\
\# & 8 \\
\# & 9 \\
\# & 10 \\
\# & 11 \\
\# & 12 \\
\# & 13 \\
\# & 14 \\
\# & 15 \\
\# & 16\end{array}$ & $\begin{array}{l}5.26 \mathrm{E}-10 \\
4.81 \mathrm{E}-10 \\
5.39 \mathrm{E}-10 \\
2.56 \mathrm{E}-10 \\
1.41 \mathrm{E}-09 \\
1.61 \mathrm{E}-09 \\
1.93 \mathrm{E}-09 \\
9.87 \mathrm{E}-10 \\
1.60 \mathrm{E}-09 \\
1.88 \mathrm{E}-09 \\
2.10 \mathrm{E}-09 \\
1.75 \mathrm{E}-09 \\
7.79 \mathrm{E}-10 \\
1.07 \mathrm{E}-09 \\
2.22 \mathrm{E}-09 \\
4.80 \mathrm{E}-09\end{array}$ & $\begin{array}{l}3.11 \mathrm{E}-8 \\
3.61 \mathrm{E}-8 \\
4.82 \mathrm{E}-8 \\
4.02 \mathrm{E}-8 \\
5.74 \mathrm{E}-8 \\
6.08 \mathrm{E}-8 \\
3.99 \mathrm{E}-8 \\
5.36 \mathrm{E}-8 \\
4.96 \mathrm{E}-8 \\
4.82 \mathrm{E}-8 \\
4.88 \mathrm{E}-8 \\
4.04 \mathrm{E}-8 \\
5.07 \mathrm{E}-8 \\
5.48 \mathrm{E}-8 \\
6.03 \mathrm{E}-8 \\
5.60 \mathrm{E}-8\end{array}$ & $\begin{array}{l}4.96 \mathrm{E}-10 \\
4.77 \mathrm{E}-10 \\
4.90 \mathrm{E}-10 \\
2.44 \mathrm{E}-10 \\
1.17 \mathrm{E}-09 \\
1.35 \mathrm{E}-09 \\
1.69 \mathrm{E}-09 \\
8.95 \mathrm{E}-10 \\
1.31 \mathrm{E}-09 \\
1.62 \mathrm{E}-09 \\
1.71 \mathrm{E}-09 \\
1.43 \mathrm{E}-09 \\
6.90 \mathrm{E}-10 \\
9.98 \mathrm{E}-10 \\
2.10 \mathrm{E}-09 \\
4.07 \mathrm{E}-09\end{array}$ & $\begin{array}{l}3.19 \mathrm{E}-8 \\
3.88 \mathrm{E}-8 \\
5.11 \mathrm{E}-8 \\
4.19 \mathrm{E}-8 \\
5.82 \mathrm{E}-8 \\
6.31 \mathrm{E}-8 \\
4.03 \mathrm{E}-8 \\
5.80 \mathrm{E}-8 \\
5.02 \mathrm{E}-8 \\
5.06 \mathrm{E}-8 \\
5.04 \mathrm{E}-8 \\
4.16 \mathrm{E}-8 \\
5.40 \mathrm{E}-8 \\
5.82 \mathrm{E}-8 \\
6.36 \mathrm{E}-8 \\
5.89 \mathrm{E}-8\end{array}$ \\
\hline
\end{tabular}

Electrode

$\begin{array}{ll}\# & 1 \\ \# & 2 \\ \# & 3 \\ \# & 4 \\ \# & 5 \\ \# & 6 \\ \# & 7 \\ \# & 8 \\ \# & 9 \\ \# & 10 \\ \# & 11 \\ \# & 12 \\ \# & 13 \\ \# & 14 \\ \# & 15 \\ \# & 16\end{array}$

Current (Amp)

at Flow Rate of

$2.86 \mathrm{~mL} / \mathrm{Min}$
Residual Net

$6.12 E-10$
$5.89 E-10$
$6.81 E-10$
$3.06 E-10$
$1.85 E-09$
$2.20 E-09$
$2.37 E-09$
$1.33 E-09$
$2.23 E-09$
$2.65 E-09$
$3.12 E-09$
$2.73 E-09$
$9.96 E-10$
$1.42 E-09$
$2.63 E-09$
$6.49 E-09$

\begin{abstract}
$3.16 \mathrm{E}-8$
\end{abstract}
$3.94 \mathrm{E}-8$

$5.21 \mathrm{E}-8$

$4.22 \mathrm{E}-8$

$6.06 \mathrm{E}-8$

$6.65 \mathrm{E}-8$

$4.22 \mathrm{E}-8$

$5.91 \mathrm{E}-8$

5. $29 \mathrm{E}-8$

5. $21 \mathrm{E}-8$

5. $34 \mathrm{E}-8$

$4.36 \mathrm{E}-8$

$5.74 \mathrm{E}-8$

$6.21 \mathrm{E}-8$

$6.51 \mathrm{E}-8$

$6.24 \mathrm{E}-8$
$3.33 \mathrm{~mL} / \mathrm{min}$

Residual Net

$\begin{array}{ll}6.12 \mathrm{E}-10 & 3.27 \mathrm{E}-8 \\ 5.85 \mathrm{E}-10 & 4.11 \mathrm{E}-8 \\ 6.34 \mathrm{E}-10 & 5.43 \mathrm{E}-8 \\ 3.10 \mathrm{E}-10 & 4.27 \mathrm{E}-8 \\ 1.74 \mathrm{E}-09 & 6.14 \mathrm{E}-8 \\ 2.07 \mathrm{E}-09 & 6.91 \mathrm{E}-8 \\ 2.28 \mathrm{E}-09 & 4.48 \mathrm{E}-8 \\ 1.23 \mathrm{E}-09 & 6.11 \mathrm{E}-8 \\ 2.13 \mathrm{E}-09 & 5.48 \mathrm{E}-8 \\ 2.49 \mathrm{E}-09 & 5.19 \mathrm{E}-8 \\ 2.97 \mathrm{E}-09 & 5.55 \mathrm{E}-8 \\ 2.38 \mathrm{E}-09 & 4.61 \mathrm{E}-8 \\ 9.05 \mathrm{E}-10 & 6.06 \mathrm{E}-8 \\ 1.35 \mathrm{E}-09 & 6 \cdot 50 \mathrm{E}-8 \\ 2.58 \mathrm{E}-09 & 6.68 \mathrm{E}-8 \\ 6.27 \mathrm{E}-09 & 6.23 \mathrm{E}-8\end{array}$


TABIE IV

CORREIATION BETWEEN FLOW RATE AND NORMALIZATION FACTORS

\begin{tabular}{ccccc} 
Electrode & \multicolumn{3}{c}{ Normalization Factor at Flow Rate (mL/Min) } \\
& 1.67 & 2.22 & 2.86 & 3.33 \\
$\# 1$ & 0.86 & 0.82 & 0.80 & 0.80 \\
$\# 2$ & 1.00 & 1.00 & 1.00 & 1.00 \\
$\# 3$ & 1.33 & 1.31 & 1.32 & 1.32 \\
$\# 4$ & 1.11 & 1.08 & 1.07 & 1.04 \\
$\#$ \# & 1.59 & 1.50 & 1.54 & 1.50 \\
$\# 6$ & 1.68 & 1.62 & 1.69 & 1.68 \\
$\# 7$ & 1.11 & 1.04 & 1.07 & 1.09 \\
$\# 8$ & 1.48 & 1.49 & 1.50 & 1.49 \\
$\# 9$ & 1.37 & 1.29 & 1.34 & 1.33 \\
$\# 10$ & 1.34 & 1.30 & 1.32 & 1.26 \\
$\# 11$ & 1.35 & 1.30 & 1.36 & 1.35 \\
$\# 12$ & 1.12 & 1.07 & 1.11 & 1.12 \\
$\# 13$ & 1.40 & 1.39 & 1.46 & 1.48 \\
$\# 14$ & 1.52 & 1.50 & 1.58 & 1.58 \\
$\# 15$ & 1.67 & 1.64 & 1.65 & 1.63 \\
$\# 16$ & 1.55 & 1.52 & 1.59 & 1.52
\end{tabular}

Electrode

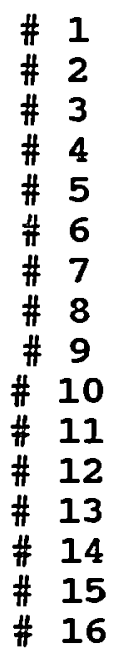

Mean

0.82

1.00

1.32

1.08

1.53

1.67

1.08

1.49

1.34

1.30

1.34

1.10

1.43

1.54

1.65

1.54
Normalization Factor std. Dev.

Rel. Std. Dev. (\%)

$\begin{array}{ll}0.03 & 3.6 \\ 0.00 & 0.0 \\ 0.01 & 0.6 \\ 0.03 & 2.7 \\ 0.04 & 2.9 \\ 0.03 & 1.8 \\ 0.03 & 2.7 \\ 0.01 & 0.5 \\ 0.03 & 2.4 \\ 0.03 & 2.4 \\ 0.03 & 2.1 \\ 0.02 & 2.1 \\ 0.04 & 2.9 \\ 0.04 & 2.7 \\ 0.02 & 1.1 \\ 0.03 & 2.1\end{array}$


reproducibility of normalization was studied at the flow rate of $3.33 \mathrm{~mL} / \mathrm{min}$. Table $\mathrm{v}$ shows the repeatability of a series of three injections of $5.45 \times 10^{-4} \mathrm{M}$ HQ in $0.1 \mathrm{M} \mathrm{AB}$ solution. The relative standard deviations of the net limiting current for 16 CFAEs in the ME cell scatters between $0.5 \%$ and $5.4 \%$. Table VI shows the reproducibility of three injections of the same HQ solution in a 6 hour period. For these injections, the relative standard deviations ranges between $2.2 \%$ and $6.9 \%$

\section{Normalization Factor}

The average of the net currents obtained at the flow rate of $3.33 \mathrm{~mL} / \mathrm{min}$ for repeatability studies, as shown in Table $v$, were used to calculate the normalization factors of CFAEs in the ME cell. The procedures are described in Appendix E. The normalization factors, as shown in Table VII, were used to normalize all amperometric data for construction of pseudo-voltammograms.

\section{MULTI-ELECTRODE VOLTAMMETRY}

The analytical responses of MEV were examined with HQ solutions at a flow rate of $3.33 \mathrm{~mL} / \mathrm{min}$. The experimental procedures were described in Chapter IV. The pseudovoltammograms are constructed by plotting the normalized amperometric data vs. the applied potentials at each CFAE. All potentials reported in this section are relative to the 
TABLE V

REPEATABILITY OF CARBON FIBER ARRAY ELECTRODE RESPONSE CURRENTS AT APPLIED

POTENTIAL OF +1.95 V

Electrode

$\begin{array}{lc}\# & 1 \\ \# & 2 \\ \# & 3 \\ \# & 4 \\ \# & 5 \\ \# & 6 \\ \# & 7 \\ \# & 8 \\ \# & 9 \\ \# & 10 \\ \# & 11 \\ \# & 12 \\ \# & 13 \\ \# & 14 \\ \# & 15 \\ \# & 16\end{array}$

Electrode

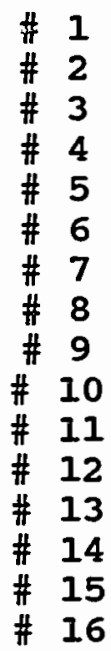

set 1

$3.27 \mathrm{E}-8$

$4.10 \mathrm{E}-8$

$5.43 \mathrm{E}-8$

$4.27 \mathrm{E}-8$

$6.14 \mathrm{E}-8$

$6.91 \mathrm{E}-8$

$4.48 \mathrm{E}-8$

$6.10 \mathrm{E}-8$

$5.48 \mathrm{E}-8$

5. 19E-8

$5.55 \mathrm{E}-8$

4. $61 \mathrm{E}-8$

$6.06 \mathrm{E}-8$

6. 50E-8

$6.68 \mathrm{E}-8$

$6.25 \mathrm{E}-8$

Mean

3. $21 \mathrm{E}-8$

4. 01E-8

$5.21 \mathrm{E}-8$

$4.12 \mathrm{E}-8$

$5.88 \mathrm{E}-8$

$6.73 E-8$

4. $39 \mathrm{E}-8$

$5.93 \mathrm{E}-8$

$5.28 E-8$

5. $12 \mathrm{E}-8$

5. $43 E-8$

4. $43 E-8$

$5.89 \mathrm{E}-8$

$6.37 \mathrm{E}-8$

$6.64 \mathrm{E}-8$

$6.03 \mathrm{E}-8$
Net Current (Amp) set 2

Set 3
3. $25 \mathrm{E}-8$
4. 0OE-8
5. 12E-8
4. $10 \mathrm{E}-8$
$5.98 \mathrm{E}-8$
$6.76 \mathrm{E}-8$
$4.34 \mathrm{E}-8$
$5.95 \mathrm{E}-8$
$5.29 \mathrm{E}-8$
$5.14 \mathrm{E}-8$
$5.44 \mathrm{E}-8$
$4.32 \mathrm{E}-8$
$5.82 \mathrm{E}-8$
$6.37 \mathrm{E}-8$
$6.65 \mathrm{E}-8$
6. 01E-8

Net Current (Amp)

std. Dev. Rel. STd. Dev.

$\begin{array}{ll}8.36 \mathrm{E}-10 & 2.6 \\ 8.64 \mathrm{E}-10 & 2.1 \\ 1.88 \mathrm{E}-09 & 3.6 \\ 1.36 \mathrm{E}-09 & 3.2 \\ 3.20 \mathrm{E}-09 & 5.4 \\ 1.95 \mathrm{E}-09 & 2.9 \\ 7.72 \mathrm{E}-10 & 1.7 \\ 1.81 \mathrm{E}-09 & 3.0 \\ 2.02 \mathrm{E}-09 & 3.8 \\ 7.57 \mathrm{E}-10 & 1.4 \\ 1.33 \mathrm{E}-09 & 2.4 \\ 1.56 \mathrm{E}-09 & 3.5 \\ 1.50 \mathrm{E}-09 & 2.5 \\ 1.30 \mathrm{E}-09 & 2.0 \\ 3.79 \mathrm{E}-10 & 0.5 \\ 2.18 \mathrm{E}-09 & 3.6\end{array}$


TABLE VI

REPRODUCIBILITY OF CARBON FIBER ARRAY ELECTRODE RESPONSE CURRENTS AT THE APPLIED

POTENTIAI OF $+1.95 \mathrm{~V}$

\section{Electrode}

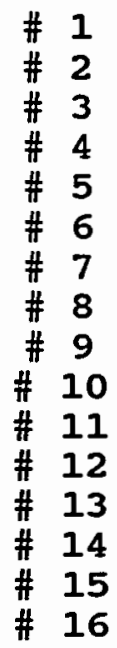

Electrode

$\begin{array}{cc}\# & 1 \\ \# & 2 \\ \# & 3 \\ \# & 4 \\ \# & 5 \\ \# & 6 \\ \# & 7 \\ \# & 8 \\ \# & 9 \\ \# & 10 \\ \# & 11 \\ \# & 12 \\ \# & 13 \\ \# & 14 \\ \# & 15 \\ \# & 16\end{array}$

\section{set 1}

$3.27 \mathrm{E}-8$

$4.11 E-8$

$5.43 E-8$

$4.27 \mathrm{E}-8$

$6.14 \mathrm{E}-8$

$6.91 \mathrm{E}-8$

$4.48 \mathrm{E}-8$

$6.11 \mathrm{E}-8$

5. $48 \mathrm{E}-8$

$5.19 \mathrm{E}-8$

$5.55 \mathrm{E}-8$

$4.61 \mathrm{E}-8$

$6.06 \mathrm{E}-8$

$6.50 \mathrm{E}-8$

$6.68 \mathrm{E}-8$

$6.23 E-8$

Mean

3. 28E-8

$4.09 \mathrm{E}-8$

$5.32 \mathrm{E}-8$

$4.42 \mathrm{E}-8$

$6.30 \mathrm{E}-8$

$6.88 \mathrm{E}-8$

$4.51 E-8$

$6.07 E-8$

$5.40 \mathrm{E}-8$

$5.13 E-8$

$5.54 \mathrm{E}-8$

$4.56 \mathrm{E}-8$

$6.29 \mathrm{E}-8$

$6.57 \mathrm{E}-8$

$6.93 \mathrm{E}-8$

$6.51 \mathrm{E}-8$
Net Current (Amp) set 2

set 3
3. $42 \mathrm{E}-8$
$4.17 \mathrm{E}-8$
5. $36 \mathrm{E}-8$
4. $77 \mathrm{E}-8$
6. $61 \mathrm{E}-8$
7. $19 \mathrm{E}-8$
4. $63 \mathrm{E}-8$
$6.21 \mathrm{E}-8$
$5.52 \mathrm{E}-8$
$5.28 \mathrm{E}-8$
$5.75 \mathrm{E}-8$
$4.63 E-8$
$6.56 \mathrm{E}-8$
$6.92 E-8$
7. $16 \mathrm{E}-8$
$6.42 \mathrm{E}-8$

Net Current (Amp)

std. Dev. Rel. STd. Dev.

1.28E-09

9. 09E-10

1. $40 \mathrm{E}-09$

3.07E-09

2. $69 \mathrm{E}-09$

3. 18E-09

$1.05 \mathrm{E}-09$

$1.60 \mathrm{E}-09$

$1.66 \mathrm{E}-09$

$1.84 \mathrm{E}-09$

$2.13 \mathrm{E}-09$

1. 02E-09

2. 52E-09

3. 14E-09

$2.42 \mathrm{E}-09$

3. 36E-09
3.9

2.2

2.6

6.9

4.2

4.6

2.3

2.6

3.0

3.5

3.8

2.2

4.0

4.7

3. 4

5.1 
TABLE VII

CARBON FIBER ARRAY ELECTRODE NORMALIZATION FACTORS FOR PSEUDO-VOLTAMMOGRAMS

\section{Electrode}

$\begin{array}{cc}\# & 1 \\ \# & 2 \\ \# & 3 \\ \# & 4 \\ \# & 5 \\ \# & 6 \\ \# & 7 \\ \# & 8 \\ \# & 9 \\ \# & 10 \\ \# & 11 \\ \# & 12 \\ \# & 13 \\ \# & 14 \\ \# & 15 \\ \# & 16\end{array}$

Ave. Net Current (Amp)

$$
\begin{aligned}
& 3.21 E-8 \\
& 4.01 \mathrm{E}-8 \\
& 5.21 \mathrm{E}-8 \\
& 4.12 \mathrm{E}-8 \\
& 5.88 \mathrm{E}-8 \\
& 6.73 \mathrm{E}-8 \\
& 4.39 \mathrm{E}-8 \\
& 5.93 \mathrm{E}-8 \\
& 5.28 \mathrm{E}-8 \\
& 5.12 \mathrm{E}-8 \\
& 5.43 \mathrm{E}-8 \\
& 4.43 \mathrm{E}-8 \\
& 5.89 \mathrm{E}-8 \\
& 6.37 \mathrm{E}-8 \\
& 6.64 \mathrm{E}-8 \\
& 6.03 \mathrm{E}-8
\end{aligned}
$$

Normalization Factor

zinc/zinc acetate reference electrode.

HQ concentrations ranging from $7.26 \times 10^{-5} \mathrm{M}$ up to 5.45 $x 10^{-4} M$ were used to study the analytical response of this instrumentation. The potential range between $+1.05 \mathrm{~V}$ and $+1.95 \mathrm{~V}$ was applied at the CFAEs in the multi-electrode cell.

Reproducibility of Multi-Electrode Voltammetry

The reproducibility of MEV was studied by a series of three injections of a $5.45 \times 10^{-4} \mathrm{M}$ HQ solution at the flow rate of $3.33 \mathrm{~mL} / \mathrm{min}$ in a 6 -hour period. The normalized net currents at each CFAE are shown in Table VIII. The relative standard deviations scatter between $167 \%$ in the residual current region and $0.6 \%$ in the limiting current region. 
TABLE VIII

REPRODUCIBILITY OF MULTI-ELECTRODE VOLTAMMETRY

\begin{tabular}{|c|c|c|c|c|}
\hline \multirow{2}{*}{ Electrode } & \multirow{2}{*}{$\begin{array}{l}\text { Potential (V) } \\
\text { Applied }\end{array}$} & \multicolumn{3}{|c|}{ Net Current (Amp) } \\
\hline & & Set 1 & set 2 & set 3 \\
\hline $\begin{array}{ll}\# & 1 \\
\# & 2 \\
\# & 3 \\
\# & 4 \\
\# & 5 \\
\# & 6 \\
\# & 7 \\
\# & 8 \\
\# & 9 \\
\# & 10 \\
\# & 11 \\
\# & 12 \\
\# & 13 \\
\# & 14 \\
\# & 15 \\
\# & 16\end{array}$ & $\begin{array}{l}1.05 \\
1.11 \\
1.17 \\
1.23 \\
1.29 \\
1.35 \\
1.41 \\
1.47 \\
1.53 \\
1.59 \\
1.65 \\
1.71 \\
1.77 \\
1.83 \\
1.89 \\
1.95\end{array}$ & $\begin{array}{r}-3.23 \mathrm{E}-11 \\
7.87 \mathrm{E}-12 \\
-3.02 \mathrm{E}-11 \\
-1.22 \mathrm{E}-11 \\
-2.72 \mathrm{E}-11 \\
1.18 \mathrm{E}-11 \\
5.23 \mathrm{E}-10 \\
3.26 \mathrm{E}-09 \\
2.51 \mathrm{E}-09 \\
7.68 \mathrm{E}-09 \\
1.13 \mathrm{E}-08 \\
1.53 \mathrm{E}-08 \\
2.25 \mathrm{E}-08 \\
2.78 \mathrm{E}-08 \\
3.27 \mathrm{E}-08 \\
3.92 \mathrm{E}-08\end{array}$ & $\begin{array}{r}4.45 \mathrm{E}-12 \\
3.46 \mathrm{E}-11 \\
-1.86 \mathrm{E}-12 \\
-8.87 \mathrm{E}-12 \\
-3.88 \mathrm{E}-11 \\
1.42 \mathrm{E}-11 \\
5.13 \mathrm{E}-10 \\
3.20 \mathrm{E}-09 \\
2.54 \mathrm{E}-09 \\
7.72 \mathrm{E}-09 \\
1.18 \mathrm{E}-08 \\
1.74 \mathrm{E}-08 \\
2.34 \mathrm{E}-08 \\
2.88 \mathrm{E}-08 \\
3.23 \mathrm{E}-08 \\
3.75 \mathrm{E}-08\end{array}$ & $\begin{array}{r}-5.67 \mathrm{E}-11 \\
6.07 \mathrm{E}-11 \\
1.08 \mathrm{E}-12 \\
-1.44 \mathrm{E}-11 \\
-2.33 \mathrm{E}-11 \\
4.20 \mathrm{E}-11 \\
5.25 \mathrm{E}-10 \\
3.20 \mathrm{E}-09 \\
2.64 \mathrm{E}-09 \\
7.99 \mathrm{E}-09 \\
1.23 \mathrm{E}-08 \\
1.72 \mathrm{E}-08 \\
2.58 \mathrm{E}-08 \\
2.90 \mathrm{E}-08 \\
3.27 \mathrm{E}-08 \\
3.72 \mathrm{E}-08\end{array}$ \\
\hline
\end{tabular}

Electrode

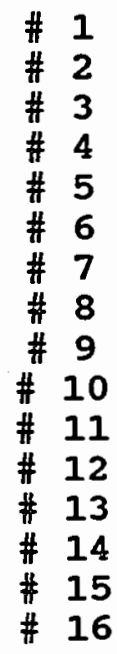

Mean

$$
\begin{array}{r}
-2.82 \mathrm{E}-11 \\
3.44 \mathrm{E}-11 \\
-1.03 \mathrm{E}-11 \\
-1.18 \mathrm{E}-11 \\
-2.98 \mathrm{E}-11 \\
2.27 \mathrm{E}-11 \\
5.20 \mathrm{E}-10 \\
3.22 \mathrm{E}-09 \\
2.56 \mathrm{E}-09 \\
7.80 \mathrm{E}-09 \\
1.18 \mathrm{E}-08 \\
1.66 \mathrm{E}-08 \\
2.39 \mathrm{E}-08 \\
2.85 \mathrm{E}-08 \\
3.26 \mathrm{E}-08 \\
3.80 \mathrm{E}-08
\end{array}
$$

Net Current (Amp)

$$
\text { std. Dev. }
$$

$$
\begin{aligned}
& 3.08 \mathrm{E}-11 \\
& 2.64 \mathrm{E}-11 \\
& 1.73 \mathrm{E}-11 \\
& 2.78 \mathrm{E}-12 \\
& 8.09 \mathrm{E}-12 \\
& 1.68 \mathrm{E}-11 \\
& 6.25 \mathrm{E}-12 \\
& 3.33 \mathrm{E}-11 \\
& 7.11 \mathrm{E}-11 \\
& 1.66 \mathrm{E}-10 \\
& 4.74 \mathrm{E}-10 \\
& 1.16 \mathrm{E}-09 \\
& 1.71 \mathrm{E}-09 \\
& 5.95 \mathrm{E}-10 \\
& 2.15 \mathrm{E}-10 \\
& 1.10 \mathrm{E}-09
\end{aligned}
$$

$$
\begin{array}{r}
-109.2 \\
76.7 \\
-167.4 \\
-23.6 \\
-27.2 \\
74.1 \\
1.2 \\
1.0 \\
2.7 \\
2.1 \\
4.0 \\
6.9 \\
7.1 \\
2.0 \\
0.6 \\
2.8
\end{array}
$$


The very large relative standard deviation at low potential end of the pseudo-voltammogram is due to the small currents and the resolution of the ADC. The low relative standard deviation at high potential range indicates that MEV has very good reproducibility over this time period.

\section{Shape of Pseudo-Voltammograms}

Figure 24 shows a set of sigmoidal-shaped pseudovoltammograms constructed from the data, shown in Table IX, obtained using different concentrations of $\mathrm{HQ}$ solution at the flow rate of $3.33 \mathrm{~mL} / \mathrm{min}$. The shapes of these voltammograms are similar to the cyclic voltammograms obtained at a CFAE in a stationary solution, shown in Figure 22. A small bump was also shown at ca. $+1.5 \mathrm{~V}$ (vs. the zinc/zinc acetate electrode), which might be caused by the trapped $\mathrm{HQ}$ in the crack adsorbing on the electrode surface. The whole instrument package worked as designed.

\section{Calibration Curve and Detection Limit of MEV}

The normalized net currents obtained at an applied potential of $+1.95 \mathrm{~V}$ were chosen for plotting a calibration curve because the currents generated at this potential represent the limiting current. The graph plotted with these limiting currents vs. the concentrations, respectively, is shown in Figure 25 . The results of the linear regression analysis of this calibration curve had a correlation coefficient of 0.9999 . Obviously, the dynamic 


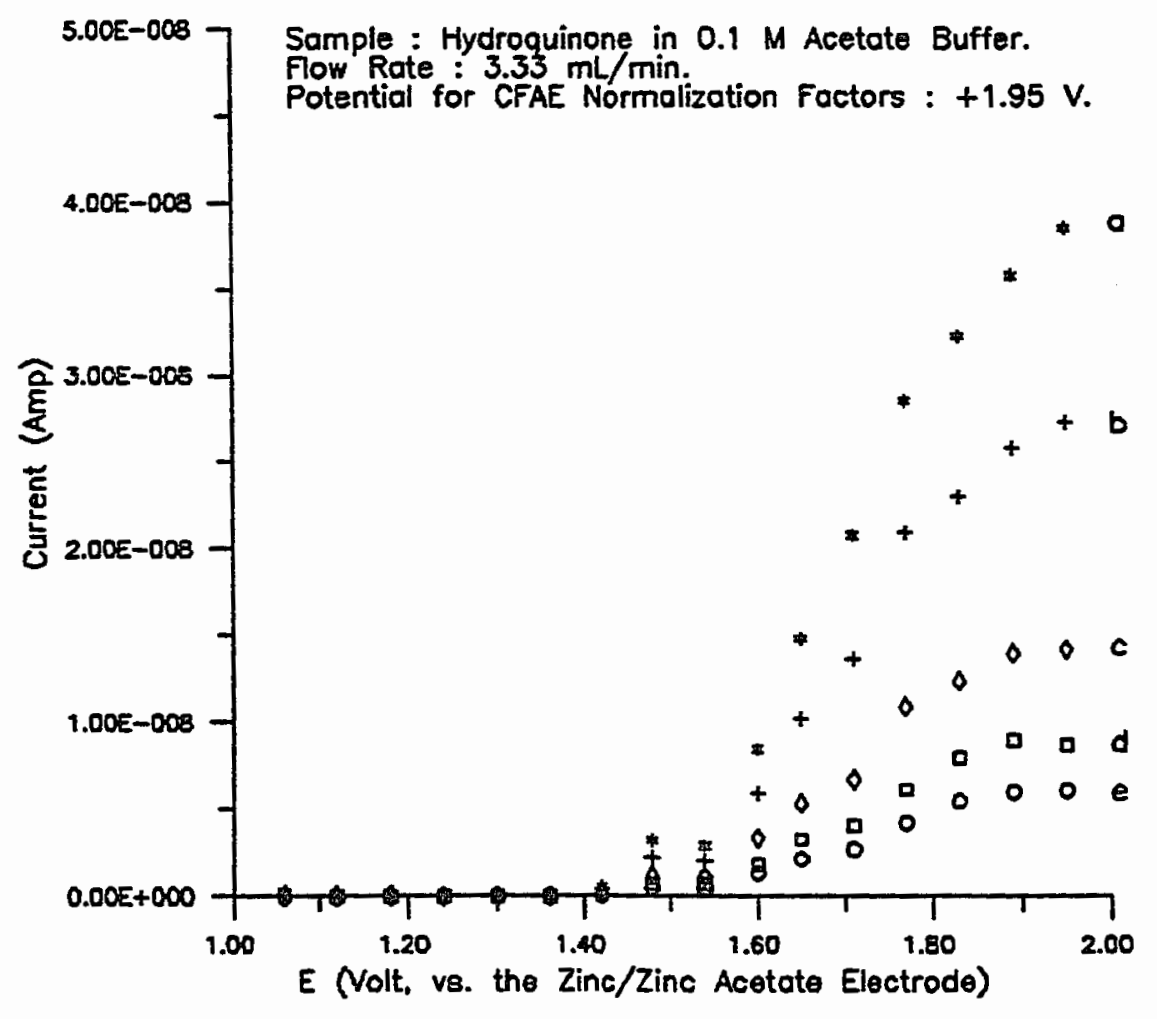

Figure 24. Pseudo-voltammograms of hydroquinone at different concentrations. Flow rate, 3.33 at different concent (a) $5.45 \times 10^{-4} \mathrm{Mi}$ (b) $3.63 \times 10^{-4} \mathrm{Mi}$ (c) $\mathrm{mL} / \mathrm{min}_{1 .}$ (a) $52 \times 10^{-4} \mathrm{M}$ (d) $1.09 \times 10^{-4} \mathrm{M} ;$ (e) $7.26 \times 10^{-5} \mathrm{M}$. 
TABLE IX

DATA OBTAINED FOR PSEUDO-VOLTAMMOGRAMS AT A FLOW RATE OF $3.33 \mathrm{ML} / \mathrm{MIN}$

Electrode Applied Potential (V)

$\begin{array}{lll}\# 1 & 1.05 \\ \# & 2 & 1.11 \\ \# & 3 & 1.17 \\ \# & 4 & 1.23 \\ \# & 5 & 1.29 \\ \# & 6 & 1.35 \\ \# 7 & 1.41 \\ \# 8 & 1.47 \\ \# & 9 & 1.53 \\ \# & 10 & 1.59 \\ \# 11 & 1.65 \\ \# 12 & 1.71 \\ \# & 13 & 1.77 \\ \# & 14 & 1.83 \\ \# 15 & 1.89 \\ \# 16 & 1.95\end{array}$

Electrode

Net Current (Amp)

\begin{tabular}{|c|c|c|c|c|c|}
\hline & $7.26 \mathrm{E}-5$ & $1.09 \mathrm{E}-4$ & $1.82 \mathrm{E}-4$ & OI $63 \mathrm{E}-4$ & $5.45 \mathrm{E}-4$ \\
\hline $\begin{array}{ll}\# & 1 \\
\# & 2 \\
\# & 3 \\
\# & 4 \\
\# & 5 \\
\# & 6 \\
\# & 7 \\
\# & 8 \\
\# & 9 \\
\# & 10 \\
\# & 11 \\
\# & 12 \\
\# & 13 \\
\# & 14 \\
\# & 15 \\
\# & 16\end{array}$ & $\begin{array}{r}-3.56 \mathrm{E}-11 \\
-2.96 \mathrm{E}-11 \\
-4.42 \mathrm{E}-12 \\
-5.96 \mathrm{E}-12 \\
-2.52 \mathrm{E}-11 \\
-1.44 \mathrm{E}-11 \\
3.74 \mathrm{E}-11 \\
4.65 \mathrm{E}-10 \\
4.45 \mathrm{E}-10 \\
1.31 \mathrm{E}-09 \\
2.16 \mathrm{E}-09 \\
2.69 \mathrm{E}-09 \\
4.20 \mathrm{E}-09 \\
5.48 \mathrm{E}-09 \\
5.99 \mathrm{E}-09 \\
6.07 \mathrm{E}-09\end{array}$ & $\begin{array}{r}3.77 \mathrm{E}-11 \\
-7.62 \mathrm{E}-12 \\
-1.34 \mathrm{E}-12 \\
-1.70 \mathrm{E}-11 \\
-3.56 \mathrm{E}-11 \\
-2.10 \mathrm{E}-11 \\
7.98 \mathrm{E}-11 \\
7.00 \mathrm{E}-10 \\
6.76 \mathrm{E}-10 \\
1.80 \mathrm{E}-09 \\
3.25 \mathrm{E}-09 \\
4.08 \mathrm{E}-09 \\
6.14 \mathrm{E}-09 \\
7.94 \mathrm{E}-09 \\
9.00 \mathrm{E}-09 \\
8.66 \mathrm{E}-09\end{array}$ & $\begin{array}{r}1.02 \mathrm{E}-11 \\
-4.98 \mathrm{E}-12 \\
-1.72 \mathrm{E}-12 \\
-2.93 \mathrm{E}-11 \\
-1.36 \mathrm{E}-11 \\
-8.95 \mathrm{E}-12 \\
1.59 \mathrm{E}-10 \\
1.16 \mathrm{E}-09 \\
1.09 \mathrm{E}-09 \\
3.08 \mathrm{E}-09 \\
5.34 \mathrm{E}-09 \\
6.69 \mathrm{E}-09 \\
1.09 \mathrm{E}-08 \\
1.24 \mathrm{E}-08 \\
1.40 \mathrm{E}-08 \\
1.42 \mathrm{E}-08\end{array}$ & $\begin{array}{r}6.28 \mathrm{E}-12 \\
3.06 \mathrm{E}-12 \\
-1.57 \mathrm{E}-11 \\
7.50 \mathrm{E}-12 \\
-2.98 \mathrm{E}-11 \\
1.28 \mathrm{E}-11 \\
3.59 \mathrm{E}-10 \\
2.24 \mathrm{E}-09 \\
2.04 \mathrm{E}-09 \\
5.96 \mathrm{E}-09 \\
1.02 \mathrm{E}-08 \\
1.36 \mathrm{E}-08 \\
2.09 \mathrm{E}-08 \\
2.30 \mathrm{E}-08 \\
2.58 \mathrm{E}-08 \\
2.72 \mathrm{E}-08\end{array}$ & $\begin{array}{r}1.72 \mathrm{E}-11 \\
-1.59 \mathrm{E}-11 \\
-3.13 \mathrm{E}-12 \\
-1.70 \mathrm{E}-11 \\
-3.85 \mathrm{E}-11 \\
3.82 \mathrm{E}-11 \\
5.07 \mathrm{E}-10 \\
3.22 \mathrm{E}-09 \\
2.88 \mathrm{E}-09 \\
8.45 \mathrm{E}-09 \\
1.48 \mathrm{E}-08 \\
2.08 \mathrm{E}-08 \\
2.85 \mathrm{E}-08 \\
3.22 \mathrm{E}-08 \\
3.57 \mathrm{E}-08 \\
3.84 \mathrm{E}-08\end{array}$ \\
\hline
\end{tabular}




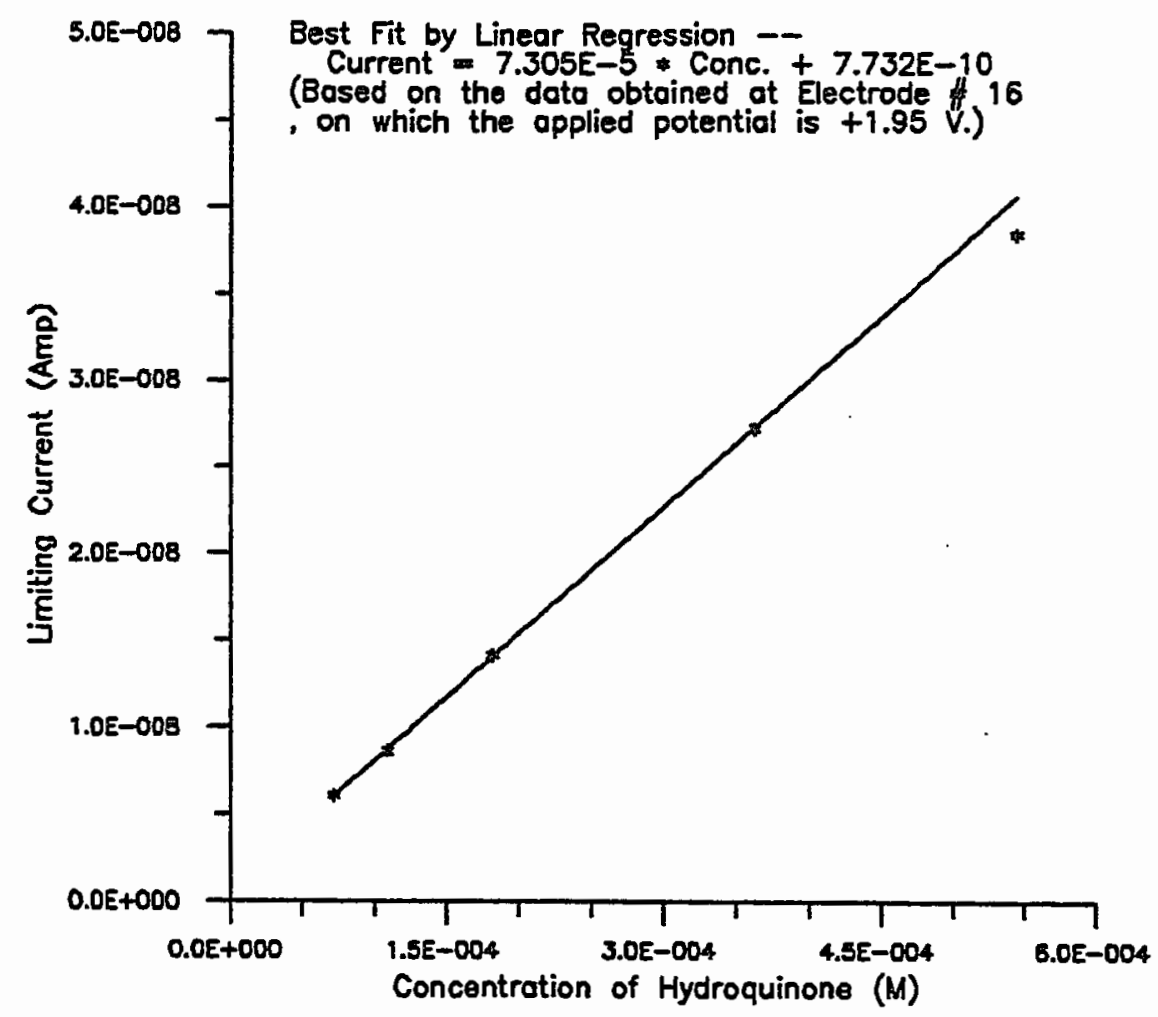

Figure 25. Calibration curve of multi-electrode voltammetry. The experimental conditions are the same as in Figure 24. 
range of linear response of MEV extends over two orders of magnitude of the concentration. The detection limit based on these conditions is estimated to be $5 \times 10^{-5} \mathrm{M} \mathrm{HQ}$ at $95 \%$ confidence level, ie., on the basis of a 2 times the standard deviation of the calibration curve. 


\section{CHAPTER VI}

\section{CONCLUSION}

Carbon electrodes have been used in electrochemical (EC) cells for a long time. There are several reasons for using them. One of the primary reasons is the applicability to anodic oxidations of many organic and inorganic species, which are not amenable to the mercury electrode. The applicable potential range on carbon electrodes is much wider compared with electrodes made of other materials. Many forms of carbon have been used to fabricate electrodes for EC detection in the oxidative mode. Among them, carbon fiber provides an inexpensive and readily fabricated alternative to materials such as glassy carbon or pyrolytic graphite, which are expensive and difficult to fabricate. Carbon fiber overcomes many drawbacks of other types of carbon electrodes (28), such as very low background current, good peak resolution, and good reproducibility.

Based on pseudo-voltammograms obtained, multi-electrode voltammetry (MEV) is an effective method for the determination of electroactive substances. The reproducibility and stability of MEV are depenaient upon the careful assembly of the flow cell, including no gas bubbles in the cell and the proper tightness of the screws. The 
sensitivity of MEV matches most of the EC methods, but with less expensive instrumentation and more convenient operation. This good sensitivity is obtained due to two reasons. First, capacitative charging current, one of the limiting factors in all EC techniques, is reduced to insignificant proportions because of the application of constant voltages at CFAEs. Second, the rate of mass transport to CFAEs increases due to the edge effect of CFAE. As a consequence of reduced capacitative charging currents and increased mass transport rates, CFAEs exhibit good sensitivity. Electrode surface fouling by electrochemically active species and impurities is diminished in this flow system because a very small sample solution is injected into the system so that the exposure of the electrode to the sample is relatively brief. Also, electrodes are always reactivated using a square wave prior to data collection in order to obtain a fresh surface.

Two improvements for this instrumentation need to be made in the future. First, building an interface with a computer which has larger RAM capacity is necessary. This is an important point because a lot of time was wasted waiting to record and transfer data. This diminished the speed advantage of using flow injection analysis. An unique feature of this system is the option to change the time interval according to the sample size and sample concentration in order to expand the dynamic range of the 
instrument. This is a very important advantage if it is used as a detector for HPLC and ion chromatography. Second, a new type of pump is needed. Gradual diminution of signal current has been occasionally observed during data collection, due to the adsorption of micro gas bubbles at CFAE surfaces. The generation of these bubbles may be caused by the combination of two factors: (1) the saturation of gas in the flow stream while the solution drips into the pulse damper in order to insulate the ground current from the AC power line and dampening the pulsating current generated by the pump; (2) the periodic pressure fluctuation in the flow cell due to the reciprocal pump.

From the constructed pseudo-voltammograms, it was shown that MEV can be used like other electrochemical techniques with minimal manipulation. It is possible that MEV can be used to determine the complexation ability between a metal ion and a ligand by the measurement of a half-wave potential shift, i.e. the stronger the binding of the complex, the larger is the shift from $\mathrm{E}_{1 / 2}$ of that metal ion. EC cells have been used as detectors for HPLC for a long time. Chemists have found that it is very unlikely that a single peak of HPLC effluent represents one and only one component of the mixture (37). The results of this study make EC detectors more important since they have the ability to determine the purity of the effluent peak. At present, EC detectors use only one or two working electrodes 
and can not distinguish between eluted species on the basis of redox properties. Its resolving ability can be enhanced by the use of more than one working electrode. Series and parallel combinations in a flow stream avoid the need for potential scans which is impractical due to short duration of solute peaks and slow decay of background currents of some electrode materials. Therefore, the possibility of incorporating MEV as a detector for HPLC should be investigated. With an MEV detector, additional resolving power is available and it can help in the identification of unresolved column effluent.

Anodic stripping techniques provide concentration measurements, not speciation unless additional chemical separation steps are included. There is a source of error that has been largely ignored even though it was identified many years ago (2). This error is due to intermetallic compound formation between metals during deposition. This may decrease anodic peak height or even eliminate the peak. Further, the peaks due to oxidation of the intermetallic compounds are displaced on the potential axis so that identification may be in error. MEV can easily alleviate this problem by deploying a coulometric electrode, such as porous carbon, upstream to completely remove selected metal ions in the flow so that other ions may be deposited free of interference on the electrodes used for anodic stripping. A coulometric electrode can also remove impurities in 
supporting electrolytes and/or certain contaminants of the sample matrix, which may interfere with species of interest. The combination of this coulometric electrode and MEV is a potentially powerful technique to improve detection limits. At present, only 16 CFAEs have been installed in MEV. This system is ready to expand to as many as 64 electrodes. Choosing different electrode materials and expanding the number of electrodes in the flow cell may be studied to extend the domain of application. 


\section{REFERENCES}

(1) A. Mazzucotelli, R. Frache, A. Viarengo, and G. Martino, Talanta, 35, 693 (1988).

(2) T.M. Florence, Analyst, 111, 489 (1986).

(3) G.F. Nordburg, Sci. of Total Environ., 71, 243 (1988).

(4) I.T. Urasa and S.H. Nam, J. Chromatogr. Sci., 27, 30 (1989).

(5) K.S. Subramanian, Anal. Chem., 60, 11 (1988).

(6) B.D. Karcher and I.S. Krull, J. Chromatogr. Sci., 25, 472 (1987).

(7) J. Osteryoung, Methods Enzymol., 158, 243 (1988) •

(8) C.E. Lunte, T.H. Ridgway, and W.R. Heineman, Anal. Chem., 59, 761 (1987).

(9) H. Gunasingham and B. Fleet, Anal. Chem., 55, 1409 (1983).

(10) W. Davison, J. Electroanal. Chem,, 87, 395 (1978).

(11) J. Wang and L.D. Hutchins, Anal. Chem., 57, 1536 (1985).

(12) E.S. Decastro, E.W. Huber, D. Villarroel, C. Galiatsatos, J.E. Mark, and W.R. Heineman, Anal. Chem., 59, 134 (1987).

(13) D.K. Roe and I.P. Ho, Pittsburgh Conference 1984, Abst. No. 532. (1984).

(14) K. Stulik and V. Pacáková, CRC Crit. Rev. Anal. Chem., 14, 297 (1984).

(15) H.B. Hanekamp and H.G. de Jong, Anal. Chim. Acta, 135, 351 (1982).

(16) M.B. Glauert, J. Fluid Mech., 1, 625 (1956).

(17) J. Yamada and H. Matsuda, J. Electroanal. Chem., 44, 189 (1973). 
(18) A.J. Dalhuijsen, Th.H. van der Meer, and C.J. Hoogendoorn, J. Electroanal. Chem., 182, 295 (1985).

(19) B. Fleet and C.J. Little, J.Chromatogr. Sci., 12, 747 (1974).

(20) D.C. Johnson, S.G. Weber, A.M. Bond, R.M. Wightman, R.E. Shoup, and I.S. Krull, Anal. Chim. Acta, 180, 187 (1986).

(21) W.J. Blaedel and G.A. Mabbott, Anal.Chem., 50, 933 (1978).

(22) G.N. Kamau, Anal. Chim. Acta, 207, 1 (1988).

(23) J.W. Dieker, W.E. van der Linden, and H. Poppe, Talanta, 25,151 (1978).

(24) S.G. Weber, Anal. Chem., 61, 295 (1989).

(25) J.L. Anderson, K.K. Whiten, J.D. Brewster, T.Y. Ou, and W.K. Nonidez, Anal. Chem., 57, 1366 (1985).

(26) R.M. Wightman, Anal.Chem., 53, 1125A (1981).

(27) W.L. Caudill, J.O. Howell, and R.M. Wightman, Anal. Chem., 54, 2532 (1982).

(28) G. Schulze and W. Frenzel, Anal. Chim. Acta, 159, 95 (1984).

(29) M.A. Dayton, J.C. Brown, K.J. Stutts, and R.M. Wightman, Anal. Chem., 52, 946 (1980).

(30) Commodore 64 Programmer's Reference Guide, p. 419, Commodore Business Machines, Inc. (1982).

(31) I.F. Hu, D.H. Karweik, and T. Kuwana, J. Electroanal. Chem., 188, 59 (1985).

(32) J. Wang and M.S. Lin, Anal. Chem,, 60, 499 (1988).

(33) L.J. Kepley and A.J. Bard, Anal. Chem., 60, 1459 (1988).

(34) J. Dash, Professor, Physics Dept., Portland state Univ., P.O. Box 751, Portland, OR 97201.

(35) H. Gunasingham, K.P.Ang, and C.C. Ngo, Anal. Chem., 57, 505 (1985). 
(36) S.B. Khoo, H. Gunasingham, K.P. Ang, and B.T. Tay, J. Electroanal. Chem., 216, 115 (1987).

(37) T. Demana, D. Peterman, J. Shaffer, and P.R. Melaragno, Anal. Chem., 61, 1216 (1989). 
APPENDIX A

SCHEMATIC DIAGRAM OF THE CIRCUITRY WITH COMPONENT IDENTIFICATIONS 


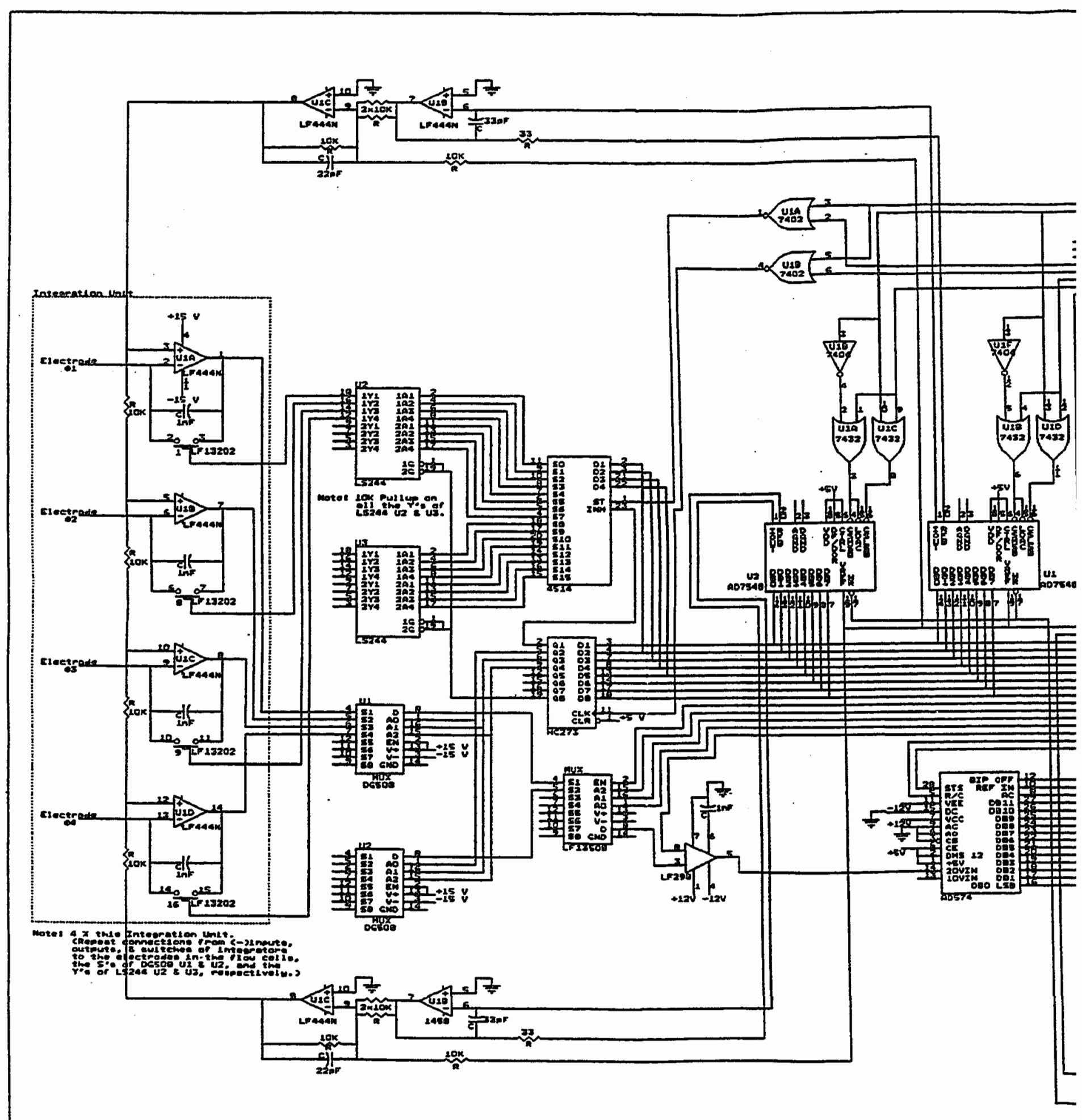





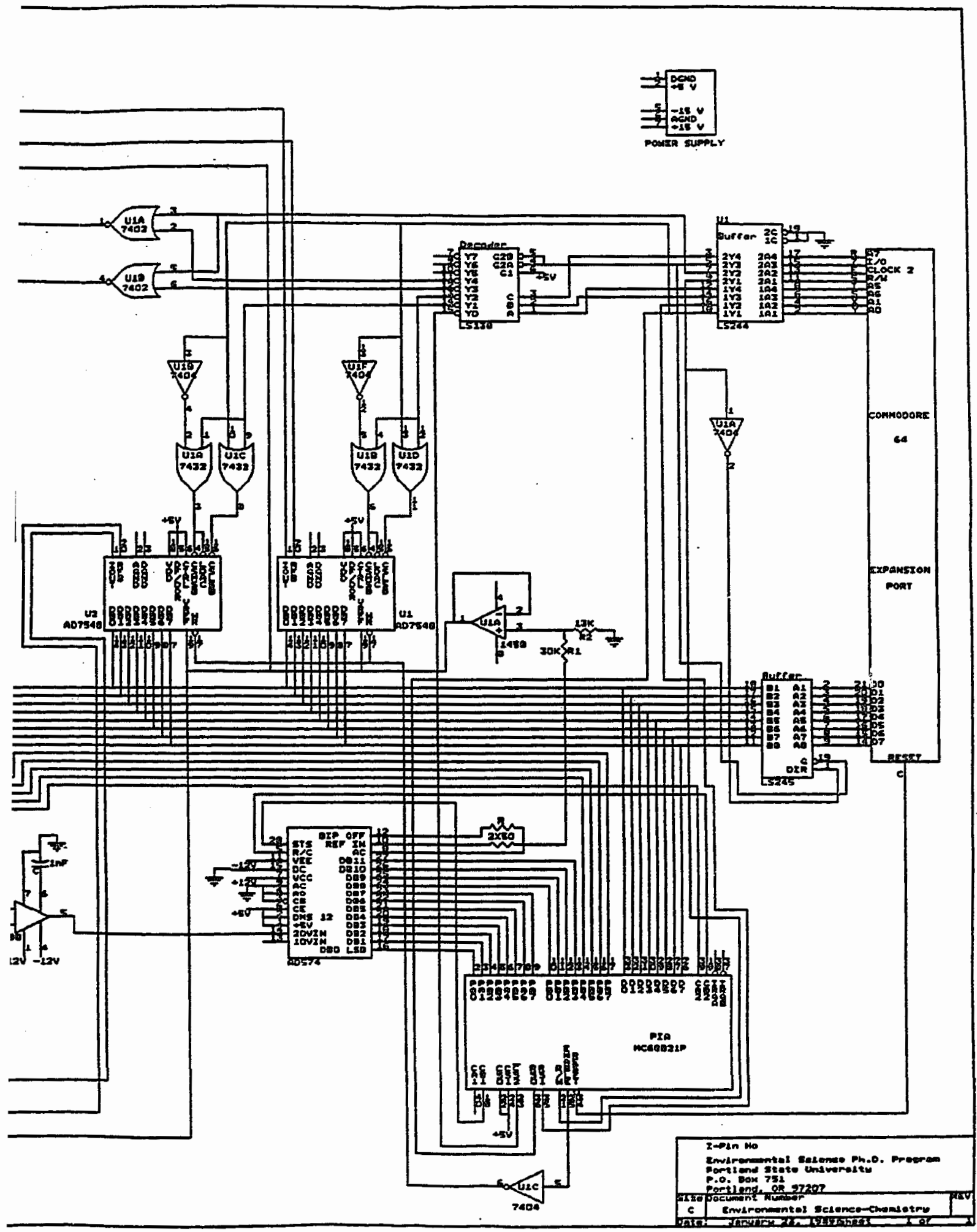



APPENDIX B

\section{SOFTWARE}

"SET. 7548 . OUTPUT" 


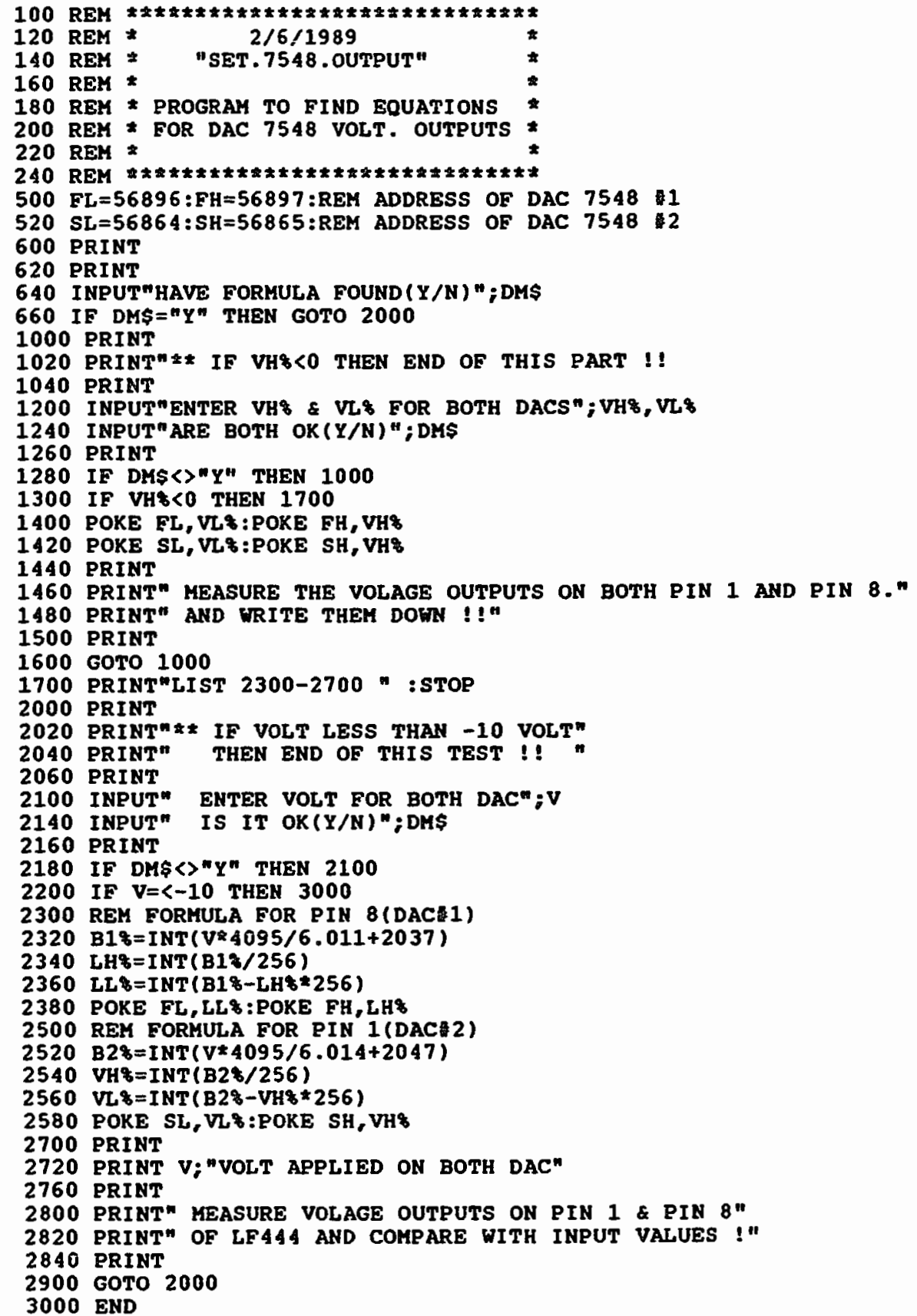


APPENDIX C

SOFTWARE "COLLEET. DATA" 
Written in BASIC language, the instruction-driven program "COLLECT.DATA" is used to instruct the experimental procedures and to perform the acquisition of coulometric data which represented the integrated analyte currents. The flow chart of this program is shown in Figure 26. The entire program is included at the end of this section. It is first used to load the assembly language subroutine "DATACQ" into the designated area in the RAM of the c-64, followed by the input of the conditions to perform the experiment. After that, the reactivation of CFAEs in the ME cell with a square wave is performed under the direction of several parameters. These parameters of electrode reactivation are the upper and lower potential limits of the square wave, the frequency of the square wave, and the duration of the reactivation process.

The experimental conditions are applied to the CFAEs after their reactivation. These conditions included the potential applied on each electrode, the setup of timer \#1 and \#2, and the delay time to allow the charging currents caused by the reactivation process to subside. After the currents subside, the assembly language subroutine is activated to perform data acquisition, as described in the next section. The collected coulometric data are temporarily stored in the RAM of the C-64 until the preset time period is over.

Since the RAM capacity of the $c-64$ is so limited, 


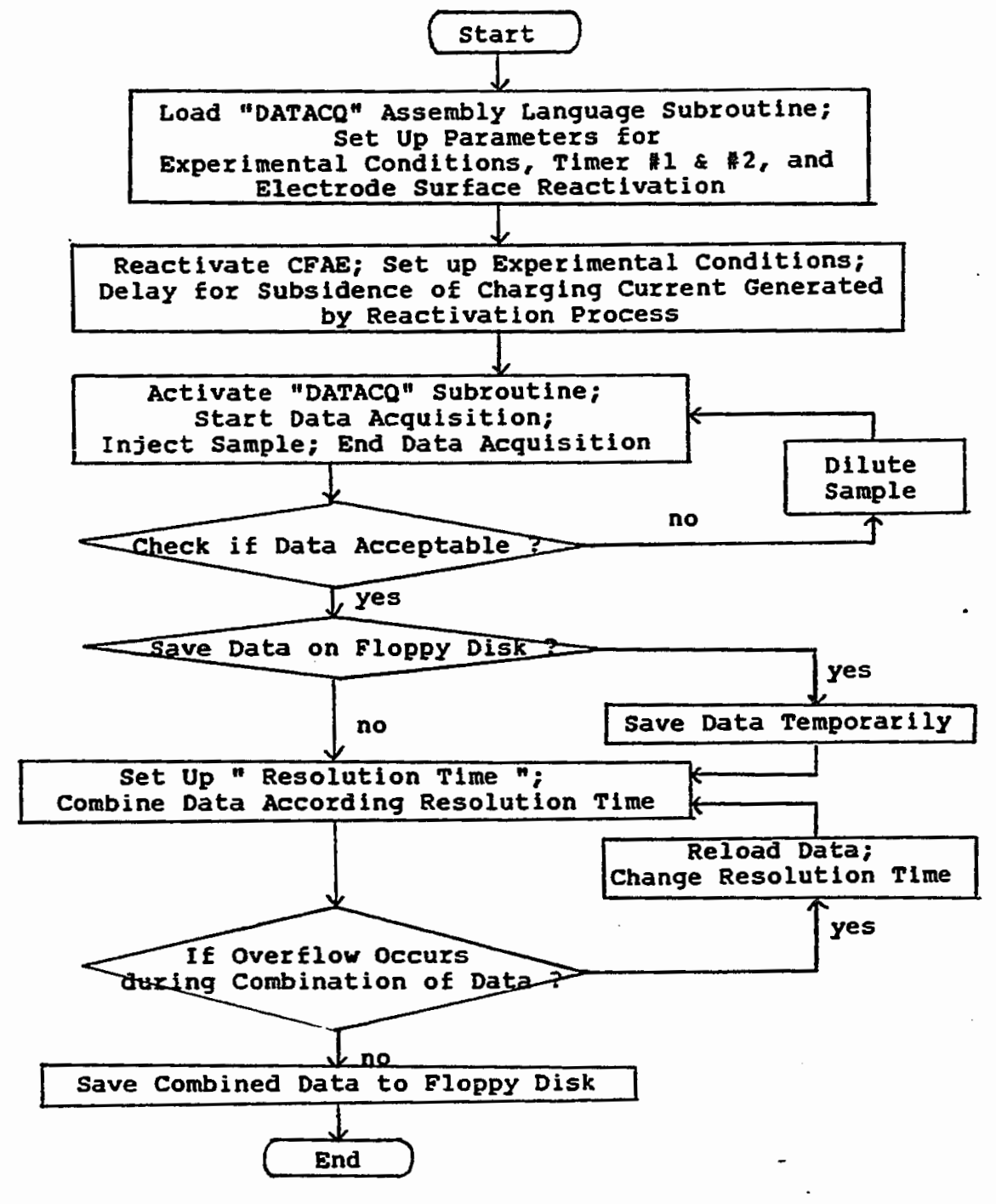

Figure 26. Flow chart of software "COLLECT.DATA". 
several sets of collected data for each CFAE are then combined together in order to reduce the requirement of the RAM according to the so-called "Resolution Time". This procedure also eliminates the random errors caused by the timing of integration. Then, these combined values are stored onto a floppy disk for further data management. If any overflow is detected during the combination of digital values, a prompt statement is printed on the monitor screen to alert the operator that the time resolution is not set appropriately. After the time resolution is changed, the data are reloaded into the matrix from the previously saved data file. Then, the combining of the digital values according to the new resolution time is performed again. The internal clock of the $c-64$ is used for timing the duration of the electrode reactivation and the delay between the end of the electrode reactivation and the beginning of the data acquisition. The two internal timers of the c-64 are used for timing the frequency of the data acquisition. The parameters of these two timers were interrelated (53). Their settings are dependent on the sample size, the sample concentration, and the RAM capacity of the C-64. The use of these two timers is a unique feature of this system. Parameters for the electrode surface activation, the setup of timer \#1 and \#2, and experimental conditions are all input through the keyboard. 


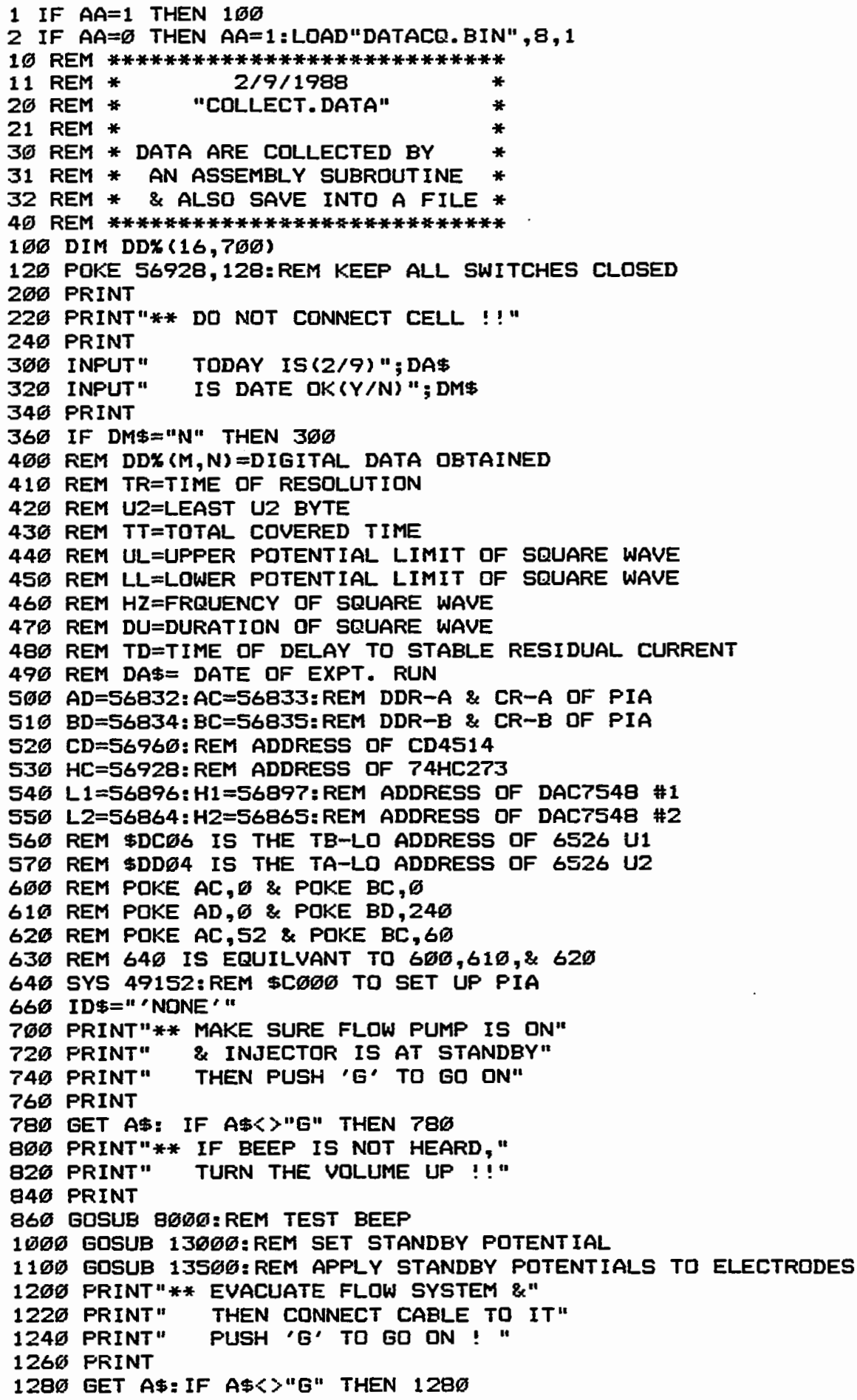




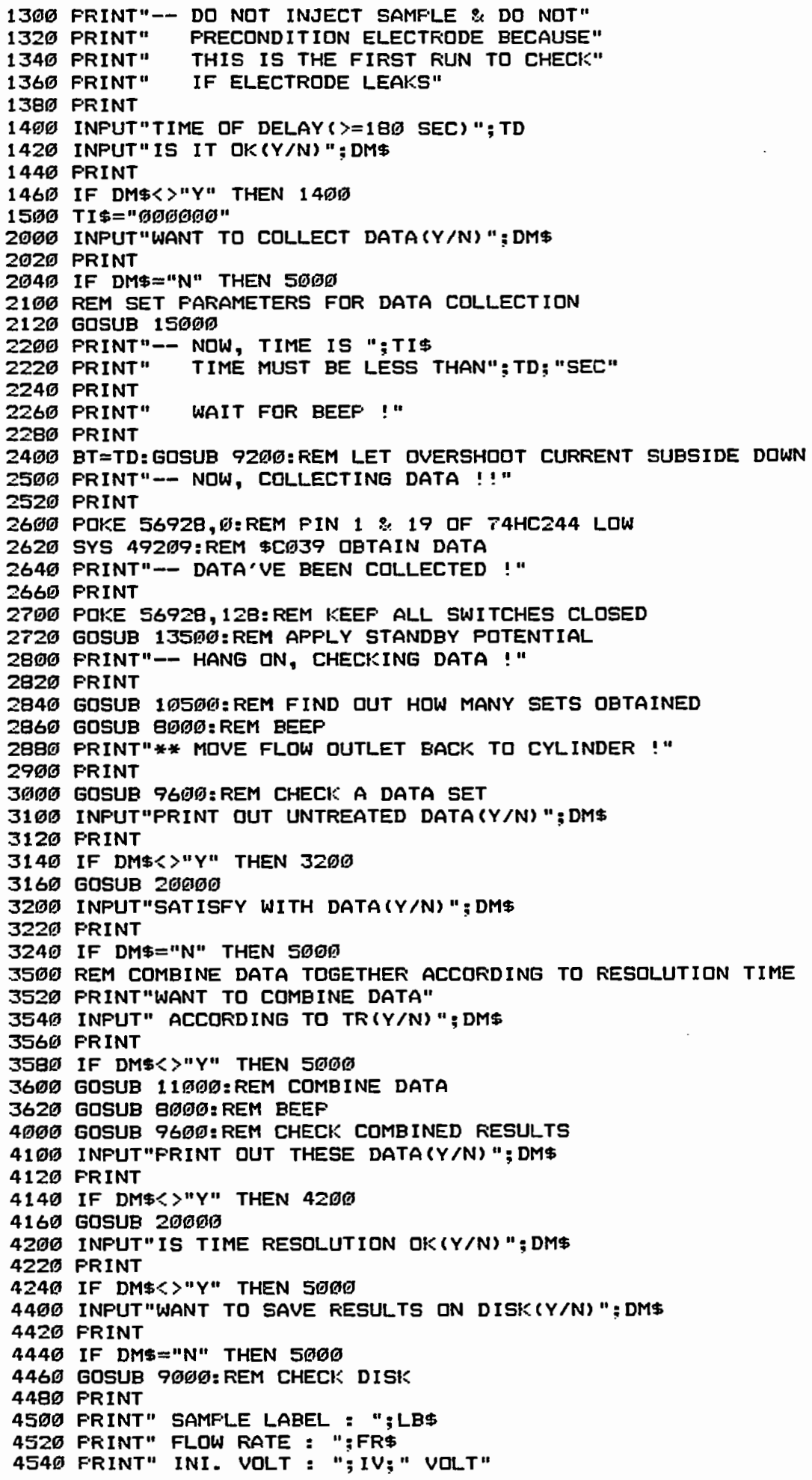




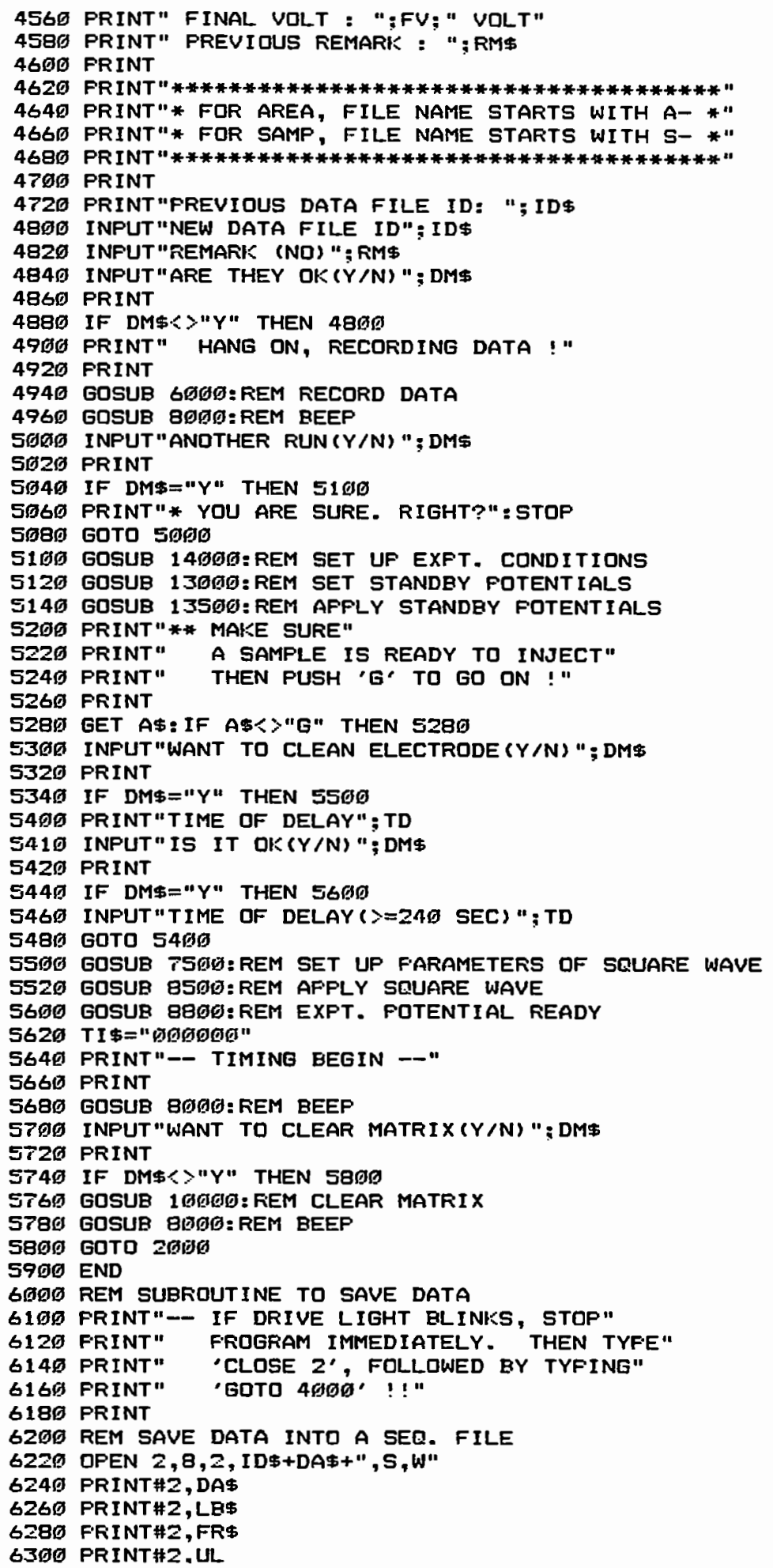




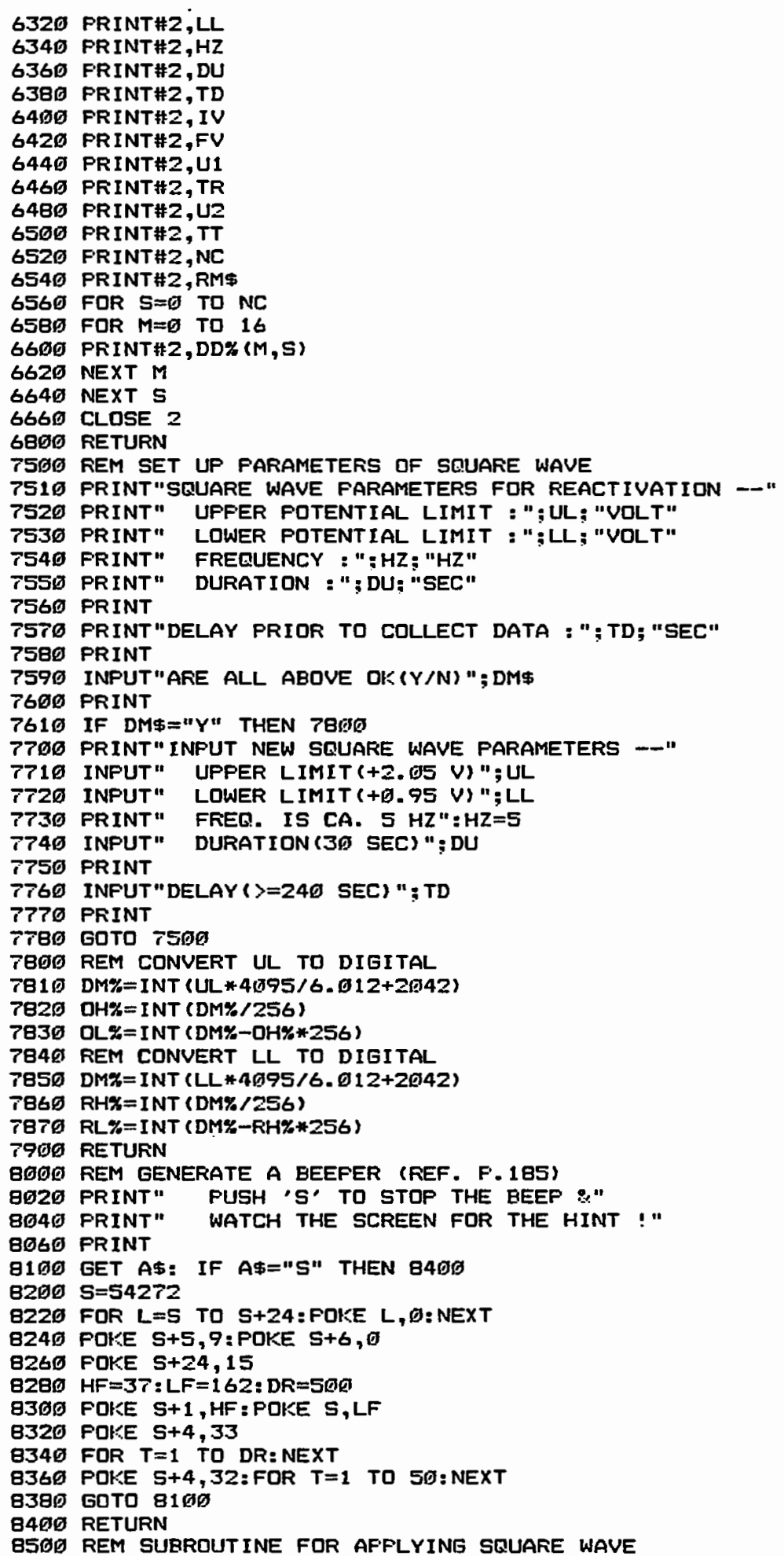


8520 PRINT"-- NOW, REACTIVATE ELECTRODES :"

8540 FRINT" WAIT"; DU; "SEC FOR ELECTRODE CLEAN !"

Q569 FRINT

QGด REM FRERUENCY OF S.W. IS $5 \mathrm{HZ}$

$862 \emptyset T I \$=" \emptyset \circ \emptyset \emptyset \emptyset \emptyset "$

8649 FEM APPLY UPPER LIMIT FIRST, THEN LOWER LIMIT

8660 POKE L1, OL\%: POKE $\mathrm{H} 1, \mathrm{OH} \%$

8689 POKE LZ, OL\%: POKE H2, OH\%

8700 FOR DM=1 T0 $8 \sigma:$ NEXT DM

8720 FDKE L1, RL\%: FOKE H1, RH\%

874の POKE L2,RL\%: POKE H2,RH\%

B76Ø FOR DM=1 TO $75:$ NEXT DM

878I IF TI/6GKDU THEN 8669

8790 RETURN

8BØळ REM AFPLY EXPT. POTENTIAL TO BOTH DAC

8B20 POKE L1, IL\%: POKE H1, IH\%

BQ4Ø POKE L2, FL\%: POKE H2,FH\%

8860 PRINT"- EXPT. POTENTIALS JUST APFLIED TQ"

8B日@ PRINT" BOTH DAC AND READY FOR ELECTRODES"

89פØ PRINT

8920 RETURN

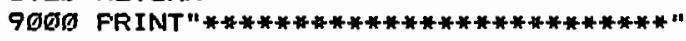

9פ20 PRINT"* MAKE SURE

9@4ø FRINT"* A RIGHT DISK IN DRIVE *"

9060 PRINT"* \% SPACE ALSO ENOUGH *"

9080 FRINT"***************************1"

9100 PRINT

9:20 INPUT"WANT TO CHECK DISK(Y/N) ";DMS

9140 PRINT

9160 IF DM\$="Y" THEN STOP

9180 RETURN

9200 REM LET OVERSHOOT CURRENT SUBSIDE DOWN

9210 IF TI/60<=BT-40 THEN 9250

9220 PRINT"** DO NOT INJECT THE SAMFLE !"

9230 PRINT" TIMING IS NOT GOOD!":FRINT

9240 GOTO 9520

9250 IF TI/60 $=B T-49$ THEN 9250

9260 GOSUB 8000: REM BEEF

9270 PRINT"-- 2ø SEC LATER, MOVE"

9280 PRINT" FLOW OUTLET INTO THE WASTE JAR !"

9290 FRINT

9300 IF TI/60K $=\mathrm{BT}-29$ THEN 939!

9329 FRINT" \#UT FLOW OUTLET INTO A WASTE JAR \&"

9340 FRINT" 15 SEC LATER, OUICK INJECT SAMPLE !"

9369 FRINT

9400 IF TI/6ब< $=8 T-5$ THEN 9499

9420 PRINT"** QUICK INJECT SAMPLE !"

9440 PRINT" \& NOW, TIME IS "; TI\$

9460 PRINT

9560 IF TI/69K $=B T$ THEN 9590

9520 RETURN

9600 REM CHECK FART OF RAW DATA BEFOFE SAVING

9620 PFIINT" - -ANY DATA SHOULD NOT = 0 OR 4995"

9640 PRINT" 2 MUST $\angle="$;N

9660 PRINT" IF $Z<\emptyset$ THEN END OF CHECKING DATA"

9680 INPUT" NEW START ING SET \#";

9796 PRINT

9720 IF $Z C 6$ THEN 9960

9746 PRINT" $M$ DDKZ DD\%Z+1 DD\%Z+2 DD\%Z+3 DD\%Z+4"

9760 FOR $M=\emptyset$ TO 16

9780 PRINT $M$; DD\% $(M, Z)$; DD\% $(M, Z+1) ; D D \%(M, Z+2) ; D D \%(M, Z+3) ; D D \%(M, Z+4)$

9809 NEXT M

9820 PRINT

984Q FRINT"STARTING SET \#(Z) =":Z

9860 FRINT

9880 GOTO 9620 


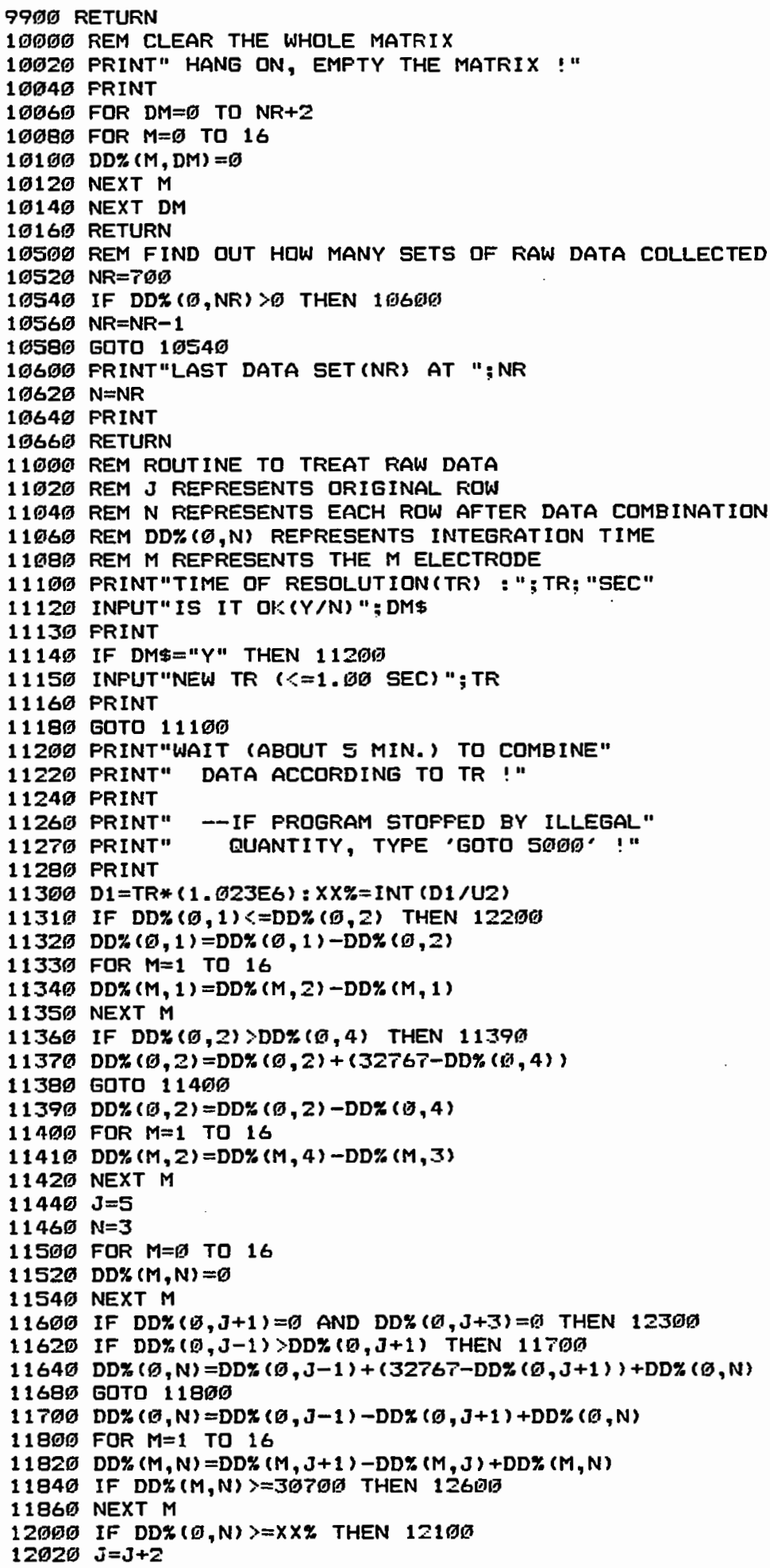




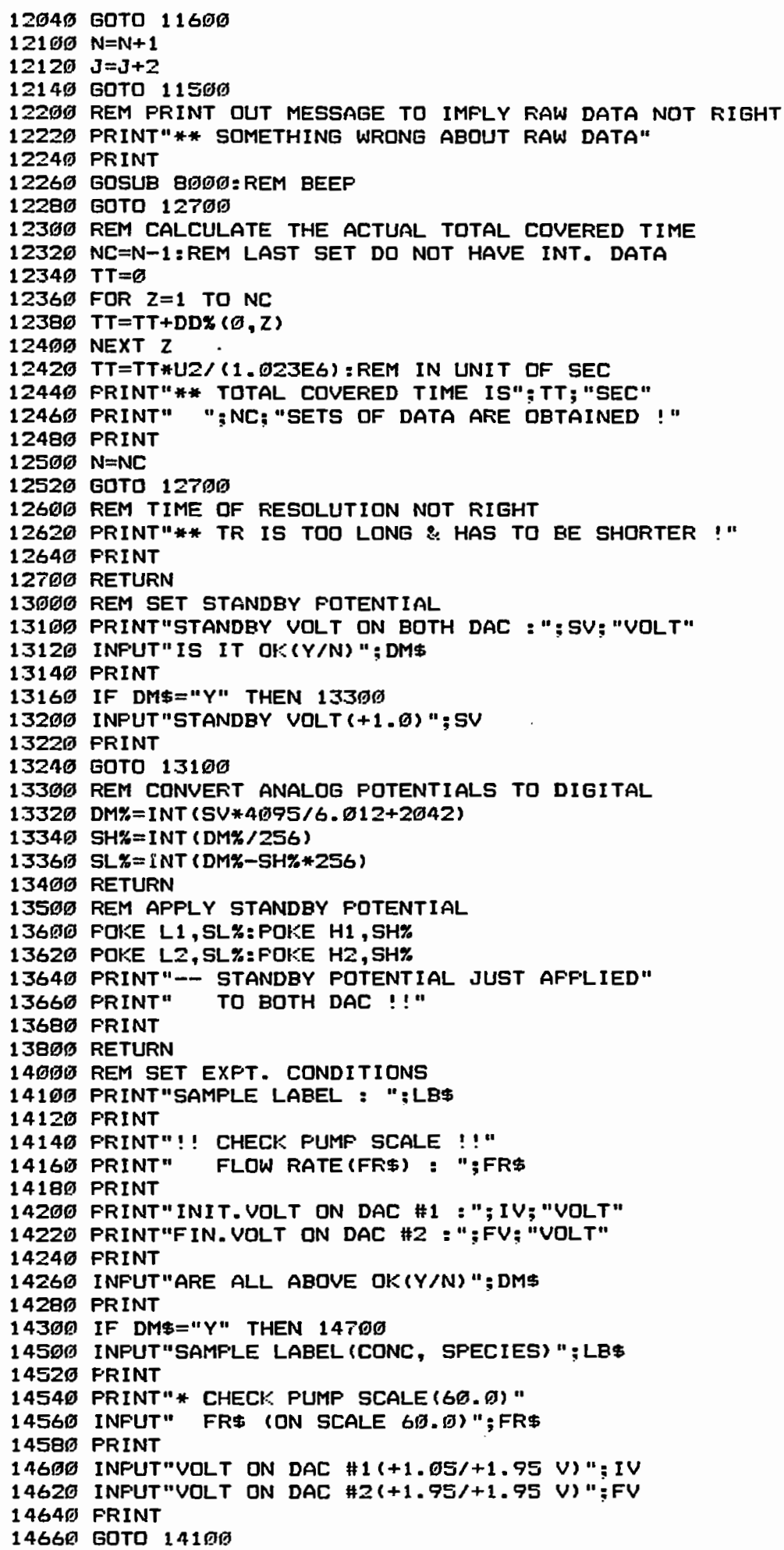


$14 T$ TI REM CONVERT ANALOG FOTENTIALS TO DIGITAL

14720 DM\% $=$ INT (IV*4095/6. $111+2037$ )

14740 IH\%=INT (DM\%/256)

14760 IL\% $=$ INT (DM\%-IH\%*256)

14890 DM\%=INT (FV*4פ95/6. $614+2947$ )

$14820 \mathrm{FH} \%=$ INT (DM\%/256)

1484פ FLz=INT (DM\%-FH\%*256)

1490 פ RETURN

15のפの REM SET TIME FARAMETERS FOR DATA COLLECTING

15010 PRINT"U1 CLOCK TIME = U1*(1/6G) SEC"

15020 FRINT" U1 VALUE : "; U1

15036 FRINT "U2 CLOCK PERIOD(CF) ="; CF; "SEC"

15049 FRINT" LEAST UZ BYTE $="$; U2

15050 FRINT"SET-UP QF COVERED TIME ="; CT; "SEC"

15060 FRINT" (GREATER THAN GO SEC BE DKO)"

15 TTO FRINT" CQUNTER HI-BYTE (CH) $=" ; \mathrm{CH}$

15080 PRINT" COUNTER LO-BYTE (CL) $=" ; C L$

15090 PRINT

15160 INFUT"ARE ALL ABOVE OK(Y/N)";DM\$

15120 PRINT

15140 IF DM\$="Y" THEN 15T 90

15290 PRINT"U1 CLOCK TIME $=U 1 *(1 / 69)$ SEC"

15220 INFUT" U1 VALUE WANTED $(<=6 \sigma) " ; U 1$

15240 FRINT

15309 FRINT"LEAST U2 BYTE DEFENDS ON U1 VALUE $(64=25) "$

15320 INPUT" LEAST U2 BYTE ( $>=64$ ) "; U2

$15360 \mathrm{CF}=(127 * 256+255) * U 2 /\left(1.023 * 10^{\wedge} 6\right)$

15380 PRINT" CLOCK FERIOD(CP) =": CF:" SEC"

15400 PRINT

15590 PRINT"TOTAL COVERED TIME = (CH*256+CL) *CF SEC"

15520 INFUT" CQUNTER HIBYTE $(=\theta)$ "; CH

$1554 \emptyset$ INFUT" COUNTER LOBYTE $(=36)$ "; CL

$15580 \mathrm{CT}=(\mathrm{CH} * 256+\mathrm{CL}) * \mathrm{CP}$

1560 PRINT" SET-UF TOTAL CQVERED TIME =";CT; "SEC"

15610 PRINT" (AROUND 60 SEC BE OK)"

15620 PRINT

15640 GOTO 15060

15700 POKE 49905,U1: REM \$CZF1 =U1BLO

15720 POKE 49906, U2: REM \$C2F2=U2ALO

$15 T 40$ POKE 49997, CL: REM \$C2F3=CNTLO

15760 POKE 4996B, CH: REM \$C2F4=CNTHI

15BOD-RETURN

16660 GOSUB BOGの:REM BEEF

2 2GOG REM PRINT OUT ORIGINAL DATA

20100 OPEN4, 4:CMD4

20200 PRINT" SAMFLE LABEL : ": LE\$

20220 PRINT

20240 FRINT" FLOW RATE : ";FR\$

20260 PRINT

20280 FRINT" POTENTIAL ON DAC\#1 : ": IV;" VOLT"

20300 FRINT" POTENTIAL ON DAC\#2 : "FV;" VOLT"

20320 FRINT

20340 FRINT" U1 VALUE : ":U1

20360 PRINT" LEAST U2 BYTE =" ; U2

2038の PRINT" U2 CLQCK PERIOD (CF) = " CP: "SEC"

ZØ4のØ FRINT" SET-UF TOTAL COVERED TIME =";CT; "SEC"

20429 PRINT

2פ44ఏ PRINT" AFTER ELECTRODES REACTIVATED,"

Z045§ PRINT" PROGRAM STARTED TO COLLECT DATA"; TD; "SEC LATER !!"

20460 FRINT

2049g FRINT\#4: CLOSE4

205のの FRINT"** Z MUST $\angle=": N ; " *=$ MULTIFLE OF 5"

29520 FRINT" IF $Z \angle \emptyset$ THEN END OF FRINTING "

20540 INPUT" NEW STARTING SET \#"; $Z$

20560 PR INT

Zøड日の IF $2<0$ THEN 21000 


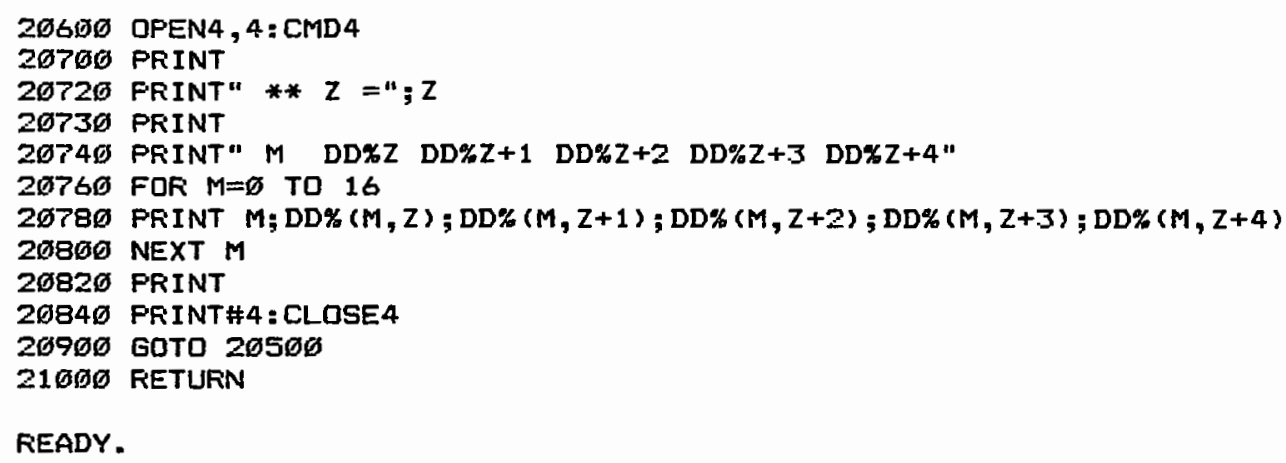


APPENDIX D

SOFTWARE

"DATACQ" 
The "DATACQ" subroutine, shown at the end of this section, is used to perform data acquisition in conjunction with the 12-bit data acquisition circuitry and is written in assembly language to increase speed of data acquisition and to reduce memory requirements of the software. The flow chart of this subroutine is shown in Figure 27.

The subroutine begins with masking all of the high level interrupts of the c-64, followed by setting up the PIA, Timer \#1, Timer \#2, and cycle counter (CC) of Timer \#2. Both timers are stopped prior to their setup. The initial setup on Timer \#2 is recorded and stored. Then, starting with the first electrode, the applied potential on each electrode is converted to a digital value while the switch of the current follower for that electrode is closed, followed by storing the digital value in the RAM of the c64. The same processes are applied to the next electrode and so on until all 16 electrodes are completed. Both timers are then started and the time on Timer \#2 is immediately recorded and stored. starting with the first electrode again, the switch is opened and the converted integrating current at the electrode is recorded and stored also. The same procedures continued until all 16 electrodes are processed.

The overflow bit of Timer \#2 is then Checked. If the bit is set, the cycle counter is decreased by one. After that, the overflow bit of Timer \#1 is checked. Otherwise, 


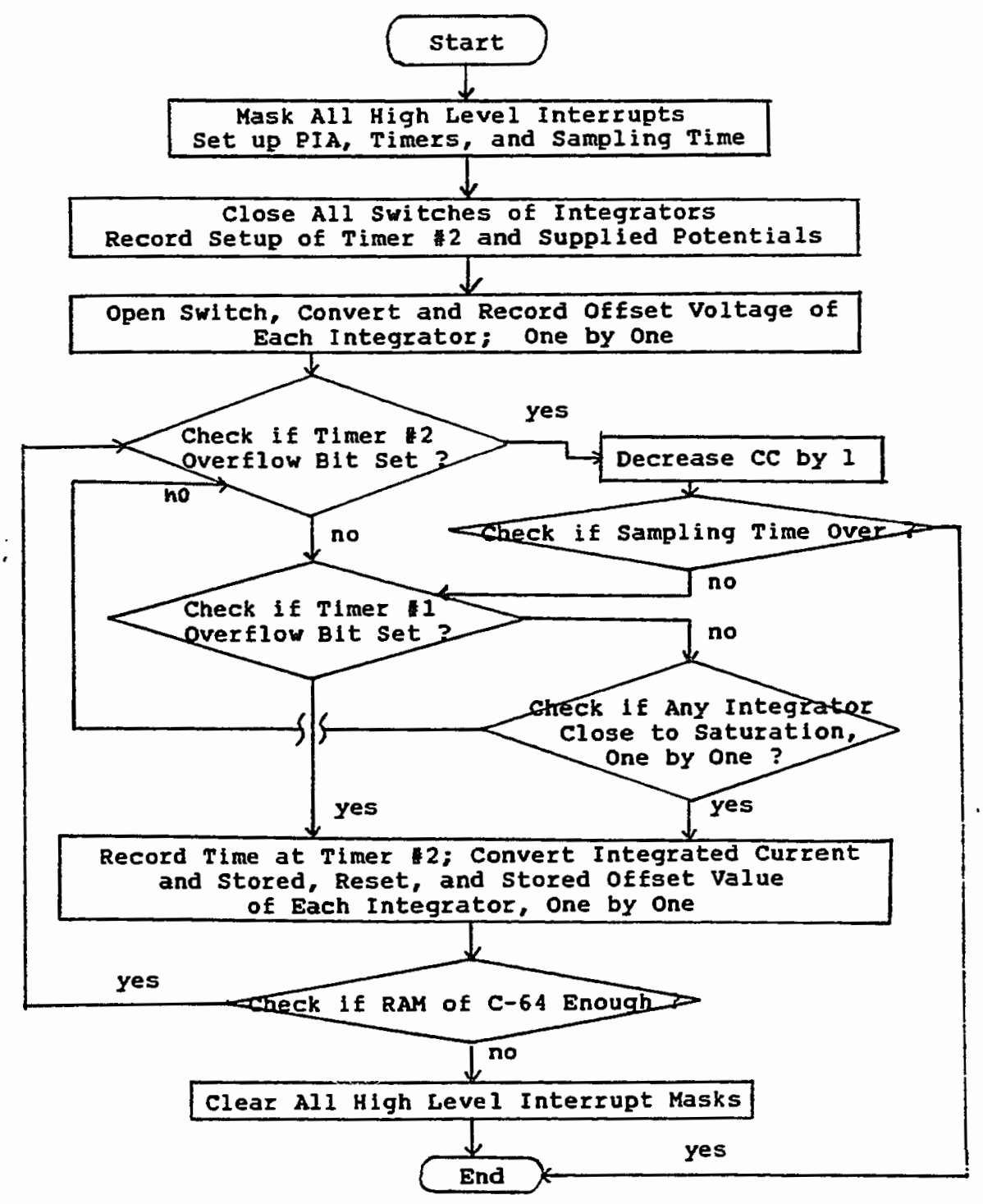

Figure 27. Flow chart of software "DATACQ". 
the overflow bit of Timer \#1 is checked directly. If the overflow bit of Timer \#1 is set, the time on Timer \#2 at that moment is stored in the RAM of the $\mathrm{C}-64$, followed by the clearing of that bit and the restarting of Timer \#1. Next, beginning with the first electrode, the analog signal generated by the electrode is converted to a digital value and stored in the RAM of the c-64. The reset switch is closed to discharge the capacitor of the current follower of this electrode and after 30 microseconds the switch is opened again. The offset value at this integrator is obtained after opening the switch of the integrator 30 microseconds. The same procedures are applied to the next electrode until all 16 electrodes are serviced.

If the overflow bit of Timer \#1 is not set, the digital values converted from the integrating current on each electrode are checked, one by one, according to their order. If any of digital values obtained on any electrode is over the preset threshold value, i.e., close to saturation, a flag is set. Then, the time at this moment on Timer \#2 is stored in the RAM. starting with the first electrode again, the present integrated current is converted to the digital value and stored in the RAM of the C-64, followed by the immediate discharge of the capacitor of the current follower of this electrode. Then, the switch is re-opened. The offset value of each integrator is obtained as previously described. The same procedures are applied to the next 
electrode until all 16 electrodes are serviced. After that, the RAM of the C-64 is checked to determine whether enough memory is available. If not enough, the subroutine will stop collecting data and clear all high level interrupt mask. Otherwise, the cycle is repeated, as shown in Figure 27.

If neither the overflow bit of Timer \#I is set nor any of the digital value readouts is over the preset threshold value, the same procedures are repeated, i.e., checking whether the overflow bits of Timer.\#2 and \#1 are set, converting the integrated analog signals to digital values, and checking whether any of the digital values was over the threshold value, etc., until the preset time period is over.

Different data acquisition rates may be accommodated by changing the setup of both timers via the "COLLECT.DATA" program. The fastest sampling rate for this data acquisition system in this subroutine is approximately 5.7 ms/datum on each electrode.

obviously, a discontinuity of integrating analyte current is created while resetting the integrator. The reset process should be as quick as possible. However, a current surge, which decays with time, is also observed after the switch of the integrator re-opens and which almost disappears within 30 microsecond. Hence, there is a short holding time of 30 microseconds before collecting the offset value of the integrator. 


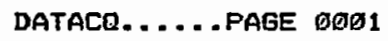

LINE\# LOC CODE

\begin{tabular}{|c|c|c|c|}
\hline எேஏே1 & Øढのの & & \\
\hline ஏФ๑ே2 & ஏøøळ & & \\
\hline$\emptyset 0603$ & घ0ळ0 & & \\
\hline องตอ4 & 0000 & & \\
\hline ஏตのด5 & 0000 & & \\
\hline 00006 & СФФஏ & & \\
\hline & $\operatorname{cog} \theta$ & & \\
\hline 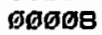 & cogo & & \\
\hline แต๑ศด & cøøo & & \\
\hline ஏேฮ1 & сøøळ & & \\
\hline ดேの1 1 & СคФด & & \\
\hline 00012 & Сロøळ & & \\
\hline 00013 & $\operatorname{co\theta } \theta$ & & \\
\hline бอด14 & Cब⿴囗十 & & \\
\hline ตஏต15 & Сøळø & & \\
\hline 00016 & Сøøの & & \\
\hline 60617 & Cøøの & & \\
\hline 00018 & Cøのळ & & \\
\hline ๑øळ19 & Сøøa & & \\
\hline 60020 & Сøøの & & \\
\hline 6ロศ21 & cøøの & & \\
\hline Ø6622 & coga & & \\
\hline 06023 & Сøのの & & \\
\hline 90024 & cøø & & \\
\hline 00025 & coøa & $A 9 D 0$ & \\
\hline 00026 & cøg2 & $8 D \curvearrowleft 1$ & $1 \mathrm{DE}$ \\
\hline 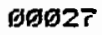 & Cøøs & $8 D$ 93 & $3 \mathrm{DE}$ \\
\hline $6 \curvearrowleft 028$ & cøøa & 8D ตб & $\mathrm{DE}$ \\
\hline 00029 & СøФв & $A 9 F \emptyset$ & \\
\hline 6øの3ด & CaOD & BD 92 & $2 \mathrm{DE}$ \\
\hline 00031 & Co10 & $A 9 \quad 3 C$ & \\
\hline 100632 & Co12 & BD & $D E$ \\
\hline 00033 & Co15 & 8D 63 & $3 \mathrm{DE}$ \\
\hline
\end{tabular}

๑๑ø34 Cब18 69 $00035 \quad \mathrm{CO} 19$

$00036 \quad 0919$

G0637 Cब19

$00038 \quad$ C619

ต0อ39 Cब1B

๑อの4の Cब1E

00641 Cפ21

$00042 \quad \mathrm{Cg} 23$

$96043 \mathrm{C}$ С26

$96944 \quad C 028$

G9045 Cब29

$00046 \quad$ Cब2B

פ๑647 Cब2E

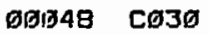

$961649 \quad \mathbf{C} 033$

ప0ต5อ Cø35

øøळ51 Cø38

$06952 \quad \mathbf{6 3 9}$
LINE

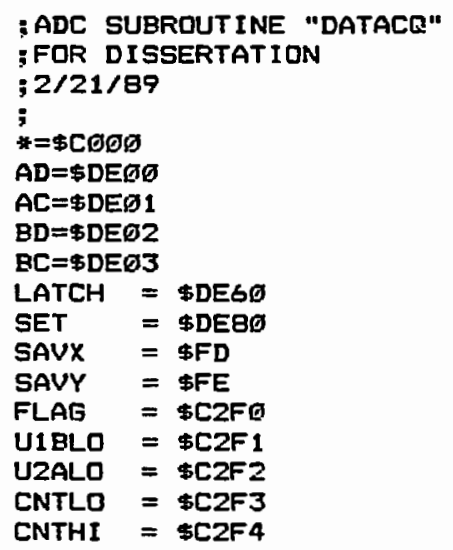


MAIN ROUTINE. . . . . FAGE פgの

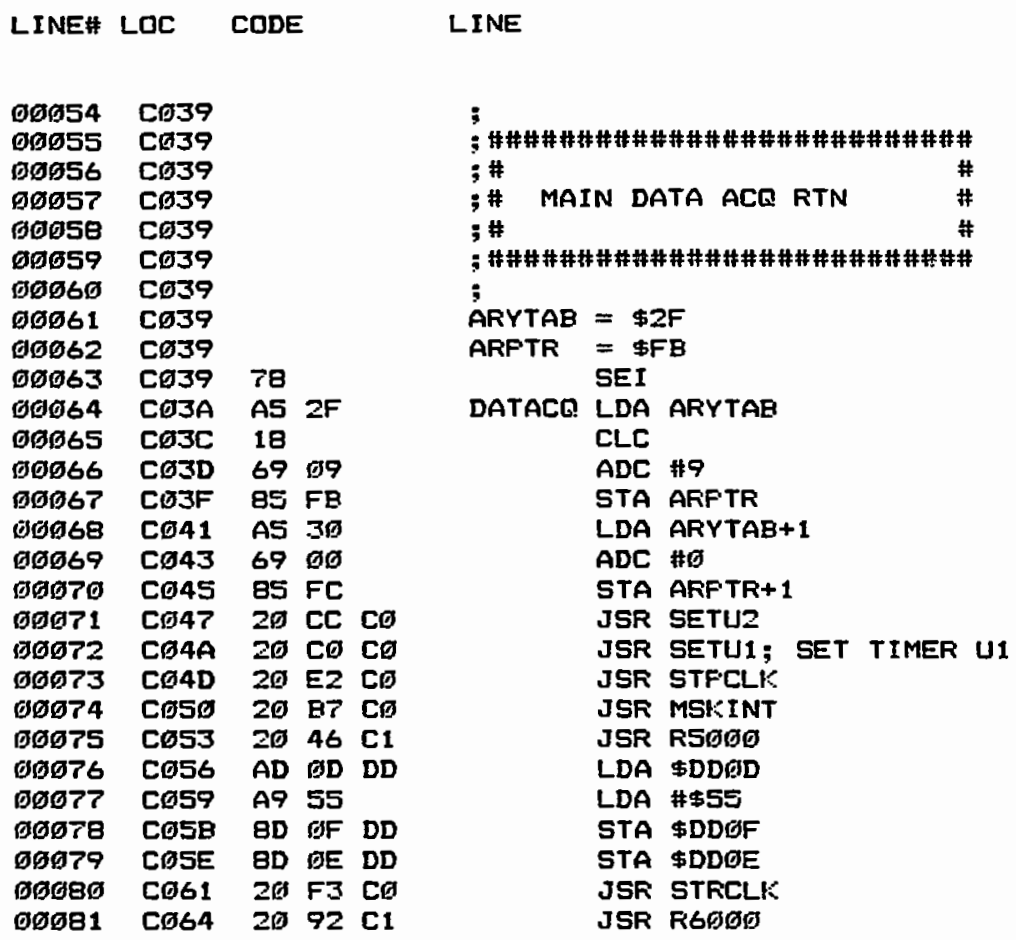


MAIN RDUTINE...... FAGE $\emptyset \emptyset 63$

\begin{tabular}{|c|c|c|c|c|c|c|c|}
\hline LINE\# & LOC & CODE & & & LINE & & \\
\hline ๑øต83 & C967 & A9 & 62 & & CHKU2 & LDA & \#\%ののஏののの1の \\
\hline ø0084 & 0069 & $2 \mathrm{C}$ & ตD & DD & & BIT & \$DDGD \\
\hline 09695 & сø6с & $F \emptyset$ & 18 & & & EEQ & CHKUI \\
\hline 00ஏ86 & COSE & 38 & & & & SEC & \\
\hline 0øg日7 & COSF & $A D$ & $\mathbf{F 3}$ & C2 & & LDA & CNTLO \\
\hline ஏ๓б88 & cפ?2 & E9 & 01 & & & SBC & $\$ 1$ \\
\hline ๓6ซ89 & cø74 & QD & F3 & $\mathrm{cz}$ & & STA & CNTLO \\
\hline ๑ே09๑ & cort & $A D$ & F4 & $\mathrm{C2}$ & & LDA & CNTHI \\
\hline 60091 & CATA & E9 & ต๓ & & & SBC & $\# \boldsymbol{\theta}$ \\
\hline 00092 & cørc & 8D & F4 & $\mathrm{C2}$ & & STA & CNTHI \\
\hline ஏб093 & CפTF & $D \sigma$ & 65 & & & BNE & CHKU1 \\
\hline ๓9694 & Cø81 & $A D$ & $\mathrm{F3}$ & c2 & & LDA & CNTLO \\
\hline 69995 & Cब84 & $\mathbf{F g}$ & 25 & & & BER & CLRMSK \\
\hline 00996 & Cפe6 & $A 9$ & פ2 & & CHKU1 & LDA & \#พ๑ดตดฮต1の \\
\hline ตซอุร & Co88 & $2 \mathrm{C}$ & $9 D$ & DC & & BIT & \$DCबD \\
\hline 60998 & CøgB & $D \emptyset$ & פF & & & BNE & SAVRST \\
\hline ஏ0099 & CøgD & $A 9$ & ๘б & & & LDA & $\# g$ \\
\hline 60100 & Cgef & GD & $F g$ & C2 & & STA & FLAG \\
\hline 00101 & cø92 & 20 & E3 & C1 & & JSR & RT̃@ด \\
\hline ๑ø1ต2 & cø95 & AD & $F G$ & $\mathrm{C} 2$ & & LDA & FLAG \\
\hline 00103 & C९98 & $\mathrm{CP}$ & 01 & & & CMF & $\# 1$ \\
\hline 00184 & CØ9A & DI & $E A$ & & & BNE & CHKU1 \\
\hline 00165 & co9c & 20 & F3 & Ca & SAVRST & JSF & STRCLK \\
\hline 9196 & CG9F & 20 & 36 & $\mathrm{C} 2$ & & JSR & R9Фのの \\
\hline 00197 & CØA2 & 20 & 15 & $C_{1}$ & & JSR & MOUFTR \\
\hline ๓の1の8 & cons & $A 9$ & 96 & & & LDA & $\# \$ 90$ \\
\hline ஏ0109 & CGAT & C5 & FC & & & CMF & ARIF'TR+1 \\
\hline 00110 & CEA9 & 10 & $\mathrm{BC}$ & & & BPL & CHKU2 \\
\hline Øஏ111 & COAB & 58 & & & CLRMSK & CLI & \\
\hline 60112 & CפAC & A9 & TE & & & LDA & \#\$7E \\
\hline 00113 & CGAE & QD & OD & DC & & STA & \$DCOD \\
\hline gִ1 14 & COE1 & $A 9$ & $T F$ & & & LDA & $\# \$ 7 F$ \\
\hline 09115 & con3 & BD & GD & DD & & STA & \$DDOD \\
\hline ஏפ116 & CaBb & 60 & & & & RTS & \\
\hline 00117 & CबB? & A9 & FF & & MSKINT & LDA & $\#$ \#FF \\
\hline 00118 & COR9 & BD & GD & DC & & STA & $\$ D C @ D$ \\
\hline 00119 & CaBc & BD & OD & DD & & STA & \$DDøD \\
\hline 00120 & CEBF & 60 & & & & RTS & \\
\hline 09121 & Coco & A9 & ஏळ & & SETU1 & LDA & $\# 0$ \\
\hline 00122 & $\mathrm{cgc2}$ & 8D & 97 & DC & & STA & \$DCब \\
\hline 90123 & cacs & $A D$ & F1 & $\mathrm{CZ}$ & & LDA & U1BLO \\
\hline 00124 & СøСв & BD & 96 & DC & & STA & $\$ D C \square 6$ \\
\hline 00125 & CøСB & 60 & & & & FTS & \\
\hline ต๑126 & сөсс & A9 & TF & & SETUZ & LDA & \#127 \\
\hline ஏの127 & COCE & 8D & $a \bar{r}$ & DD & & STA & \$DDET \\
\hline$\sigma \sigma 128$ & COD 1 & A9 & FF & & & LDA & \#255 \\
\hline ஏ0129 & CODJ & 8D & 96 & DD & & STA & \$DD\$6 \\
\hline 09130 & CODG & A9 & $\emptyset \emptyset$ & & & LDA & $\#$ \\
\hline 00131 & CODB & 8D & 65 & DD & & STA & \$DD95 \\
\hline 90132 & CøDB & $A D$ & $F 2$ & $\mathrm{C} 2$ & & LDA & UZALO \\
\hline 69133 & CODE & 8D & 04 & DD & & STA & \$DDG4 \\
\hline ๒6134 & CØE1 & 60 & & & & RTS & \\
\hline 09135 & CबE2 & A9 & 54 & & STFCLK & LDA & \#544 \\
\hline ๑ற136 & COE 4 & BD & GF & DC & & STA & $\$ D C G F$ \\
\hline $0013 r$ & CQET & 8D & $\theta \mathrm{F}$ & DD & & STA & $\$ D D G F$ \\
\hline
\end{tabular}


MAIN ROUTINE. ...... PAGE DgD4

\begin{tabular}{|c|c|c|c|c|c|c|c|}
\hline LINE\# & LOC & CODE & & & LINE & & \\
\hline 00138 & CפEA & $A 9$ & 54 & & & LDA & \#\$54 \\
\hline 60139 & CबEC & BD & gE & DC & & STA & \$DCबE \\
\hline 00140 & COEF & 80 & GE & DD & & STA & $\$ D D Q E$ \\
\hline ספ141 & CBFZ & 60 & & & & RTS & \\
\hline 90142 & Cof 3 & $A D$ & פD & DC & STRCLK & LDA & $\$ D C \emptyset D$ \\
\hline 09143 & COFG & $A 9$ & 55 & & & LDA & $\# \$ 55$ \\
\hline 69144 & CofB & BD & GF & DC & & STA & \$DCबF \\
\hline 90145 & CEFB & BD & GE & $D C$ & & STA & \$DCGE \\
\hline 69146 & COFE & 60 & & & & RTS & \\
\hline 90147 & COFF & $A O$ & 60 & & SAVINF & LDY & $\# 9$ \\
\hline 09148 & C101 & 91 & FB & & & STA & (ARPTR) ,Y \\
\hline 09149 & C103 & BA & & & & TXA & \\
\hline 00150 & C194 & $\mathrm{CB}$ & & & & INY & \\
\hline 013151 & C105 & 91 & FB & & & STA & (AFPTE), $Y$ \\
\hline 00152 & C167 & A5 & $\mathrm{FB}$ & & & LDA & ARPTR \\
\hline 99153 & C109 & 18 & & & & CLC & \\
\hline ดפ154 & C1EA & 69 & 02 & & & $A D C$ & $\# 2$ \\
\hline ng155 & C1øc & 85 & $\mathrm{FB}$ & & & STA & ARPTR \\
\hline 00156 & CIOE & AS & FC & & & LDA & ARPTR+1 \\
\hline 00157 & $\operatorname{ci1} 10$ & 69 & 00 & & & $A D C$ & $\#$ \\
\hline 09158 & C112 & 85 & FC & & & STA & ARF'TR+1 \\
\hline ๑の159 & C114 & 60 & & & & RTS & \\
\hline 00160 & Ci15 & AS & $F B$ & & MOUPTR & LDA & ARPTR \\
\hline 00161 & C117 & 18 & & & & $\mathrm{CLC}$ & \\
\hline 06162 & C118 & 69 & 22 & & & ADC & $\# 34$ \\
\hline 90163 & C11A & 85 & $F \mathbf{F}$ & & & STA & AFPTR \\
\hline 90164 & C11 & A5 & FC & & & LDA & ARPTR+1 \\
\hline 00165 & C11E & 69 & 60 & & & $A D C$ & $\$ \theta$ \\
\hline 90166 & C120 & 85 & FC & & & STA & ARFTR+1 \\
\hline 69167 & C122 & 60 & & & & RTS & \\
\hline 09168 & C123 & A6 & $F D$ & & RSTLCH & LDX & SAVX \\
\hline 69169 & C125 & CA & & & & DEX & \\
\hline ต曰170 & 0126 & BE & 60 & DE & & STX & LATCH \\
\hline Øळ1?1 & C129 & 20 & $3 \mathrm{C}$ & $\mathrm{Cl}_{\mathbf{l}}$ & & JSR & DELAY \\
\hline 96172 & $C_{12 C}$ & $E B$ & & & & INX & \\
\hline 06173 & C12D & BE & 60 & $\mathrm{DE}$ & & STX & LATCH \\
\hline $991>4$ & C13a & 20 & 17 & CO & & JSR & ENURT \\
\hline פ๑175 & C133 & $A C$ & 22 & & & LDY & \#34 \\
\hline 00176 & C135 & 91 & $F B$ & & & STA & (ARF'TR), $Y$ \\
\hline 0017 & C137 & BA & & & & TXA & \\
\hline ஏ๓178 & C138 & $\mathrm{Cg}$ & & & & INY & \\
\hline 90179 & C139 & 91 & $\mathrm{FB}$ & & & STA & (ARF'TF), $Y$ \\
\hline 06180 & C13B & 60 & & & & RTS & \\
\hline 00181 & C13C & EA & & & DELAY & NDF & \\
\hline ด6182 & C13D & $E A$ & & & & NOP & \\
\hline 90183 & C13E & EA & & & & NOF & \\
\hline (2061 184 & C13F & $E A$ & & & & NOP & \\
\hline g0185 & C140 & $E A$ & & & & NOF & \\
\hline 09186 & C141 & $E A$ & & & & NOP & \\
\hline 90187 & C142 & EA & & & & NoF & \\
\hline 90188 & C143 & EA & & & & NOP & \\
\hline 00189 & C144 & $E A$ & & & & NOF & \\
\hline 00190 & C145 & 60 & & & & RTS & \\
\hline
\end{tabular}




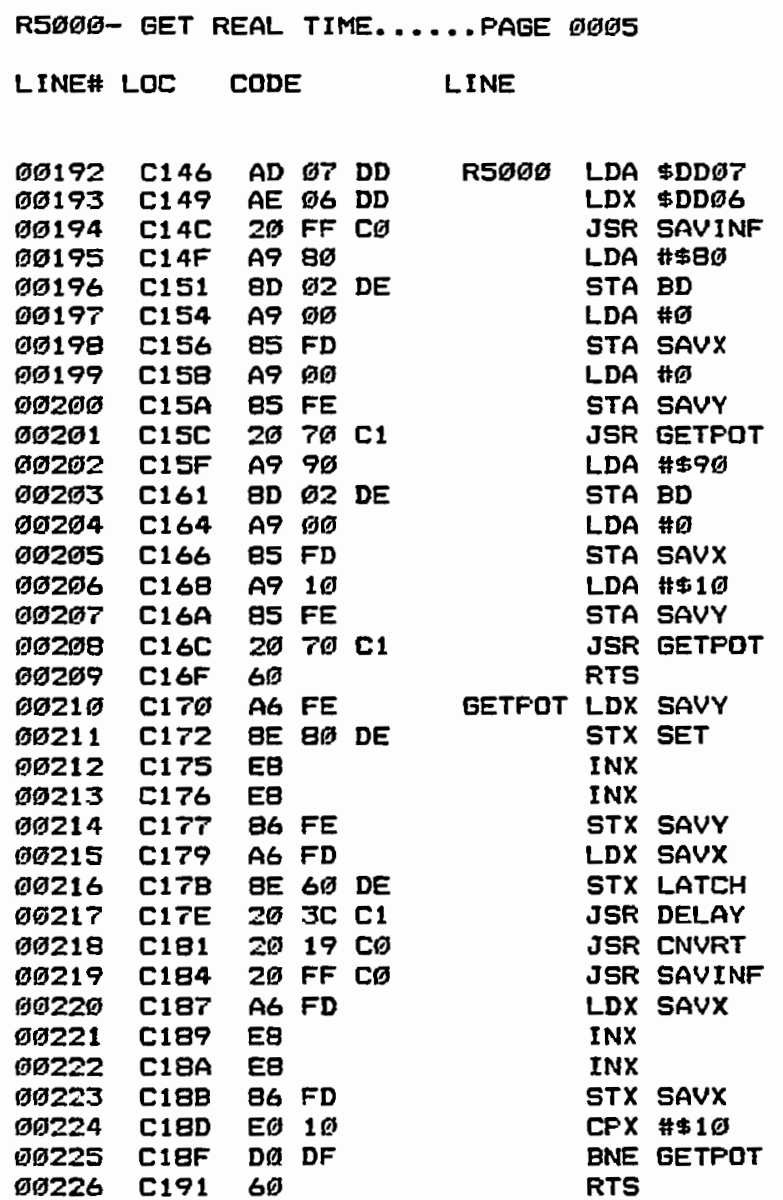




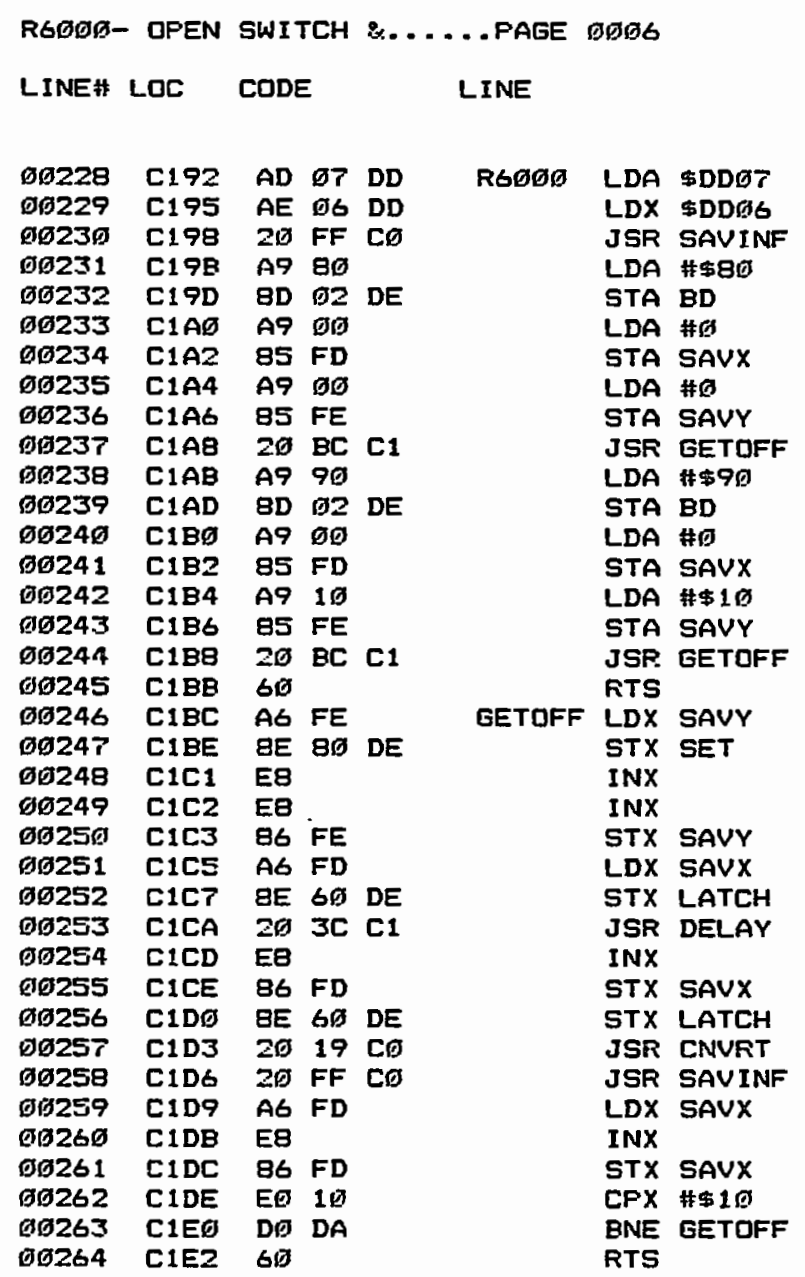




\begin{tabular}{|c|c|c|c|c|c|c|c|}
\hline LINE\# & LOC & CODE & & & LINE & & \\
\hline 50266 & CIE3 & A9 & 80 & & R7ののの & LDA & $\# \$ 80$ \\
\hline $\begin{array}{l}\text { 0267 } \\
\text { ஏ0268 }\end{array}$ & $\begin{array}{l}\text { CIES } \\
\text { CIEB }\end{array}$ & $\begin{array}{l}80 \\
A 9\end{array}$ & $\begin{array}{l}02 \\
01\end{array}$ & $D E$ & & $\begin{array}{l}\text { STA } \\
\text { LDA }\end{array}$ & $\begin{array}{l}\text { BD } \\
\# 1\end{array}$ \\
\hline ต0269 & CIEA & 85 & FD & & & STA & SAUX \\
\hline ๑๐2тด & CIEC & A9 & $\theta 0$ & & & LDA & $\#$ \\
\hline 00271 & CIEE & 85 & FE & & & STA & SAVY \\
\hline 00272 & CIFG & 20 & GB & $C Z$ & & JSR & CMFVAL \\
\hline 90273 & CIF 3 & $A D$ & $\mathbf{F} \boldsymbol{\sigma}$ & $\mathrm{C2}$ & & LDA & FLAE \\
\hline 69274 & C1FG & $c 9$ & 01 & & & CMP & $\# 1$ \\
\hline 66275 & C1FB & $F \emptyset$ & 10 & & & RER & RTTॄøøの \\
\hline 66276 & C1FA & A9 & 90 & & & LDA & $\# \$ 9 \emptyset$ \\
\hline 60277 & C1FC & $8 D$ & 02 & $D E$ & & STA & BD \\
\hline ๓627日 & C1FF & A9 & 01 & & & LDA & $\# \$ 01$ \\
\hline 60279 & $C 201$ & 85 & FD & & & STA & SAVX \\
\hline 00280 & C203 & A9 & 10 & & & LDA & $\# \$ 10$ \\
\hline 66281 & C205 & 85 & FE & & & STA & SAUY \\
\hline 69282 & C207 & 20 & $\theta \mathrm{B}$ & $\mathrm{C2}$ & & JSR & CMFUAL \\
\hline ஏ6283 & C2GA & 60 & & & 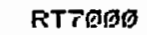 & FTS & \\
\hline ๓6284 & $C 29 B$ & $A 6$ & FE & & CMPVAL & LDX & SAVY \\
\hline g0285 & $C 2 \Omega D$ & $\mathrm{BE}$ & 80 & $D E$ & & STX & SET \\
\hline פG286 & c210 & E日 & & & & INX & \\
\hline 00287 & $C 211$ & E8 & & & & INX & \\
\hline 00288 & $C 212$ & 86 & FE & & & STX & SAVY \\
\hline 69289 & C214 & $A 6$ & FD & & & LDX & SAVX \\
\hline 00290 & $C 216$ & BE & 60 & $D E$ & & STX & LATCH \\
\hline 00291 & $C 219$ & 20 & 19 & $\mathrm{Cg}$ & & JSR & CNURT \\
\hline 60292 & C21C & C9 & aF & & CHKHI & CMP & $\# \$ \sigma F$ \\
\hline 69293 & CZ1E & Fo & 10 & & & BEQ & SETFLG \\
\hline 99294 & $\cos 2 \theta$ & $C 9$ & as & & CHKLO & CMP & \#\$の \\
\hline 60295 & C222 & $F \emptyset$ & ac & & & BEQ & SETFLG \\
\hline 00296 & C2224 & $A B$ & FD & & & LDX & SAVX \\
\hline 60297 & $c 226$ & $E B$ & & & & INX & \\
\hline 60298 & $\mathrm{C} 22 \mathrm{~T}$ & E日 & & & & INX & \\
\hline 60299 & C228 & 86 & FD & & & STX & SAVX \\
\hline g6309 & C22A & Eg & 11 & & & CPX & $\# \$ 11$ \\
\hline б0361 & $c \geq 2 c$ & Dø & DD & & & BNE & CMPVAL \\
\hline 69362 & C2ZE & $F \emptyset$ & 05 & & & EES & RTCMPV \\
\hline ๔03ด3 & C230 & A9 & 01 & & SETFLG & LDA & \#1 \\
\hline 60364 & C232 & 8D & $F \emptyset$ & $\mathrm{C} 2$ & & STA & FLAG \\
\hline 09305 & C235 & 60 & & & RTCMPV & RTS & \\
\hline
\end{tabular}




\begin{tabular}{|c|c|c|c|c|c|c|}
\hline LINE将 & LOC & CODE & & LINE & & \\
\hline ๑63ø7 & C236 & $A D$ & פTे DD & R9ด90 & LDA & \$DDG7 \\
\hline 003ø8 & $c 239$ & $A E$ & O6 DD & & LDX & \$DDø6 \\
\hline 60309 & C23C & 20 & $F F C \theta$ & & JSR & SAUINF - \\
\hline 69310 & $\mathrm{CZ3F}$ & A9 & $8 \varnothing$ & & LDA & \#\$89 \\
\hline 60311 & C241 & BD & $62 \mathrm{DE}$ & & STA & BD \\
\hline 66312 & C244 & A9 & 01 & & LDA & $\# 1$ \\
\hline 09313 & C246 & 85 & FD & & STA & SAVX \\
\hline 00314 & $C 248$ & A9 & ๑๐ & & LDA & $\#$ \# \\
\hline 60315 & C24A & 85 & FE & & STA & SAUY \\
\hline 09316 & C24C & $2 \sigma$ & $60 \mathrm{CZ}$ & & JSR & SAVVAL \\
\hline 00317 & C24F & A9 & $9 \pi$ & & LDA & $\# \$ 96$ \\
\hline 00318 & C251 & GD & פ2 DE & & STA & BD \\
\hline 90319 & C254 & $A 9$ & 01 & & LDA & \#\$01 \\
\hline פอ320 & C256 & 85 & FD & & STA & SAVX \\
\hline 06321 & $C 258$ & A9 & 10 & & LDA & $\# \pm 10$ \\
\hline 90322 & C25A & 85 & FE & & STA & SAVY \\
\hline 00323 & C25C & 20 & $60 \mathrm{C2}$ & & JSR & SAVVAL \\
\hline 00324 & C25F & 60 & & & RTS & \\
\hline 09325 & C26 & Ab & FE & SAUVAL & LDX & SAVY \\
\hline 00326 & C262 & 8E & $B D D E$ & & STX & SET \\
\hline 60327 & C265 & E8 & & & INX & \\
\hline 60328 & c266 & EB & & & INX & \\
\hline 00329 & C267 & 86 & FE & & STX & SAVY \\
\hline 60330 & C269 & A6 & FD & & LDX & SAUX \\
\hline g9331 & $\mathrm{C} 26 \mathrm{~B}$ & $\mathbf{B E}$ & $69 \mathrm{DE}$ & & STX & LATCH \\
\hline 00332 & C26E & 20 & $19 \mathrm{CO}$ & & JSR & CNURT \\
\hline 09333 & cE71 & $A \emptyset$ & 6g & & LDY & \#⿰木 \\
\hline 00334 & $c 273$ & 91 & $\mathrm{FB}$ & & STA & (ARPTR), Y \\
\hline 000335 & cars & BA & & & TXA & \\
\hline 00336 & C2T6 & $\mathrm{Cg}$ & & & INY & \\
\hline $6633 \bar{r}$ & C277 & 91 & $\mathrm{FB}$ & & STA & (AFFTR), $Y$ \\
\hline 66338 & $\cos 9$ & $2 \emptyset$ & $23 \mathrm{Cl}$ & & JSR & RSTLCH \\
\hline פ9339 & carc & A5 & $F B$ & & LDA & AFPTR \\
\hline 0934の & C2TE & 18 & & & CLC & \\
\hline 00341 & CZTF & 69 & 62 & & $A D C$ & $\# 2$ \\
\hline 60342 & C281 & 85 & $F B$ & & STA & ARFTR \\
\hline 60343 & c:e3 & A5 & FC & & LDA & ARPTR+1 \\
\hline 60344 & C285 & 69 & $\theta 0$ & & ADC & $\# \square$ \\
\hline ஏø345 & $\mathrm{C} 2 \mathrm{~B} T$ & 85 & FC & & STA & ARF'TR +1 \\
\hline 00346 & $C 289$ & $A B$ & FD & & LDX & SAVX \\
\hline ฮต34 & C28B & $E 8$ & & & INX & \\
\hline 69348 & $\mathrm{c} 28 \mathrm{C}$ & E8 & & & INX & \\
\hline ø0349 & C2ED & 86 & FD & & STX & SAVX \\
\hline ஏ9350 & C2BF & EO & 11 & & CFX & $\# \$ 11$ \\
\hline 96351 & C271 & Dø & $C D$ & & ENE & SAVVAL \\
\hline ga352 & C293 & 60 & & & RTS & \\
\hline 06353 & $c: 94$ & & & . END & & \\
\hline
\end{tabular}


APPENDIX E

SOFTWARE

"NORMALIZE 
The program "NORMALIZE", shown at the end of this section, is used to obtain the normalization factors of all CFAEs in the ME cell. The flow chart of this software is shown in Figure 28.

The program first transfers the coulometric data, which has been saved on the floppy disk for the normalization factors of CFAEs, back to the RAM of the c-64. Then the first set of digital values are converted into the potentials which represent the applied potentials on each CFAEs. The rest of data are converted into the amperometric data. After screening all amperometric data, a band of data at each CFAE obtained prior to the injection of the sample solution is chosen to represent the residual current generated by the supporting electrolyte solution. Also, a band of highest data is chosen to represent the current which is generated by the sample solution. The representative sample solution currents and the residual currents within the resolution time period at each CFAE are obtained through the average of these two band of data, respectively. The net current on each electrode, which is generated by the sample species only, is obtained by subtracting the residual current from the current generated by the sample solution. Then one averaged net current of a CFAE is chosen. All net current values are divided by this chosen value to get the normalization factors for all 16 CFAEs in the ME cell. Finally, these factors are saved onto 


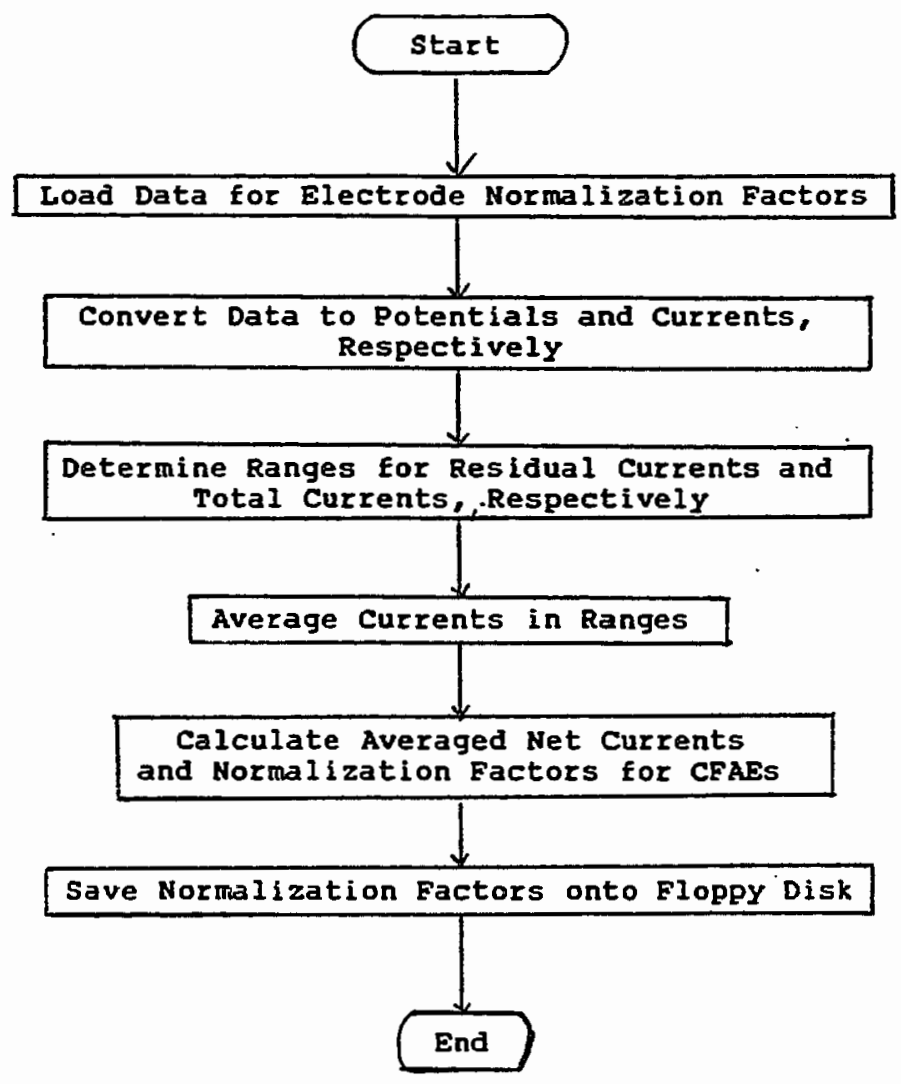

Figure 28. Flow chart of software "NORMALIZE". 
a disk for normalization of the data for pseudo-voltammetry. 


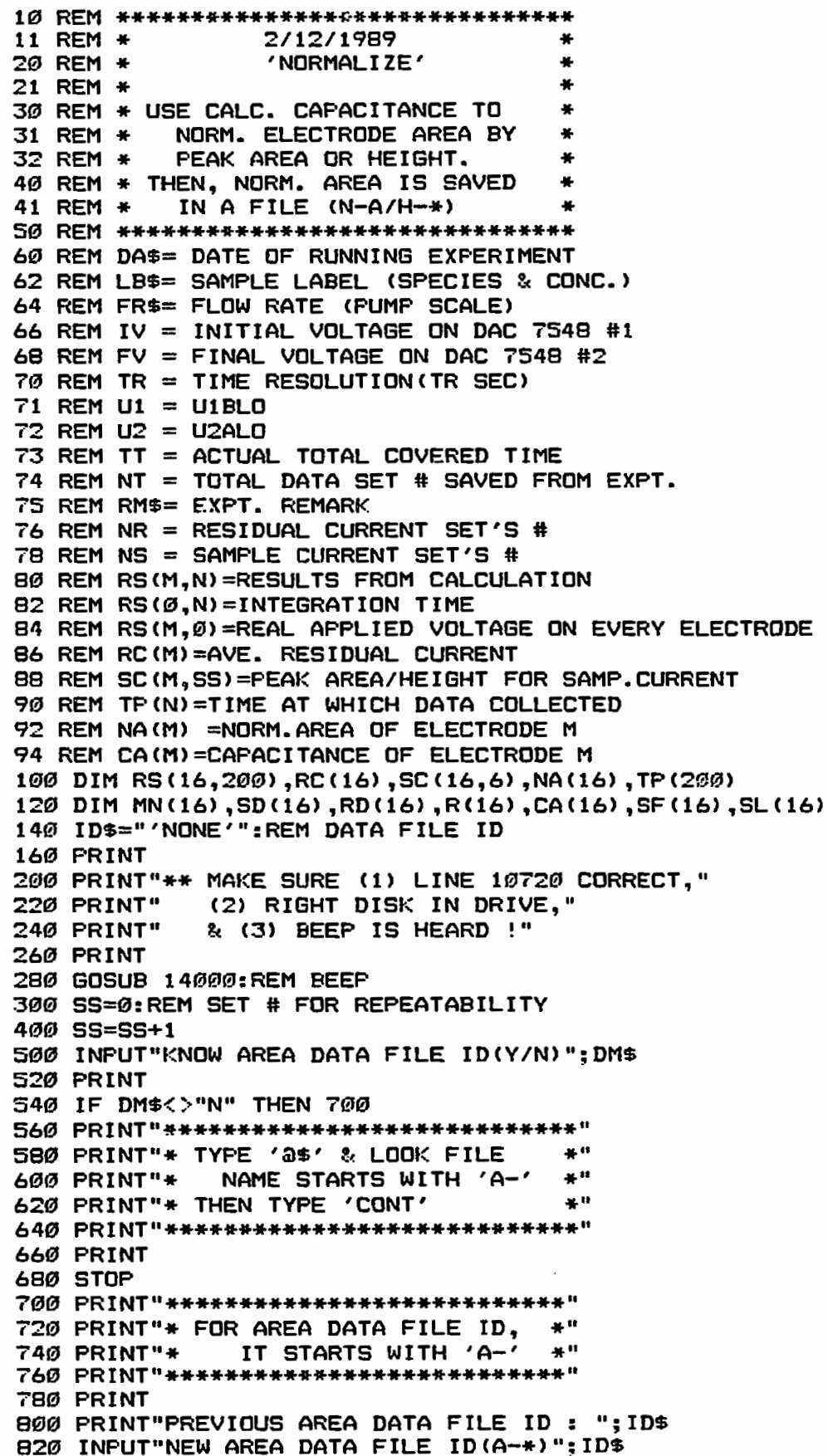




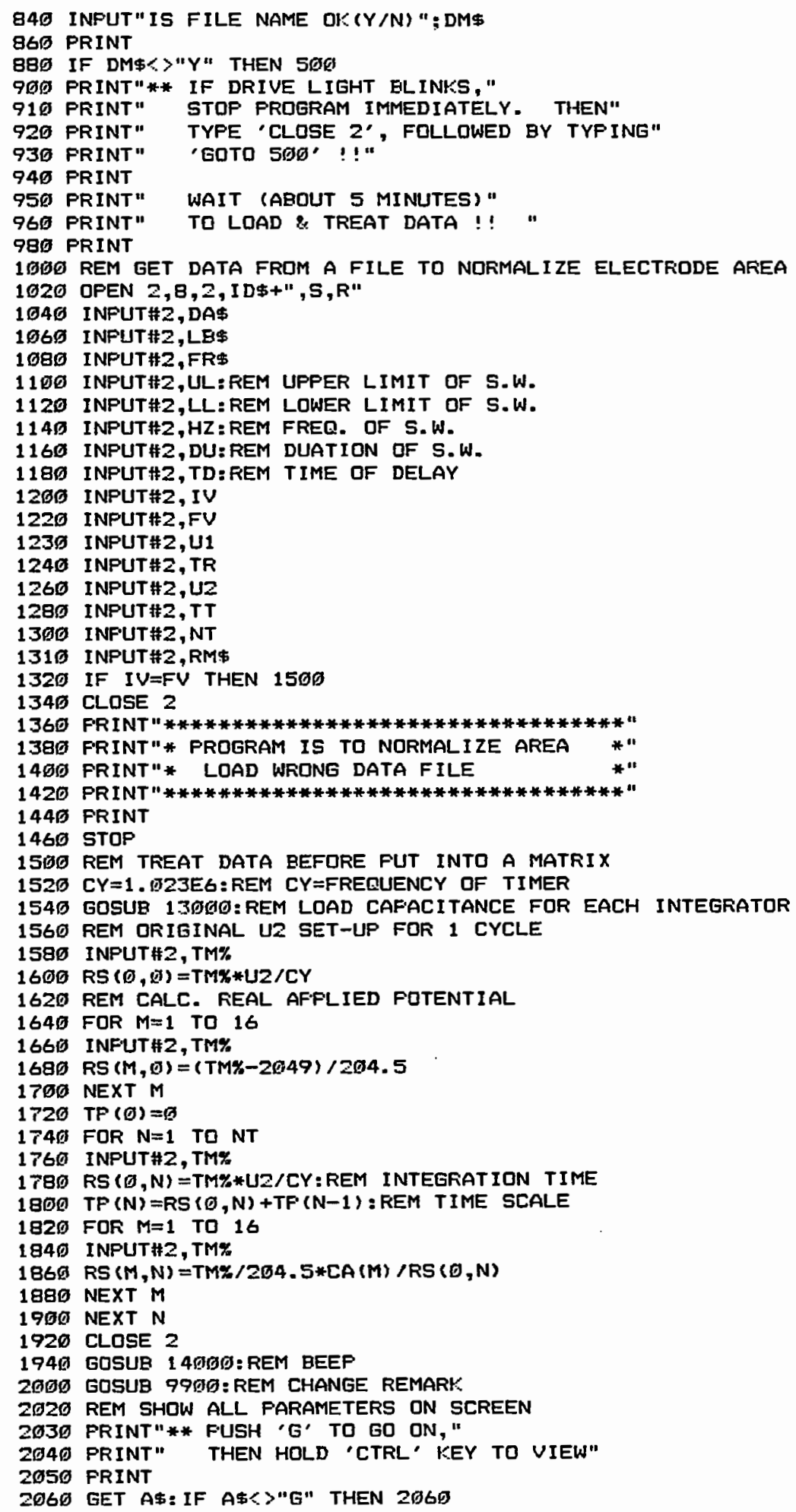




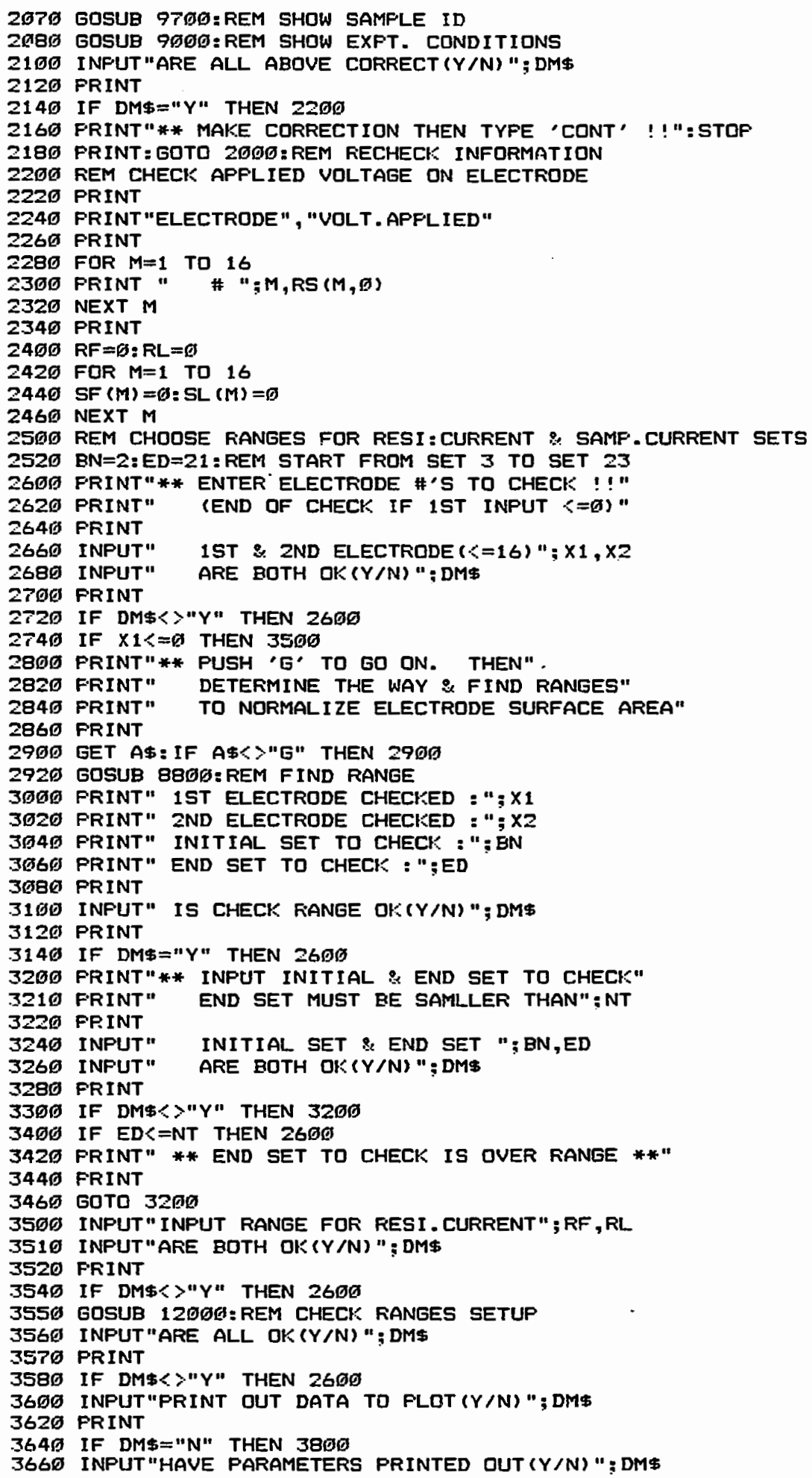




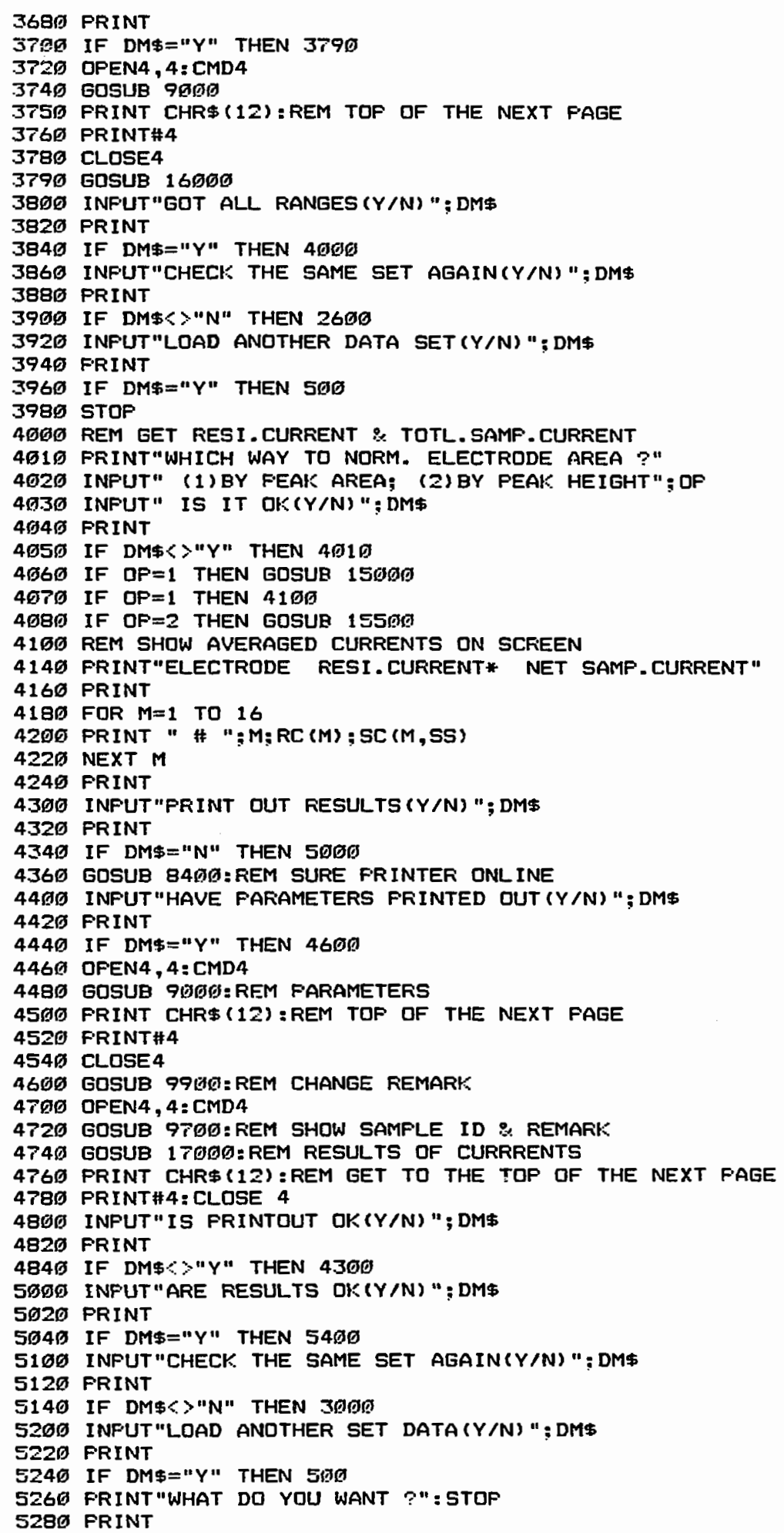


5300 GOTO 5006

5409 INFUT"RESULTS FOR STATISTICS $(Y / N)$ ": DM\$

542の PRINT

544の IF DM\$="Y" THEN S59の

5460 GOTD 5100

550D FRINT"PRESENT DATA FILE ID : "I ID\$

SS20 FRINT"PRESENT SET \# FOR REFEATABILITY : ";SS

5540 PRINT

5600 INPUT"DONE REPEATABILITY CALC. (Y/N) "; DM\$

5620 FRINT

5640 IF DMS="Y" THEN 5B日0

5660 INFUT"MORE? ARE YOU SURE (Y/N) " : DM\$

$56 B 0$ FRINT

5Tのの IF DM\$="Y" THEN 460

5720 STOP

5740 EOTD 5600

58G0 INPUT "DONE? ARE YOU SURE (Y/N) "; DM\$

5820 PRINT

5849 IF DMS="N" THEN 5720

5900 PRINT"-- APPLY STATISTICS TO THE RESULTS NOW!"

592ø PRINT

5949 I=SS:REM TOTAL SET FOR REPEATABILITY IS 'SS'

5960 GOSUB 10000

6ФØळ REM CALCULATE NORM. AREA FROM A SINGLE SET OF DATA

6100 PRINT"** NORMALIZE ELECTRODE SURFACE AREA !"

612ø PRINT" \#";ES; "ELECTRODE AS STANDARD"

614 INPUT" IS IT OK (Y/N) " DMS

6160 PRINT

6180 IF DMS="Y" THEN 6300

620Ø INFUT" NEW STANDARD ELECTRODE $(Z)$ ";ES

6220 PRINT

6240 GOTO 6100

630ळ BA=MN(ES): REM TAKE ES ELECTRODE AS STANDARD

6320 FOR $M=1$ TO 16

$6346 N A(M)=M N(M) / B A$

6360 NEXT M

63ED GOSUB $7500:$ REM SHOW NORM. AREA

6400 INFUT"PRINT OUT THE NORM. AREA (Y/N)": DM\$

6410 PRINT

6420 IF DM\$ $=" N "$ THEN 6509

6430 GOSUG 9901: REM CHANGE REMARK

6440 OFENA, 4 : CMD4

6450 GOSUB 18@のळ: REM SHOW SAMPLE, EXFT. DATE, : REMARK

6469 GOSUE TSEO:GDSUE TTGD

648G FRINT CHR\$(12): FEM TOP OF THE NEXT F.AGE

6490 PRINT\# : CLOSEA

65פの INFUT"SAVE NORM. AREA ON DISK $(Y / N)$ " DME

6526 FRINT

6540 IF DM\$="N" THEN TDVI

6560 F'RINT"** MAKE SURE RIGHT DISK IN DRIVE !!"

658Ø FRINT

66פØ INPUT" WANT TO CHECK DISK(Y/N)":DM\$

6620 FRINT

6640 IF DM\$="N" THEN 6700

6669 STOP

6689 G0TO 6500

GTפ0 REM SAVE ELECTROdE SURFACE AREA TO A SEQ. FILE

6720 REM $\mathrm{N}-\mathrm{A}-*(\mathrm{~N}-\mathrm{H}-*)=$ NDRM. ELECTRDDE SURFACE AREA

674G FRINT

G760 FRINT"LATEST DATA FILE ID : "; ID\$

6BDD INPUT"NORM. AREA ID (N-A/H-*) ";NI\$

6B20 INFUT"IS FILE NAME DK(Y/N)":DM\$

6B4פ PRINT

6860 IF DME=" $N "$ THEN 6890

6909 OPEN $2,8,2, N I \$+", 5, W "$

6920 FOR $M=6$ TO 16 


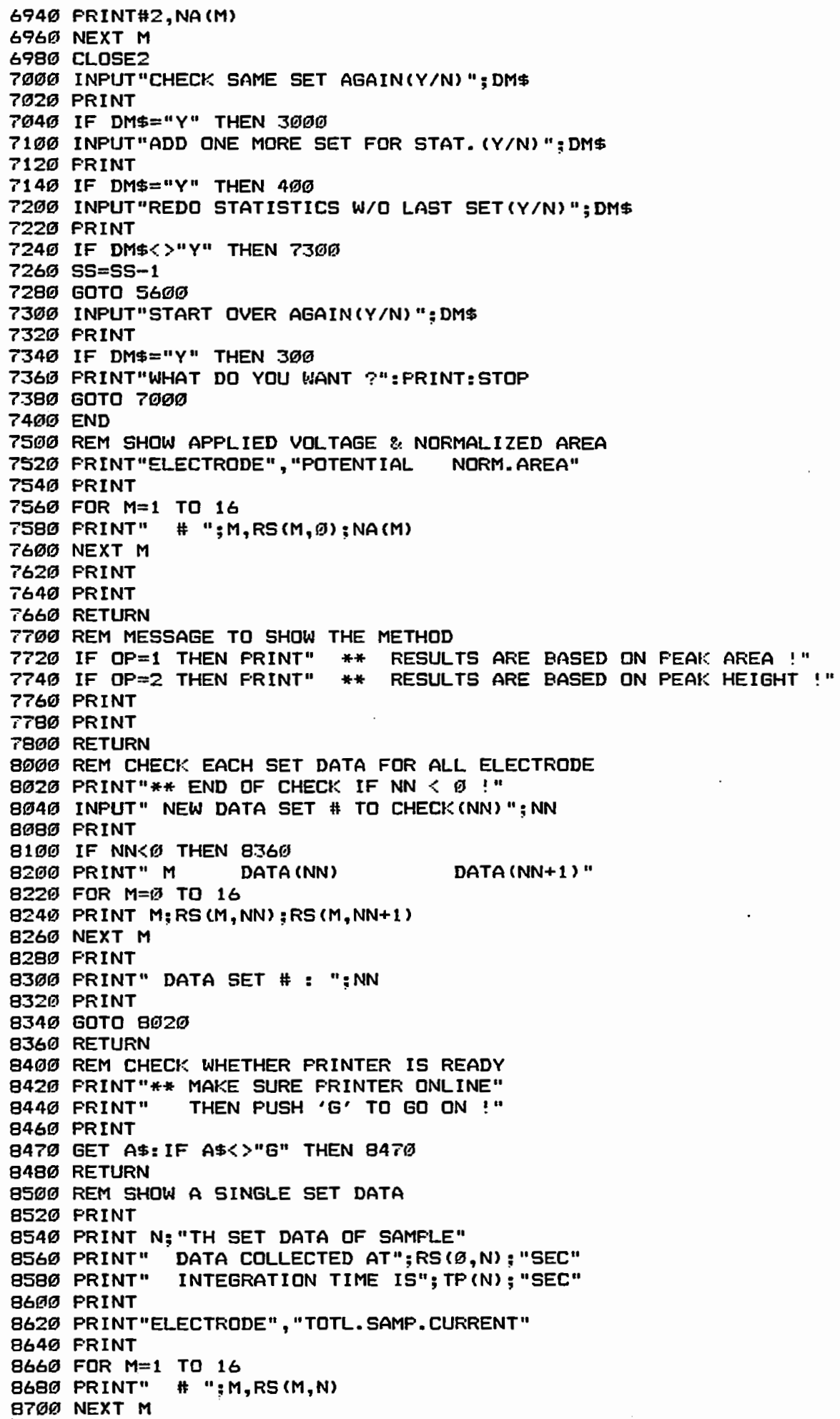


8T20 PRINT

QT40 RETURN

8Bøの REM SUBROUTINE TO SEE ALL DATA ON TWO ELECTRODES

8820 FRINT"SET"; " ELECTRODE" ; $X 1$; " ELECTRODE" ; XZ

884の FDR $N=B N$ TO ED

8860 FPINT $N ; R S(X 1, N) ; R S(X 2, N)$

日8Bの NEXT N

B960 PRINT

9920 GOSUB 13506: REM RECORD RANGE

8940 RETURN

9000 REM SHOW ALL FARAMETERS ON SCREEN

9020 PRINT "EXPERIMENTAL CONDITIONS --"

9Я40 PRINT

9๑6の PRINT" FLOW RATE - ";FR\$

9G日G PRINT

916פ PRINT" SQUARE WAVE FGR PRECONDITION --"

9120 PRINT" POTENTIAL OF UPPER LIMIT : "; UL:; "VOLT"

9140 PRINT" FOTENTIAL OF LOWER LIMIT : ";LL; "VOLT"

9160 PRINT" FREQUENCY : "; HZ; "HERTZ"

9180 PRINT" DURATION : " कU: "SEC"

9200 FRINT

9220 PRINT IV; "VOLTS OUTPUT FROM DACT548 \#1"

9240 PRINT FV; "VOLTS OUTPUT FROM DACT548 \#2"

9260 FRINT

9280 PRINT" WAIT"; TD; "SEC TO SUBSIDE CHARGING CURRENT DOWN !"

9300 PRINT

9320 PRINT" U2ALO IS"; U2

9340 PRINT" TOTAL COVERED TIME IS"; TT; "SEC"

9360 FRINT" U1 TIMER SETUF AS":U1;"* (1/6G) SEC"

9380 PRINT" TIME OF RESQLUTION IS ABOUT": TR; "SEC"

9400 PRINT NT; "SETS DF DATA COLLECTED"

9420 FRINT

9440 FRINT" REFERENCE ELECTRODES : ZINC IN 1 M SODIUM ACETATE SOLUTION."

9460 PRINT" WORKING ELECTRODES : CARBON FIBER ARRAY ELECTRODE"

948Ø. PRINT

950 FRINT

9520 FRINT" ** REMARK : ";RM\$

9540 FRINT

9600 RETURN

9700 REM SHOW SAMPLE ID

$9 T 20$ PRINT"SAMPLE - " " LB\$

9740 PRINT" AREA DATA FILE ID: "; ID\$

9760 PRINT" DATE OF EXFERIMENT : ";DA\$

9TEG FRINT

980の FRINT" ** REMARK : "; RM

9820 PRINT

984פ PRINT

9869 RETURN

9909 REM CHANGE REMARK

9910 FRINT"PREVIQUS REMARK : ":RM\$

9920 INFUT"IS IT OK(Y/N)";DM\$

9930 PRINT

9940 IF DM\$="Y" THEN 9990

9960 INPUT "NEW REMARK"; RM\$

9970 PRINT

9989 GOTO 9910

9990 RETURN

1000の REM STATISTICS FOR MEAN, STANDARD DEVIATION(SD), AND RELATIVE SD

10100 REM MEAN

10200 FDR $M=1$ TO 16

$10249 \mathrm{D} 1=\emptyset$

10260 FOR $X=1$ TO I

$1028 g$ D1 $=S C(M, X)+D 1$

10300 NEXT $X$

$10340 \mathrm{MN}(M)=\mathrm{D} 1 / \mathrm{I}$

16500 REM SD \& RELATIVE SD (RD) 


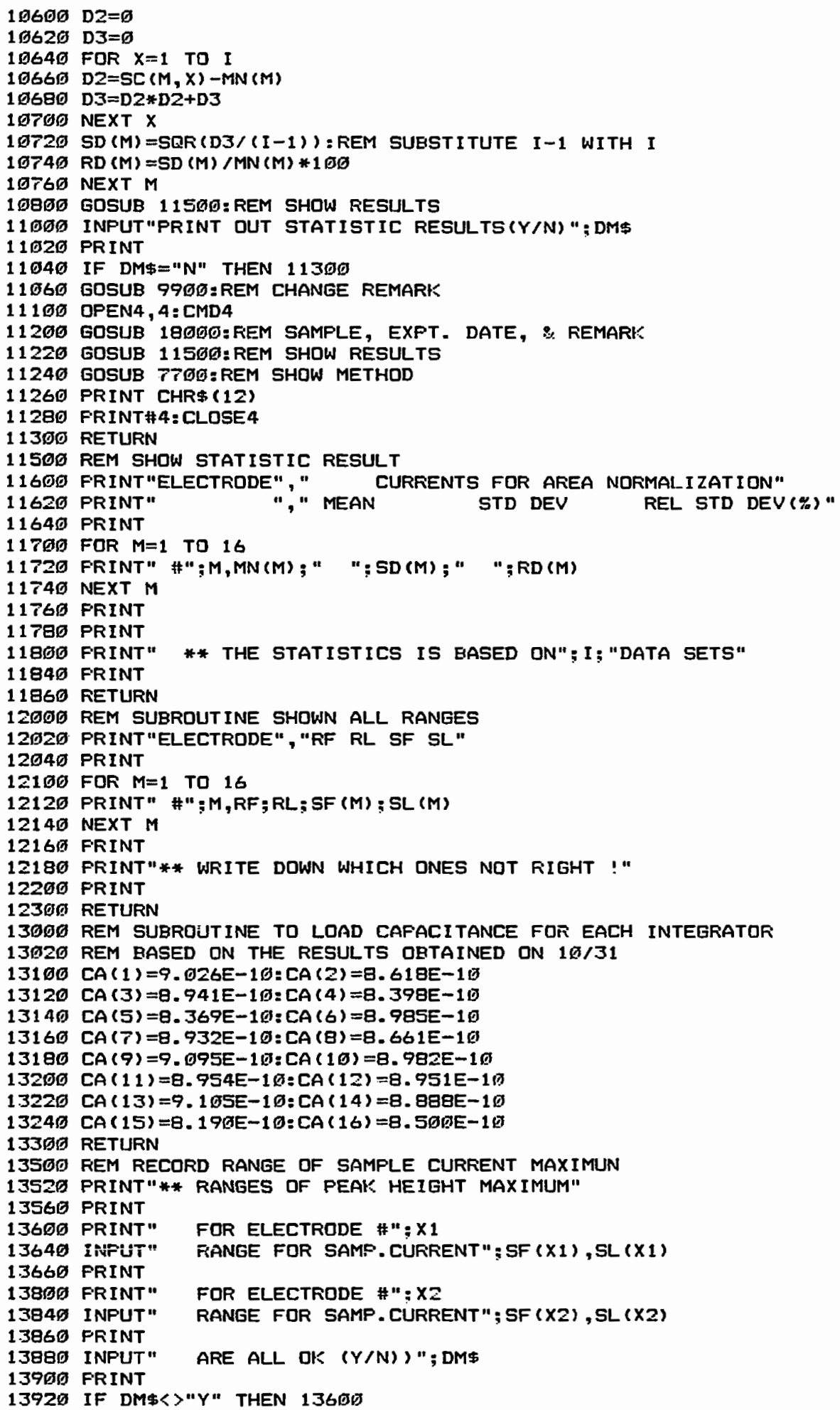




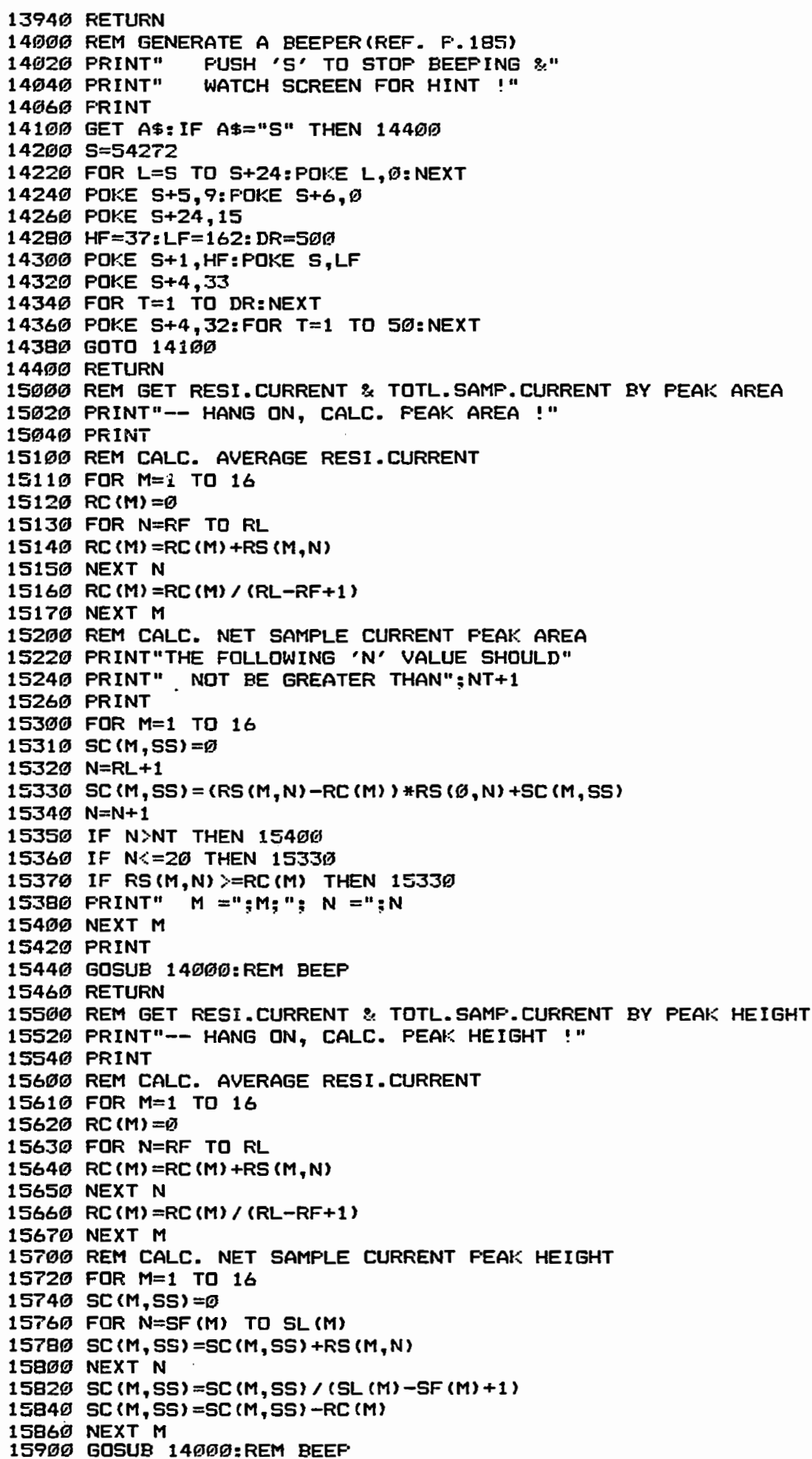


15920 RETURN

16 16D REM FRINT DUT DATA FOR FLOTTING

$16 \emptyset 20$ PRINT"** INPUT THE RANGE OF DATA TO PRINT"

16940 PRINT" END OF PRINT IF $15 T<\emptyset ! "$

16060 FRINT

16100 INFUT" 1ST SET, LAST SET "; BN,ED

16120 INPUT" ARE BOTH $\dot{O} K(Y / N) " ; D M \$$

16140 FRINT

16160 IF DM\$C> "Y" THEN 16100

16180 IF BN

16200 REM PRINT OUT THE TIME AT WHICH DATA WERE COLLECTED

16220 OPEN $4,4:$ CMD 4

16240 PRINT"AREA DATA FILE ID: "; ID\$

16260 FRINT

16280 PRINT

16300 FRINT"SET", "TIME (DATA COLLECTED) "

16329 FRINT

16349 FOR $N=E N$ TO ED

16360 PRINT $N, R S(\emptyset, N)$

$163 B 0$ NEKT $N$

16409 PRINT CHR\$(12): REM GET TO THE TDF OF NEXT FAGE

16420 FRINT\#4

16449 CLOSEA

165のの FRINT"** END OF PRINT IF FT

$1654 \emptyset$ FRINT" CHOOSE 4 ELECTRODES TO FRINT DATA !"

16569 INFUT" 1ST, 2ND, 3RD, 4TH ELECTRODE" ; FT, SD , TD , FH

16620 INFUT "ARE ALL ABDVE OKC $(Y / N)$ "; DM\$

16649 FRINT

16660 IF DH\$S $>$ "Y" THEN 16500

16680 IF FT<ब THEN 1 Tि00

$16 T$ TO OFEN $4,4:$ CMD 4

16 T20 FRINT"SET","

16746 FRINT" \# ":"

16620 DM\%=INT (1LL"4095/6. "1FT,"

16649 RH\% $=$ INT (DM\%/256)

16660 RL\%=INT (DM\%-RH\%*256)

16790 RETURN

17 GOG REM FRINT QUT AUE. RESIDUAL \& NET SAMFLE CURRENT

17100 PRINT"ELECTRODE" ,

17120 FRINT" "," CURRENT *

ELECTRODE"

17140 FRINT

17160 FOR $M=1$ TO 16

17180 FFINT" \# ";M," ";RE (M);SC $(M, S S)$ :" ";SF (M);" ";SL (M)

17200 NEXT M

1 T220 FRINT

17240 FRINT

17260 FRINT" * PRESENT AS AVERAGED FESULTS !!"

17280 FRINT

1730Ø PRINT" FQR THE RANGE OF AVE. RESIDUAL CUFRENTS"

17320 FRINT"

1ST SET IS"; RF; ": LAST SET IS";RL

1740 G RETURN

$1800 \emptyset$ REM SHOW SAMFLE, EXFT. DATE, \& REMAFK

18100 PRINT"SAMFLE -- "; LB\$

18120 FRINT

18140 FRINT" DATE OF EXPERIMENT : ";DA\$

18160 PRINT

191日] FRINT" ** FEMARK : "; FM\$

18200 FRINT

19220 PRINT

19300 RETURN

ZDOOG FEM FRINT OUT ORIGINAL DATA

2010の OPEN4, 4: CMD4

20200 PRINT" SAMFLE LABEL : ";LB\$

20220 FRINT

20240 PRINT.

2G269 FRINT

SAMPLE FANGE"

1ST LAST" 


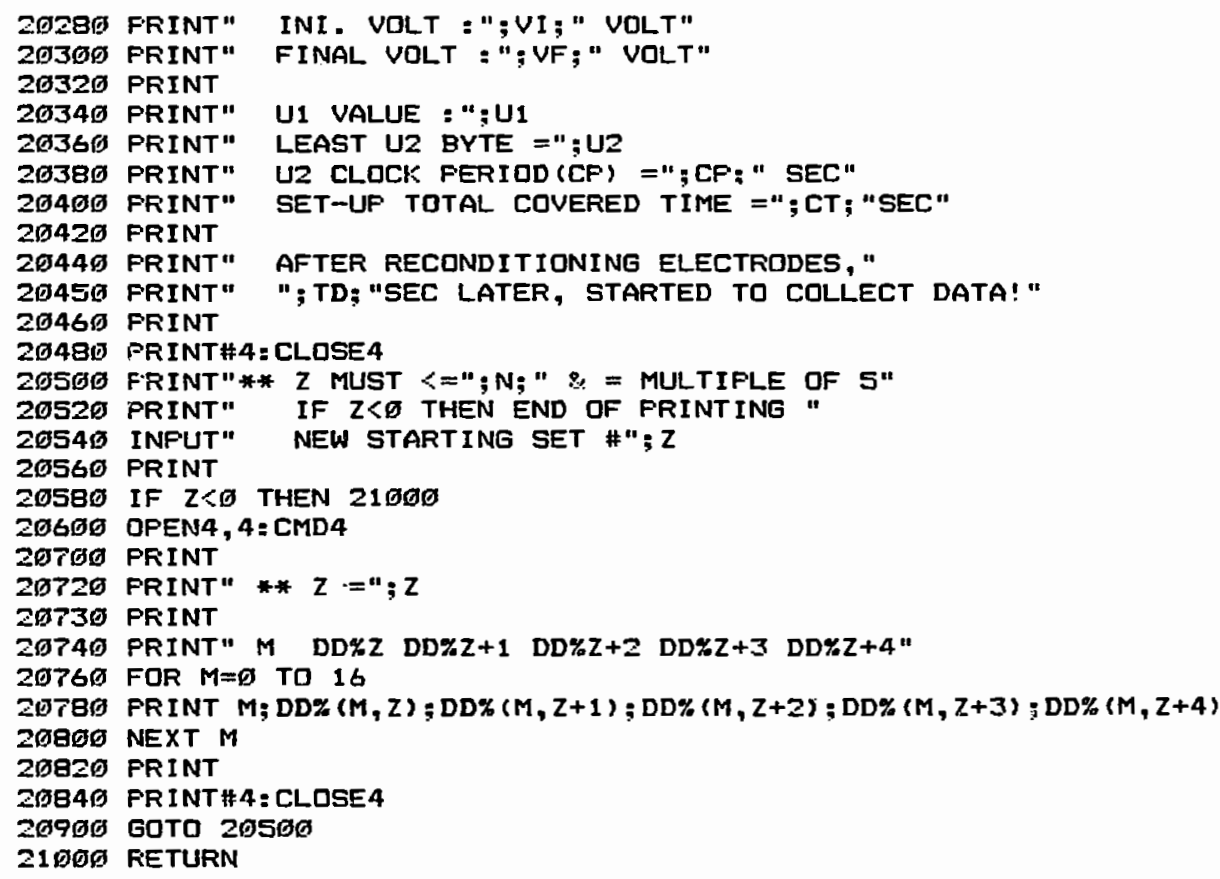


APPENDIX F

SOFTWARE

"RESULT" 
The program "RESULT", shown at the end of this section, is used to get the normalized amperometric data for the construction of pseudo-voltammograms. The flow chart of this software is shown in Figure 29.

This program first loads the saved coulometric data for the construction of a pseudo-voltammogram from a disk to the RAM of the C-64 and the normalization factors of all 16 CFAEs. Then the applied potentials at each CFAE are obtained as described in the previous section. The coulometric data are normalized with normalization factors, then converted into the amperometric data by dividing by the integration time. The net currents at each CFAE, which are used to construct a pseudo-voltammogram, are obtained as described in the previous section too. Finally, all these normalized net currents for plotting a pseudo-voltammogram are printed out. 


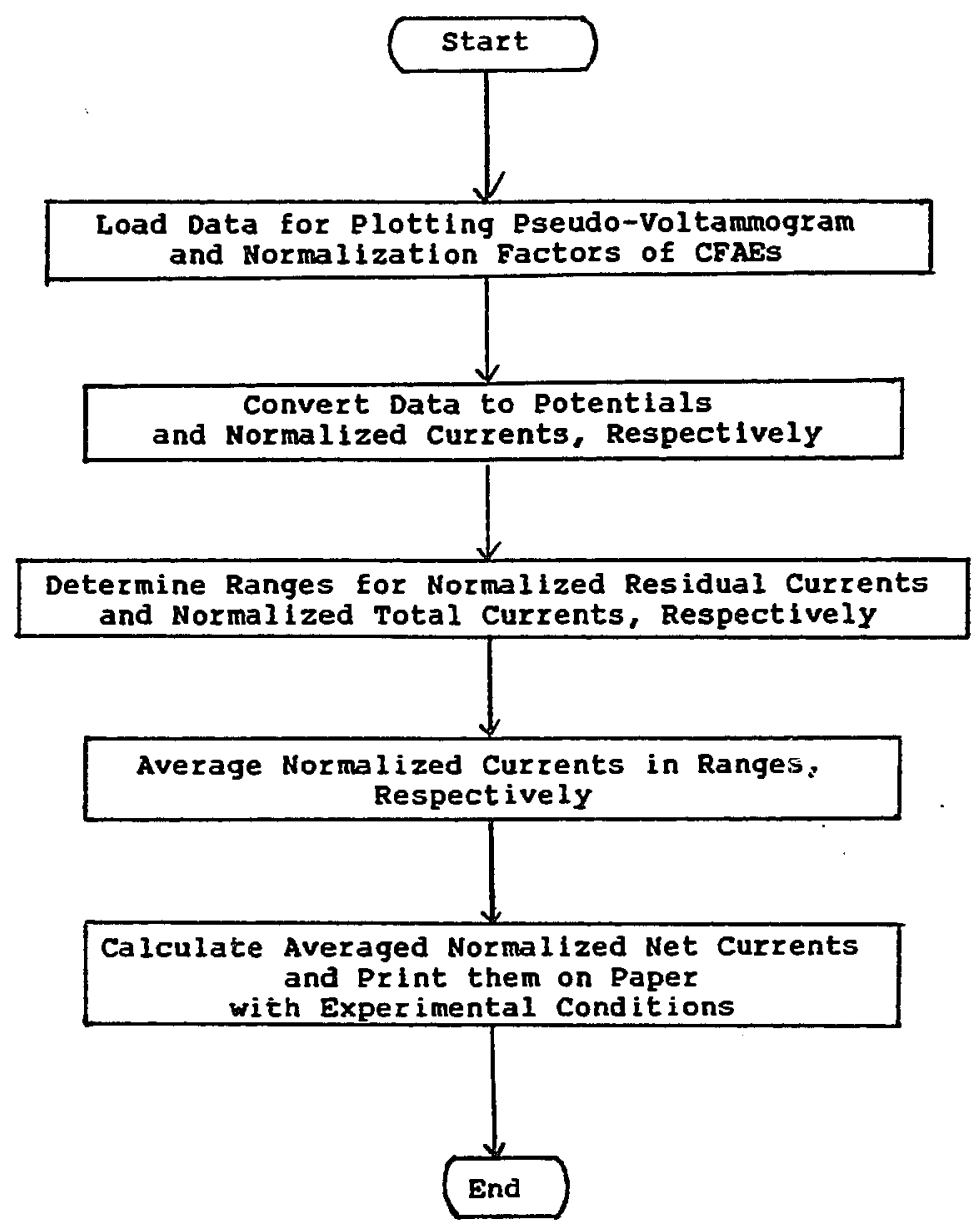

Figure 29. Flow chart of software "RESULT". 


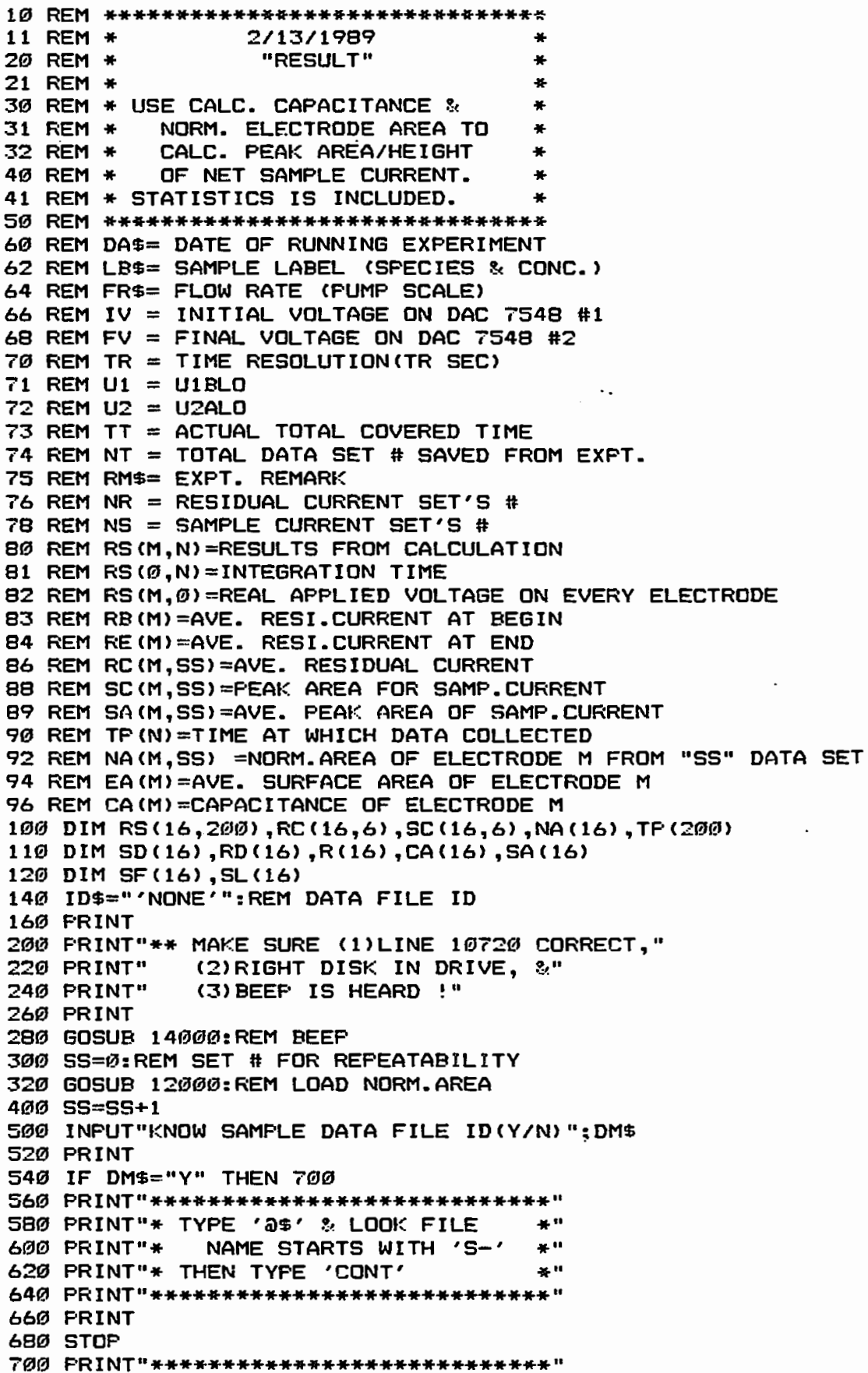




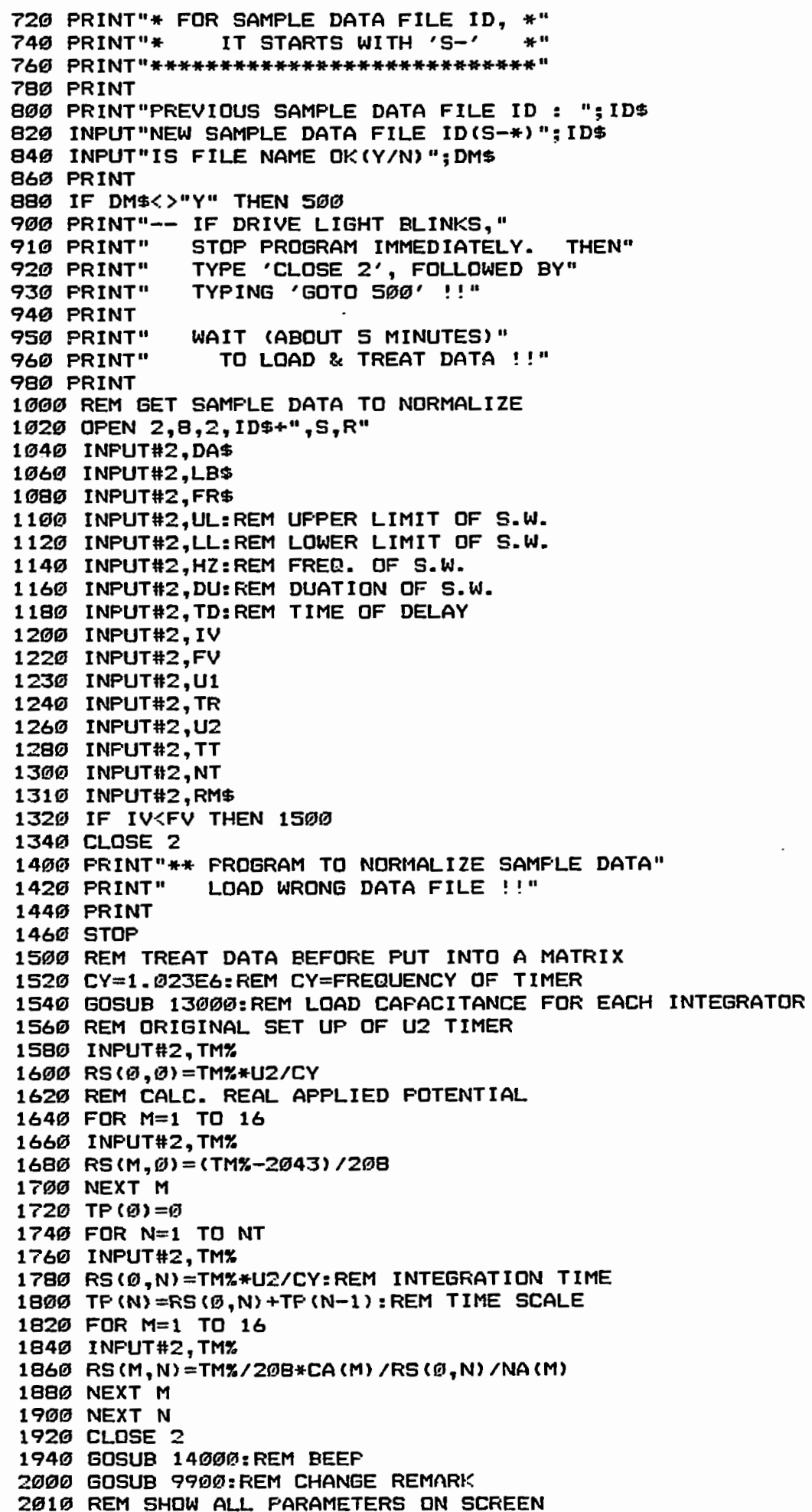




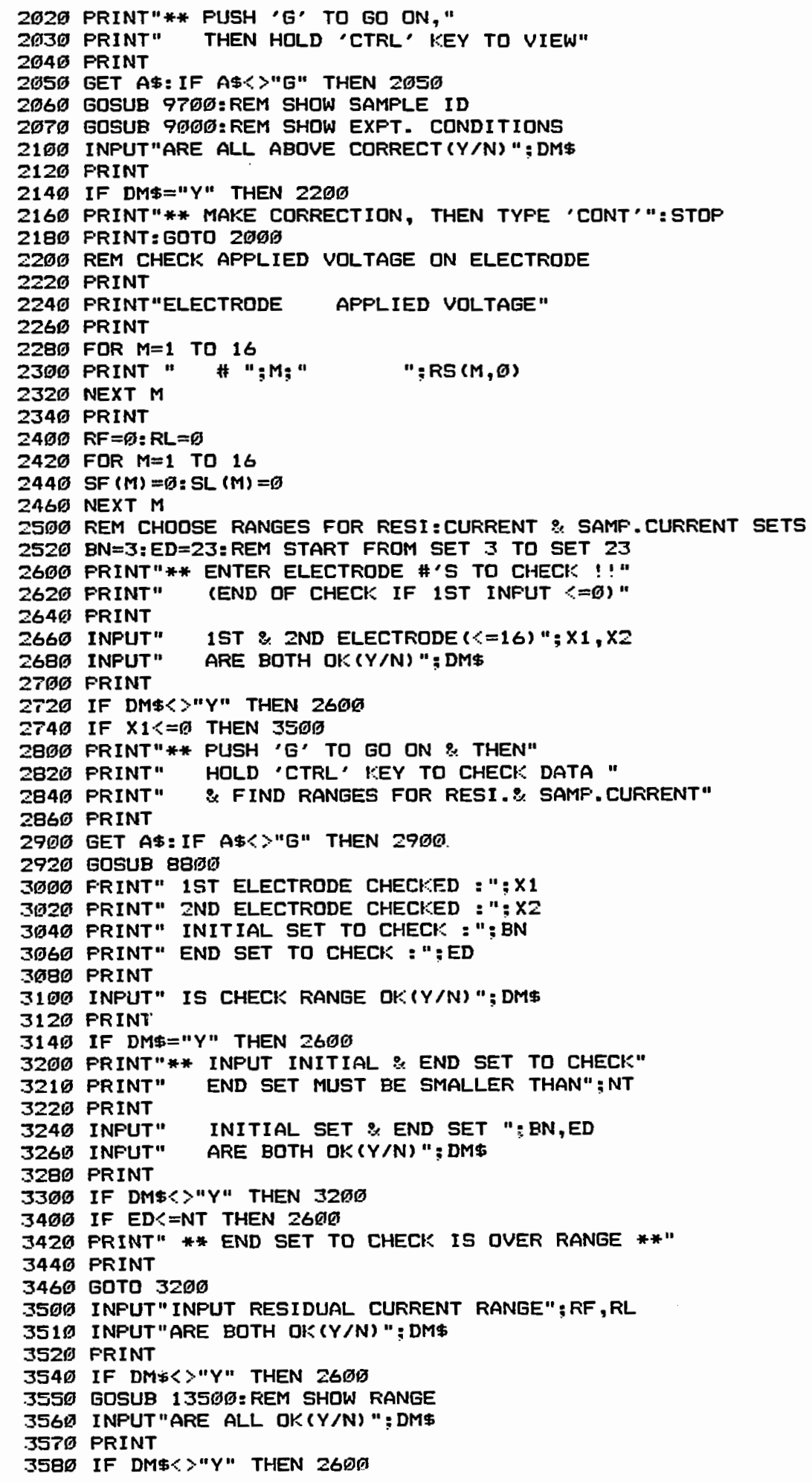




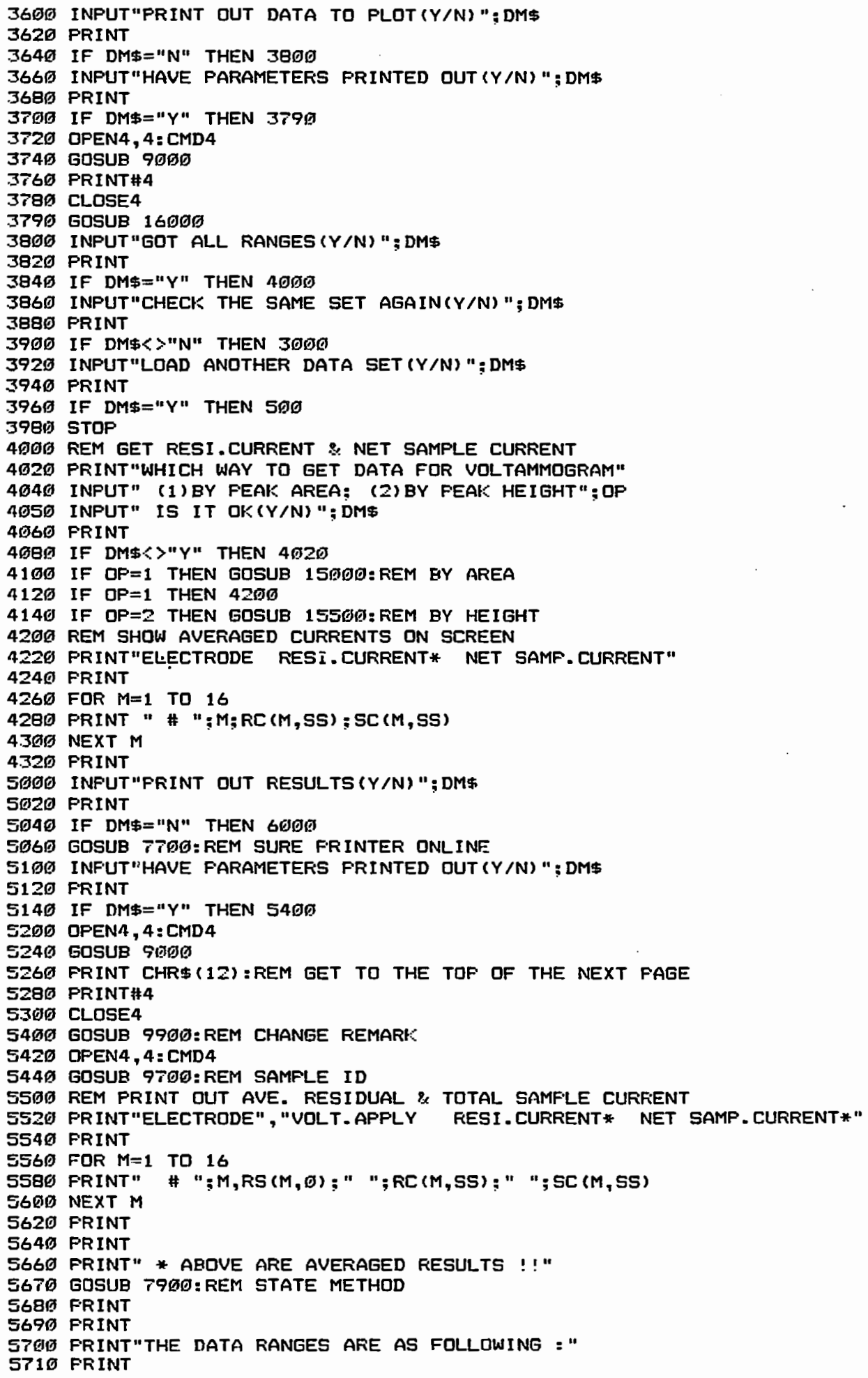




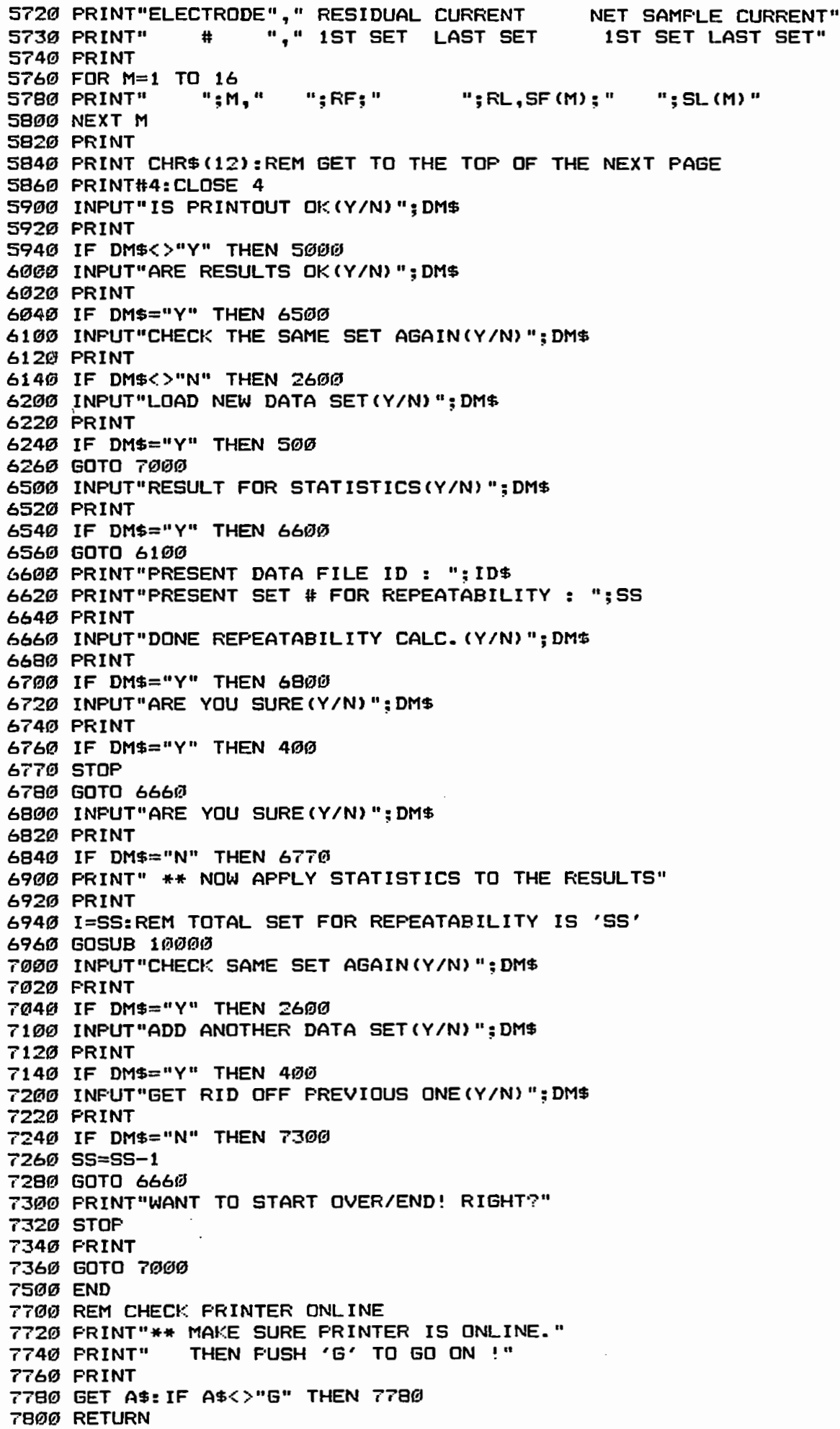


79ØØ REM STATE METHOD

7920 IF OF=1 THEN FRINT" * RESULTS ARE BASED QN FEAK AREA !"

794ף IF OP=2 THEN PRINT" ** RESULTS ARE BASED ON PEAK HEIGHT !"

T960 FRINT

T9BØ RETURN

8ののの REM SUBROUTINE TO CHECK WHOLE SET DATA

8๑2ø FRINT"** END OF CHECK TF NN $<$ क ! "

8940 INFUT" NEW DATA SET \# TO CHECK(NN) "; NN

B๑8Ø PRINT

8100 IF NNKG THEN 8360

B2øの PRINT" $M$ DATA(NN) DATA(NN+1)"

8220 FOR $M=G$ TO 16

Q24Ø PRINT M:RS (M,NN) : RS (M, NN+1)

B26Я NEXT M

B2BO PRINT

B3G PRINT" DATA SET \# : ";NN

B320 PRINT

8340 BOTO 8620

8360 RETURN

85øळ REM SHOW A SINGLE SET DATA

852Ø FRINT

8549 PRINT N; "TH SET DATA OF SAMPLE"

8560 PRINT" DATA COLLECTED AT":RS $(\emptyset, N)$; "SEC"

858 PRINT" INTEGRATION TIME IS"; TP (N) " "SEC"

869@ FRINT

8620 PRINT"ELECTRODE", "TOTL. SAMP. CURRENT"

8640 FRINT

8660 FOR $M=1$ TO 16

8680 PRINT" \# ";M,RS (M,N)

BTøळ NEXT M

BT20 FRINT

BTAפ RETURN

89øの REM SUBROUTINE TO SEE ALL DATA ON TWD ELECTRODES

8820 PRINT"SET"; " ELECTRODE"; $\times 1$; " ELECTRODE"; $\times 2$

884の FOR $N=B N$ TO ED

8860 PRINT $N: R S(X 1, N) ; R 5(X 2, N)$

B88G NEXT N

89øळ PRINT

B92の GOSUB 14500:REM SET RANGE

8940 RETURN

9GのØ REM SHOW ALL FARAMETERS ON SCREEN

9620 FRINT"EXPERIMENTAL CONDITIONS --"

9640 PRINT

9060 FRINT" FLOW RATE -- "gFR\$

9980 FRINT

91 GØ PRINT" SQUARE WAVE FOR FRECONDITIONING --"

9120 PRINT" FOTENTIAL OF UFFER LIMIT : ": UL: "VOLT"

9140 FRINT" FOTENTIAL OF LOWER LIMIT : "; LL; "VOLT"

9160 PRINT" FREQUENCY : "; HZ; "HERTZ"

$918 \sigma$ PRINT" DURATION : "; DU; "SEC"

9200 PRINT

9220 PRINT IV; "VOLTS OUTFUT FROM DACT548 \#1"

9240 PRINT FV; "VOLTS OUTPUT FROM DACT548 \#2"

9260 FRINT

9280 PRINT" WAIT"; TD; "SEC TO SUBSIDE CHARGING CURRENT DOWN"

9300 PRINT

9320 PRINT" UZALO IS";U2

934Ø FRINT" TOTAL COUERED TIME IS"; TT;"SEC"

9360 PRINT" U1 TIMER SETUF AS";U1;"* (1/60) SEC"

9380 PRINT" TIME DF RESOLUTION IS ABOUT"; TR; "SEC"

$94 G 0$ FRINT NT; "SETS OF DATA COLLECTED"

$942 \emptyset$ PRINT

9440 PRINT" FEFERENCE ELECTFODES : ZINC IN 1 M SODIUM ACETATE SOLUTION." 9460 FRINT" WORKING ELECTRODES : CAREON FIBEF AFRAY ELECTRODE"

9486 PRINT

95øの FRINT 


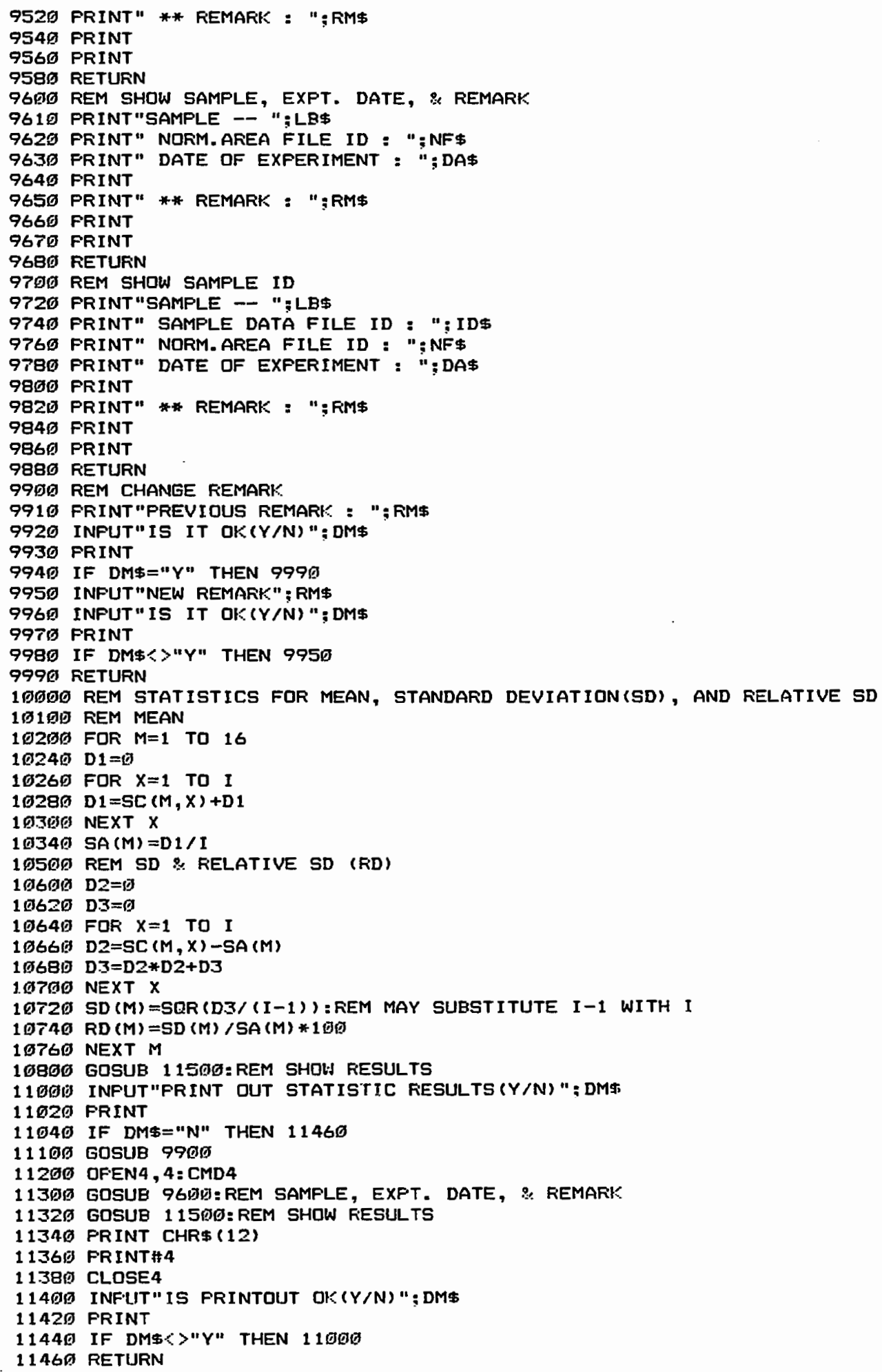




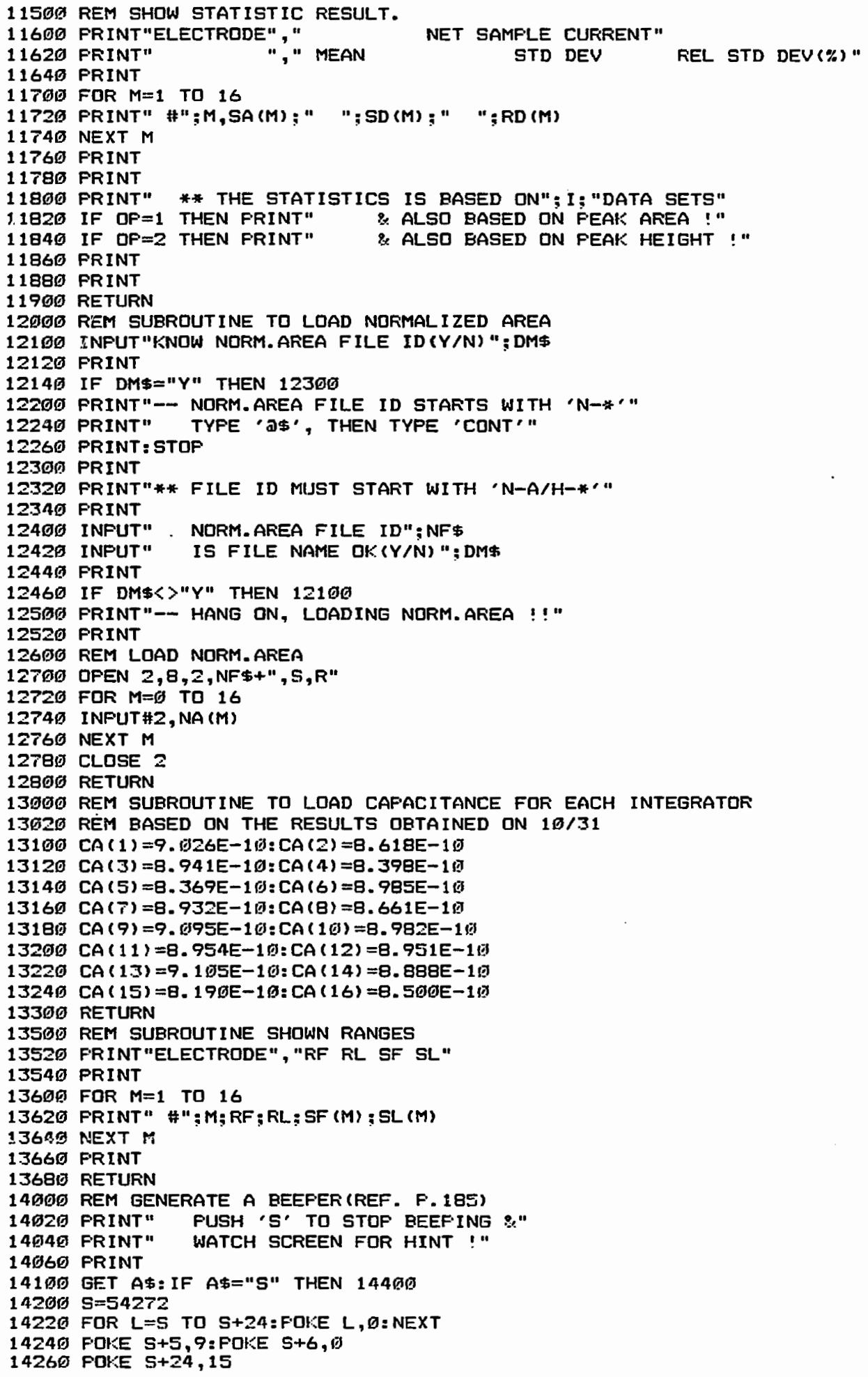


$14280 \mathrm{HF}=3 \overrightarrow{7}: \mathrm{LF}=162: D R=500$

14300 POKE $S+1, H F=$ POKE $S, L F$

14320 POKE $5+4,33$

14340 FOR $T=1$ TO DR: NEXT

14369 POKE $S+4,32: F O R T=1$ TO $50: N E X T$

14389 GOTO 14109

$1446 \%$ RETURN

14500 FEM SET FANGE FQF SAMF. CURRENT PEAK HEIGHT MAXIMUM

14606 FRINT" FOR ELECTRODE \#"; $X 1$

14640 INPUT" RANGE OF SAMPLE CURRENT"; SF (X1), SL (X1)

14660 PRINT

$1479 \emptyset$ PRINT" FOR ELELTRODE \#"; $X 2$

14740 INFUT" RANGE OF SAMFLE CURRENT";SF (X2), SL (X2)

14760 PRINT

14899 INFUT" ARE BOTH OK $(Y / N) ": D M \$$

1482 (SRINT

14840 IF DM\$<>"Y" THEN 14690

$1486 \sigma$ RETUFN

15 15G REM GET RESI.CLFRENT \& TOTL.SAMP.CURRENT BY FEAK AREA

1502ø PRINT"-- HANG QN, CALC. PEAK AREA !"

15049 FRINT

151@g REM CALC. AVERAGE RESI . CURRENT

15110 FOR $M=1$ TO 16

$1512 \sigma \operatorname{RC}(M, S 5)=\emptyset$

15130 FOF $N=R F$ TQ RL

$15149 R C(M, S S)=R C(M, 55)+R S(M, N)$

15150 NEXT $N$

$15160 \mathrm{RC}(M, S S)=\mathrm{RC}(M, 5 S) /(\mathrm{RL}-\mathrm{RF}+1)$

15170 NEXT M

15200 FEM CALC. PEAK AFEA OF NET SAMFLE CURRENT

$1522 \%$ FRINT"-- THE FQLLOWING ' $N$ ' VALUE SHOULD BE"

15246 PRINT" NOT GREATER THAN" - NT+1

15260 FRINT

15.306 FOR $M=1$ TO 16

$1531 \emptyset \mathrm{SC}(M, S S)=\emptyset$

$15320 \quad N=F L+1$

$1533 \sigma S C(M, S S)=(R S(M, N)-R C(M, S S)) * R S(9, N)+S C(M, S S)$

$1534 \Omega \quad N=N+1$

1535ब IF N>NT THEN 15410

$153 a ́ g$ IF $\mathbf{N}<=20$ THEN 15330

15370 IF RS $(M, 20)<F C(M, S S)$ THEN 1540\%

15380 IF RS(M,N)>RC (M,SS) THEN 15330

15390 GOTO 15416

154@の IF RS(M,N) KRC (M,SS) THEN 15330

15410 PRINT" $M=" M: " N=" ; N$

15420 NEXT M

15440 FFINT

1546D GOSUB $140100:$ REM EEEP

15480 RETUFN

15500 REM GET RESI.CURFENT \& SAMF. CURFENT BY FEAK HEIGHT

155.20 PFINT"- HANG ON, CALC. PEAK HEIGHT !"

15549 PRINT

$1560 \emptyset$ FEM CALC. AVERAGE RESI , CURRENT

15616 FOR $M=1$ TO 16

$15620 \mathrm{RC}(\mathrm{M}, \mathrm{SS})=\emptyset$

15630 FOR $N=F F$ TO RL

1564 RC $(M, S S)=R C(M, 5 S)+R S(M, N)$

$1565 \%$ NEXT N

$15660 \mathrm{RC}(M, 5 S)=\mathrm{RC}(M, 55) /(R L-F(F+1)$

15670 NEXT M

$1579 \%$ REM CALC. FEAK HEIGHT DF NET SAMFLE CURRENT

15720 FOR $M=1$ TO 16

$15746 \mathrm{SC}(\mathrm{M}, \mathrm{SS})=0$

15760 FOR $N=S F(M)$ TO $S L(M)$

$15780 S C(M, S S)=S C(M, S S)+F S(M, N)$

$158 \sigma \emptyset$ NEXT $N$ 


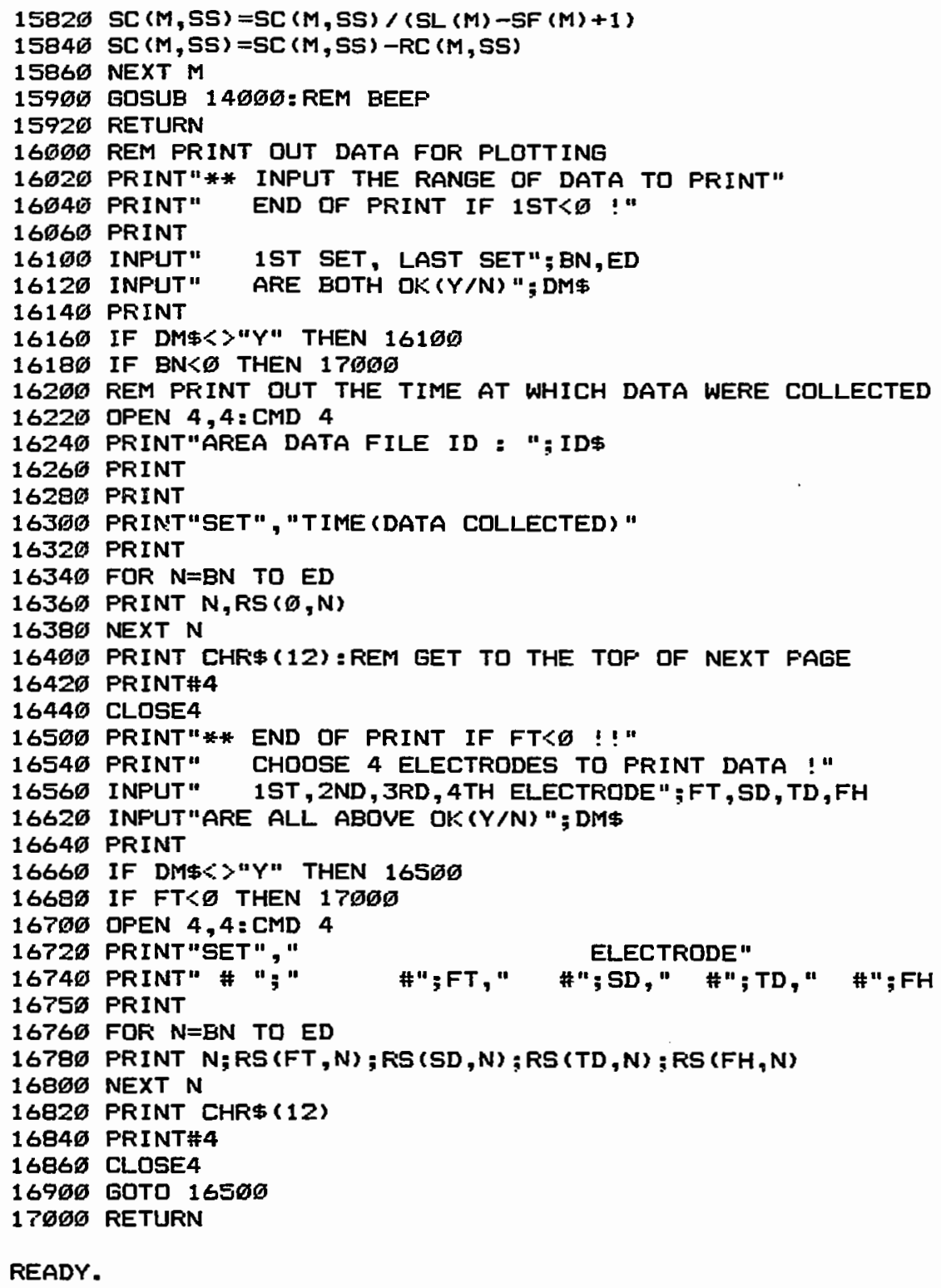

READY. 